\title{
Multimodal Porphyrin-Based Conjugates Synthesis and characterization for applications as amyloid ligands, photodynamic therapy agents and chiroptical materials
}

\author{
Katriann Arja
}

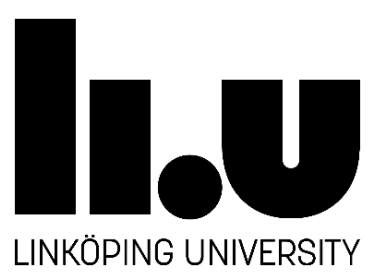

Division of Chemistry

Department of Physics, Chemistry and Biology

Linköping University, Sweden

Linköping 2018 
(C) Copyright Katriann Arja, 2018, unless otherwise noted.

Published articles have been reprinted with the permission of the copyright holder.

Paper I. (C) 2013 Wiley-VCH Verlag GmbH \& Co. KGaA

Paper II. (C) 2018 The Authors. Published by Wiley-VCH Verlag GmbH \& Co. KGaA

Paper III. (C) 2018 The Authors. Published by Frontiers Media SA

Cover: Illustrates the colorful nature of porphyrins, depicted by a glimpse into an extraction funnel.

\section{Katriann Arja}

\section{Multimodal Porphyrin-Based Conjugates}

Synthesis and characterization as amyloid ligands, photodynamic therapy agents and chiroptical materials

ISBN: 978-91-7685-255-2

ISSN: 0345-7524

Linköping Studies in Science and Technology Dissertations No. 1947

Printed by LiU-Tryck, Linköping, Sweden, 2018 
A prudent question is one-half of wisdom.

Francis Bacon 



\section{Abstract}

Organic compounds that interact both with certain biological targets and display specific photophysical properties can be utilized as molecular tools to visualize and possibly affect disease related processes taking place in living organisms. In this regard, porphyrins are a class of naturally occurring molecules that possess intriguingly interesting photophysical properties where they can act as luminescent probes by emitting detectable light, as well as photosensitizers in the light mediated therapy denoted photodynamic therapy. In this thesis, the porphyrin structure has been synthetically combined with other types of molecules to achieve compounds with desirable multimodal characteristics.

Firstly, luminescent conjugated oligothiophenes (LCOs) that have extensively, and with great success, been utilized as fluorescent ligands for amyloid formations, have been conjugated to porphyrins to render oligothiophene porphyrin hybrids (OTPHs) comprising two modalities with optical properties. When applied as fluorescent ligands for visualization of amyloid- $\beta(A \beta)$ aggregates, one of the pathological hallmarks in Alzheimer's disease, an enhanced optical assessment of distinct aggregated forms of A $\beta$ was afforded. Thus, properly functionalized OTPHs could give us more information about pathological processes underlying devastating disorders, such as Alzheimer's disease. In addition, the OTPHs can be associated with synthetic peptides inducing peptide folding into certain three-dimensional helical structures giving rise to novel optically active materials.

Secondly, this thesis embraces porphyrins' potential as photosensitizers in photodynamic therapy to kill cancer cells. Grounded on the prerequisites for an optimal photosensitizer, we designed porphyrin-based conjugates equipped with common carbohydrates for improved cancer cell selectivity and with a fluorinated glucose derivative, 2-fluoro-2-deoxy-D-glucose, for advantageous metabolism in cancer cells. Furthermore, incorporation of a radioisotopic fluorine-18 atom into the glycoporphyrins could give the means for diagnostic use of the conjugates in positron emission tomography (PET).

In order to tether together the above-mentioned molecular moieties in a controlled fashion, we developed a robust synthetic strategy for asymmetric functionalization of a porphyrin core. The method involves chlorosulfonation of this otherwise inert tetrapyrrolic structure, followed by alkynylation. Parallelly to amide coupling reactions, copper(I)-catalyzed alkyne azide cycloaddition is used for fast and high-yielding latestage conjugations. Overall, this thesis demonstrates how combining different molecular moieties in synthetic organic chemistry yields novel molecules with combined and improved multimodal properties for biological and medicinal applications, guided by the design-by-function methodology. 


\section{Populärvetenskaplig sammanfattning}

Det finns en nyfikenhetsdriven begäran hos människor att förstå hur vår organism är uppbyggd och hur den fungerar. Denna kunskap är än mer viktig för att kunna förebygga och bota allvarliga sjukdomar som demens och cancer, som dessvärre har blivit allt vanligare i dagens värld. Organiska ämnen som kan binda till en viss biologisk målstruktur och kan samtidigt interagera med ljus genom att absorbera det, utgör attraktiva molekylära verktyg för att studera och eventuellt påverka sjukdomsprocesser som sker i människokroppen.

Porfyriner är organiska molekyler som förekommer naturligt i våra kroppar och även $\mathrm{i}$ andra levande organismer som växter och bakterier. Porfyriner utgör den centrala delen av proteinet hemoglobin som ansvarar för syretransporten $\mathrm{i}$ kroppen, och det är på grund av porfyrinens speciella struktur som blodet får sin karaktäristiska röda färg. Tack vare sin cykliskt konjugerade struktur kan porfyriner interagera med ljusenergi på ett sätt så att de kan användas som fluorescerande färgämnen för att märka in och studera små biologiska objekt som celler. Porfyriner kan dessutom omvandla den absorberade ljusenergin till cellskadliga syreradikaler, vilket under kontrollerade förhållanden kan utnyttjas $\mathrm{i}$ en ljusmedierad cancerterapi, så kallad fotodynamisk terapi. I denna avhandling har vi med hjälp av organiska reaktioner kopplat samman porfyriner med andra typer av molekylära motiv, vilket möjliggör en rad intressanta tillämpningar.

På så sätt har vi byggt samman porfyriner med luminiscenta konjugerade oligotiofener (LCOs) som är kända för att kunna binda till och detektera aggregerade proteiner, så kallade amyloider. Amyloida fibrer och -plack från felveckade proteiner förekommer vid olika neurodegenerativa sjukdomar, till exempel Alzheimers och Parkinsons sjukdom, men även vid typ 2 diabetes. Konjugaten mellan porfyriner och LCOs (så kallade OTPHs från engelskan oligothiophene porphyrin hybrids) innehåller två optiskt komplementära delar som interagerar med ljus och med varandra, och lämpar sig därför bra som fluorescerande färgämnen för att studera proteinaggregat.

Dessa OTPHs kan dessutom interagera med syntetiska peptider som sedan veckar sig till bestämda tredimensionella helixar. De välstrukturerade peptid-OTPH hybriderna har intressanta optiska egenskaper vilket gör dem attraktiva från ett materialvetenskapligt perspektiv.

I denna avhandling beskrivs även syntesen av glykosylerade porfyriner, vilket innebär att porfyrinstrukturen har kopplats samman med olika kolhydrater. Syftet med dessa molekyler är att kombinera porfyrinens egenskaper att kunna generera cytotoxiska syreradikaler med kolhydraternas förmåga att kunna dirigera molekylerna till cancerceller. Vi har låtit oss vägledas av de skillnaderna i egenskaper som föreligger mellan cancerceller och friska celler, samt hur fotodynamisk terapi fungerar. Utifrån denna kunskap har vi med hjälp av kemiska reaktioner byggt ämnen som i framtiden ska kunna fungera som selektiva läkemedel mot cancer. Framtida inkorporering av den 
radioaktiva fluorisotopen, fluor-18, skulle generera en lovande ny klass av radiomarkörer för cancerdiagnostik med hjälp av positronemissionstomografi (PET). 


\section{Acknowledgements}

During my doctoral studies at Chemistry department at Linköping university, several people have contributed to the scientific work that I carried out, helped me with the everyday matters or supported me in general. I would like to thank all these fantastic people and especially acknowledge some of them:

Professor Peter Nilsson, my supervisor, for all the guidance and support through the years. You are an expert on helping me see the possibilities in seemingly tiny things that would eventually lead to fascinating research projects.

Professor Peter Konradsson, my co-supervisor, for the help in navigating in the world of organic chemistry and for the all the philosophical discussions about the rest of the world.

All the past and present members of the Nilsson group: Therése for always being the wise and calm ideal of a researcher; Hamid with his never-disturbed and inspiring enthusiasm in synthetic chemistry; the chatty and positive Bisse for all her advice on chemistry and life, and for all the enjoyable coffee breaks and lunches; Elisabet for being one of the few downright good people left in this world and surely one of the persons with the highest number of different interests; Hanna for the fruitful collaborations and pleasant company; Karin, Rozalyn, Leffe, Jeff, Andreas, Timmy and Mikaela for all the help and for all the memorable moments at works.

Mathias Elgland, another downright good person with a plethora of positive qualities ranging from being an excellent chemist to a worthy friend. I am deeply grateful for all the scientific collaborations and the friendship along the side. Thank you for your most enjoyable company over my many years at Linköping university!

Linda Lantz, my roomie and a dear colleague and a friend, for cheering my days with interesting scientific and even more interesting non-scientific talk. You inspire with you strong and independent angles of life philosophy.

Marcus Bäck, for being a truly understanding and reliable friend and a helpful colleague, and for backing me up with "Det gör du rätt i".

Jakob Wallgren for m/baking my days with all these splendid pastries and with your pleasant company!

People in Organic chemistry corridor: Xiongyu $W u$, a true sensei in chemistry; Yun, Tobias, Roger. People who have left the corridor: Alma, Mattias, Edwin.

Professor Per Hammarström and all the past and present members of his group: Sofie, Alexander, Maria, Ashfan. 
Colleagues at IFM: Gunilla, Annika, Rita, Helena Herbertsson, Patrik Lundström, Maria Lundqvist, Cissi, Emelie for helping me with a variety of matters during my time as a $\mathrm{PhD}$ student.

Our collaborator in Trondheim, Mikael Lindgren, for his expertise in porphyrins.

Daniel Aili and Robert Selegård for the interesting collaboration on peptide-based materials.

My large family-in-law in Sweden and in Iran and my almost as large family in Estonia for all the support. To my parents, Ene and Kunnar, for doing whatever you did from the day I was born - it obviously worked out well-: Thank you for giving me the freedom to get the perspective of the life and to get the independence to achieve my goals! My sisters Elen, Elina, Reena and Liisa for being the best sisters and friends I could get! I truly appreciate everything you have done for me and with me!

My little family in Sweden: my sons Dorian and Tristan for being the gems in my life. Thank you for distracting me from my work and not letting me grow up! My beloved husband Reza for your constant support and love. Thank you for encouraging me in everything I undertake and for sharing my view of life! 


\section{Papers Included in the Thesis}

I. Enhanced Fluorescent Assignment of Protein Aggregates by an Oligothiophene-Porphyrin-Based Amyloid Ligand

Katriann Arja*, Daniel Sjölander*, Alma Åslund, Stefan Prokop, Frank L. Heppner, Peter Konradsson, Mikael Lindgren, Per Hammarström, K. O. Andreas Åslund, K. Peter R. Nilsson. Macromol. Rapid Commun. 2013, 34 (9), 723-730.

II. Synthesis and Characterization of Oligothiophene-Porphyrin-Based Molecules That Can Be Utilized for Optical Assignment of Aggregated Amyloid- $\beta$ Morphotypes

Katriann Arja, Mathias Elgland and K. Peter R. Nilsson. Front. Chem. 2018, 6, 391.

III. Self-assembly of chiro-optical materials from nonchiral oligothiopheneporphyrin derivatives and random coil synthetic peptides Katriann Arja, Robert Selegård, Daniel Aili, K. Peter R. Nilsson. In Manuscript

IV. Synthesis and Characterization of Novel Fluoro-Glycosylated Porphyrins that can be Utilized as Theranostic Agents

Katriann Arja*, Mathias Elgland*, Hanna Appelqvist, Peter Konradsson, Mikael Lindgren and K. Peter R. Nilsson. ChemistryOpen 2018, 7, 495-503.

*These authors contributed equally. 


\section{Contribution to the Included Papers}

I. Actively participated in the planning of the synthesis. Performed all the synthetic work and chemically characterized all synthesized compounds. Wrote parts of the paper.

II. Planned and performed most of the synthetic work and chemically characterized all synthesized compounds. Wrote parts of the paper.

III. Planned and performed all the synthetic work and chemically characterized all synthesized compounds. Wrote parts of the paper.

IV. Actively participated in the planning of the project. Performed the synthesis and characterization of the porphyrin scaffold and all the conjugates. Took part in planning the biological analyses. Wrote parts of the paper. 


\section{Papers Not Included in the Thesis}

Red junglefowl have individual body odors

A.-C. Karlsson, P. Jensen, M. Elgland, K. Laur, T. Fyrner, P. Konradsson and M. Laska, J. Exp. Biol., 2010, 213, 1619-1624. 


\section{Conference Contributions}

Synthesis of Glycosylated Porphyrin-Oligothiophene Conjugates

Mathias Elgland, Katriann Arja, Peter Konradsson and K. Peter R. Nilsson.

$X V^{\text {th }}$ Conference on Heterocycles in Bio-organic Chemistry, 2014, Riga, Latvia.

Synthesis of Novel Porphyrin-Oligothiophene Conjugates

Katriann Arja, Mathias Elgland and K. Peter Nilsson.

Organikerdagarna, 2014, Stockholm, Sweden.

Synthesis of Oligothiophene-Porphyrin Conjugates for Potential Use in Photodynamic Therapy

Katriann Arja, Mathias Elgland and K. Peter R. Nilsson

Organikerdagarna, 2016, Umeå, Sweden.

Novel Fluoro-Glycosylated Porphyrins: Synthesis and Characterization Katriann Arja, Mathias Elgland and K. Peter R. Nilsson. ACS national meeting, 2017, San Francisco, USA.

Multimodal Oligothiophene-Conjugates for Improved Amyloid Detection Katriann Arja, Linda Lantz and K. Peter R. Nilsson $6^{\text {th }}$ Amyloid Disease Annual Meeting, 2017, Kolmården, Sweden.

Synthesis and Characterization of Novel Fluoro-Glycosylated Porphyrins for Theranostic Use

Katriann Arja, Mathias Elgland, Hanna Appelqvist, K. Peter R. Nilsson $1^{\text {st }}$ National Meeting of the Swedish Chemical Society, 2018, Lund, Sweden.

Synthesis and Characterization of Novel Fluoro-Glycosylated Porphyrins for Theranostic Use

Katriann Arja, Mathias Elgland, Hanna Appelqvist, K. Peter R. Nilsson $19^{\text {th }}$ Tetrahedron Symposium, 2018, Riva del Garda, Italy. 


\section{Thesis Committee}

SUPERVISOR

K. Peter R. Nilsson, Professor

Division of Organic Chemistry, Department of Physics, Chemistry and Biology

Linköping University, Sweden

CO-SUPERVISOR

Peter Konradsson, Professor

Division of Organic Chemistry, Department of Physics, Chemistry and Biology

Linköping University, Sweden

FACULTY OPPONENT

Fredrik Almqvist, Professor

Department of Chemistry

Umeå University, Sweden

COMMITTEE BOARD

Kajsa Uvdal, Professor

Department of Physics, Chemistry and Biology

Linköping University, Sweden

Jerker Mårtensson, Professor

Division of Organic Chemistry, Department of Chemistry and Engineering

Chalmers University of Technology, Sweden

Dag Sehlin, Associate Professor

Department of Public Health and Caring Science, Geriatrics; Molecular Geriatrics, Rudbeck Laboratory

Uppsala University, Sweden 


\section{Abbreviations}

$\mathrm{A} \beta \quad$ Amyloid beta fragment from amyloid beta precursor protein

AD Alzheimer's disease

ATP Adenosine triphosphate

Boc tert-Butyloxycarbonyl

CuAAC Copper(I) catalyzed azide-alkyne [3+2] cycloaddition

DAST Diethylaminosulfur trifluoride

DCM Dichloromethane

DDQ 2,3-Dichloro-5,6-dicyano-1,4-benzoquinone

DIPEA $\quad N, N$-Diisopropylethylamine

DMDO Dimethyldioxirane

DMSO N,N-dimethylsulfoxide

DMF $\quad N, N$-dimethylformamide

DPM Dipyrromethane

EDC $\quad N$-(3-Dimethylaminopropyl)- $N$ '-ethylcarbodiimide hydrochloride

EtOAc Ethyl acetate

FDA Food and Drug Administration

FDG 2-deoxy-2-fluoro-D-glucose

FLIM Fluorescence lifetime imaging

FRET Förster resonance energy transfer

GLUT Glucose transporter

HATU Hexafluorophosphate Azabenzotriazole Tetramethyl Uronium

LC-MS Liquid chromatography - mass spectrometry

LCO Luminescent conjugated oligothiophene

MEG Monoethyleneglycol linker 


$\begin{array}{ll}\text { MRI } & \text { Magnetic resonance imaging } \\ \text { MW } & \text { Microwave } \\ \text { NBS } & \text { N-bromosuccinimide } \\ \text { NHS } & \text { N-hydroxysuccinimide } \\ \text { NIR } & \text { Near infrared } \\ \text { NMR } & \text { Nuclear magnetic resonance } \\ \text { OTPH } & \text { Oligothiophene porphyrin hybrid } \\ \text { PBS } & \text { Phosphate buffered saline } \\ \text { PDT } & \text { Photodynamic therapy } \\ \text { PEPPSI-IPr } & \text { Pyridine-Enhanced Precatalyst Preparation Stabilization and Initiation } \\ \text { PET } & \text { Positron emission tomography } \\ \text { PPTS } & \text { Pyridinium } p \text {-toluenesulfonate } \\ \text { PS } & \text { Photosensitizer } \\ \text { ROS } & \text { Reactive oxygen species } \\ \text { TBA } & \text { Tetrabutylammonium } \\ \text { TEG } & \text { Tetraethyleneglycol linker } \\ \text { TFA } & \text { Trifluoroacetic acid } \\ \text { THF } & \text { Tetrahydrofuran } \\ \text { TPP } & \text { Tetraphenylporphyrin } \\ \text { TPPS } & \text { meso-tetrakis }(p \text {-sulfonatophenyl)porphyrin } \\ \end{array}$




\section{Table of Contents}

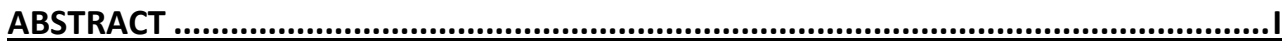

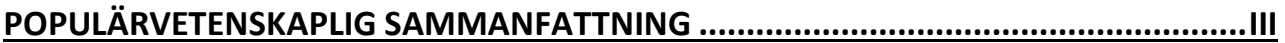

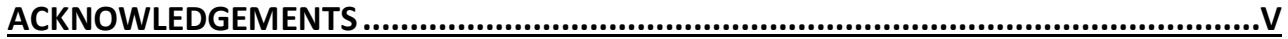

PAPERS INCLUDED IN THE THESIS ........................................................................ VII

CONTRIBUTION TO THE INCLUDED PAPERS............................................................ VIII

PAPERS NOT INCLUDED IN THE THESIS ...................................................................

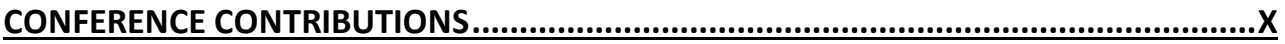

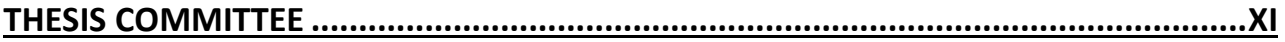

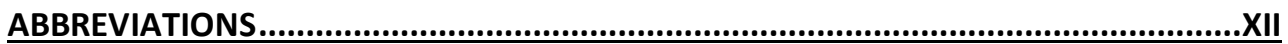

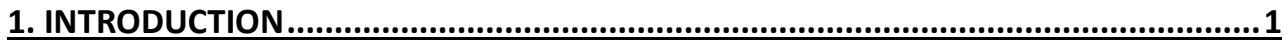

1.1. PORPHYRINS

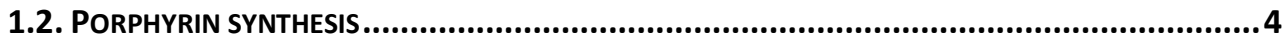

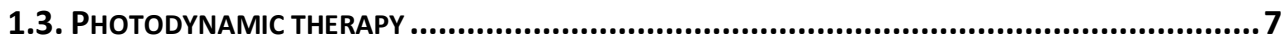

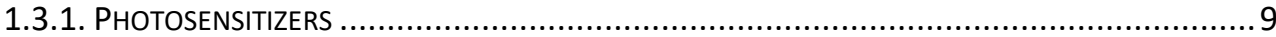

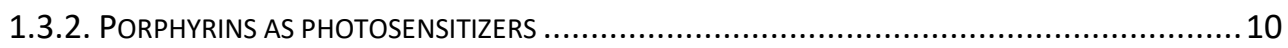

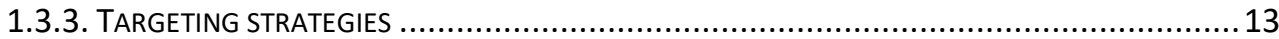

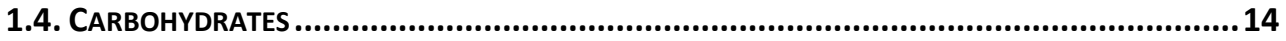

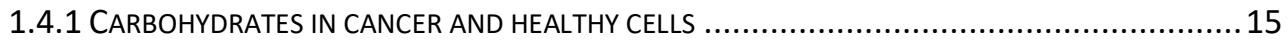


1.5. PROTEIN MISFOLDING AND AMYLOID DISEASE...................................................... 18

1.6. LUMINESCENT CONJUGATED OLIGOTHIOPHENES ...................................................21

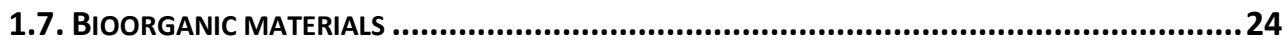

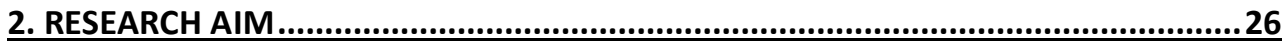

3. DESIGN AND SYNTHESIS OF OLIGOTHIOPHENE PORPHYRIN HYBRIDS (OTPHS) ...27

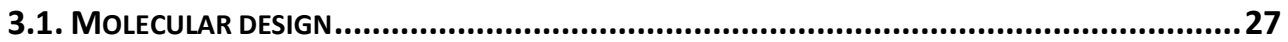

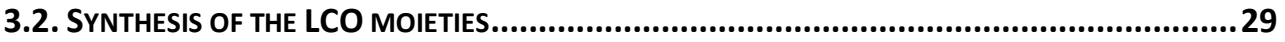

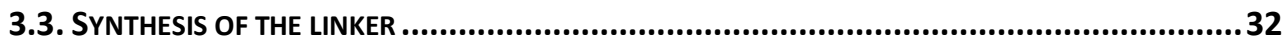

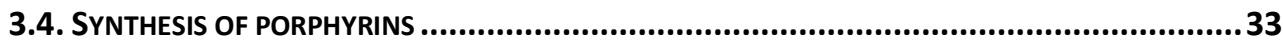

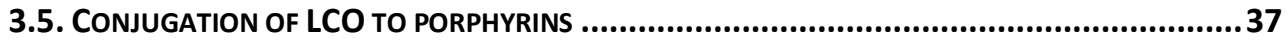

4. OLIGOTHIOPHENE PORPHYRIN HYBRIDS AS FLUORESCENT PROBES..................41

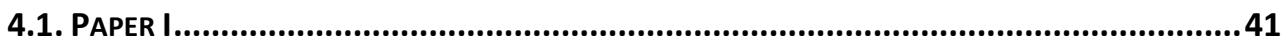

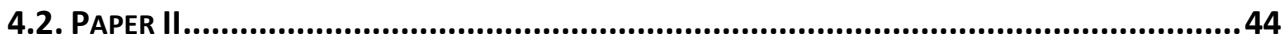

5. OLIGOTHIOPHENE PORPHYRIN HYBRIDS IN CHIROPTICAL BIOORGANIC

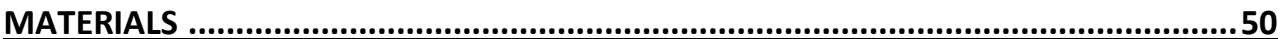

6. DESIGN AND SYNTHESIS OF FLUOROGLYCOSYLATED PORPHYRINS ..................57

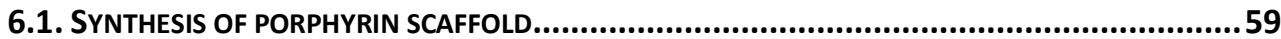

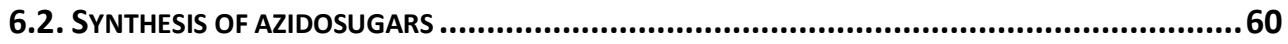

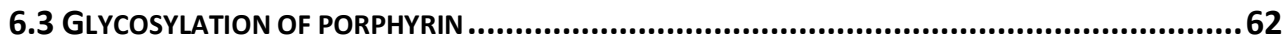

7. EVALUATION OF FLUOROGLYCOSYLATED PORPHYRINS AS POTENTIAL

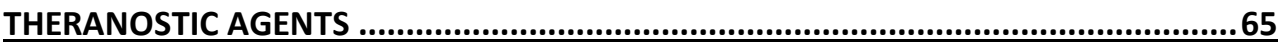

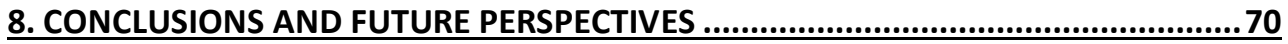


1. SYNTHESIS OF NON-FLUORINATED 2-AZIDOETHYL B-D-GLYCOSIDES..................................72

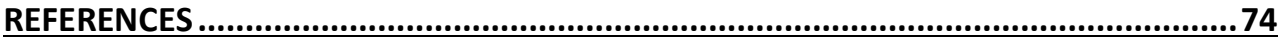




\subsection{Porphyrins}

Porphyrins and porphyrin-related compounds, i.e. porphyrinoids, are endogenously found aromatic heterocycles that take part in some of the life's most important phenomena. A porphyrin contains a porphin core, made up of four alternating pyrrole units and four methin bridges, and peripheral substituents on the porphin (Figure 1). The possible positions for substitution on a porphyrin are the pyrrolic $\beta$-positions, often called just $\beta$, and the methin carbons, designated as meso-positions. The porphyrin core is a fully conjugated structure with a total of $22 \pi$-electrons around it. Eighteen of these $\pi$-electrons participate in the aromatic electron flow, adding up to the Hückel's rule of aromaticity of $4 n+2 \pi$-electrons. ${ }^{1-3}$

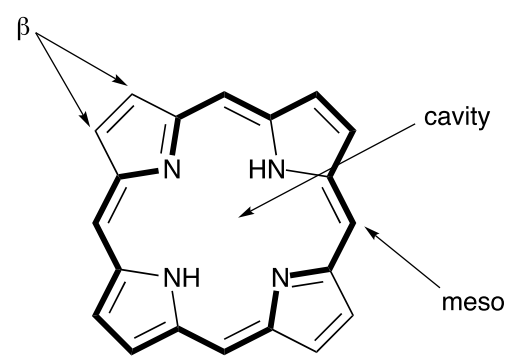

Figure 1. Structure of porphyrin core. The bold line indicates the electron flow inducing the aromaticity.

Two pyrrolic double bonds are therefore excluded from the aromatic unity, which makes them more prone to undergo saturation reactions and electrophilic additions, when compared to the other double bonds in the porphyrin structure. Upon saturating one of these double bonds, a new porphyrinoid is received, called chlorin. When reducing even the other double bond, yet another porphyrinoid is born - bacteriochlorin. Porphyrins, chlorins and bacteriochlorins are the most common and biologically and synthetically the most important porphyrinoids. They are all highly aromatic planar macrocycles with a cavity at the center containing four inner nitrogens. Porphyrinoids can insert a coordinating metal ion into its core with the nitrogen atoms constituting for four possible ligands. There is a plethora of metal ions that can be used to metallate porphyrins. Together with the possibility to functionalize the porphin core with any available side chain and functional group, the metalation renders a way to produce porphyrins of various chemical, physical and biological properties, which has made these compounds the target of interest for both nature and the human kind.

Porphyrinoids are naturally occurring pigments. Their highly conjugated structure makes them deeply colored with porphyrins shifting in various shades of red and purple, whilst chlorins and bacteriochlorins appear in green colors. A typical absorption 
spectrum of a porphyrin exhibits its highest band at around $400 \mathrm{~nm}$, called the Soret band, and four lower secondary bands, the Q-bands, between $500 \mathrm{~nm}$ and $700 \mathrm{~nm}$ (Figure 2A). Upon coordinating a metal ion, however, the higher symmetry introduced into the porphyrin ring induces the merging of the four Q-band into two new Q-bands with a slightly higher intensity. 1,2
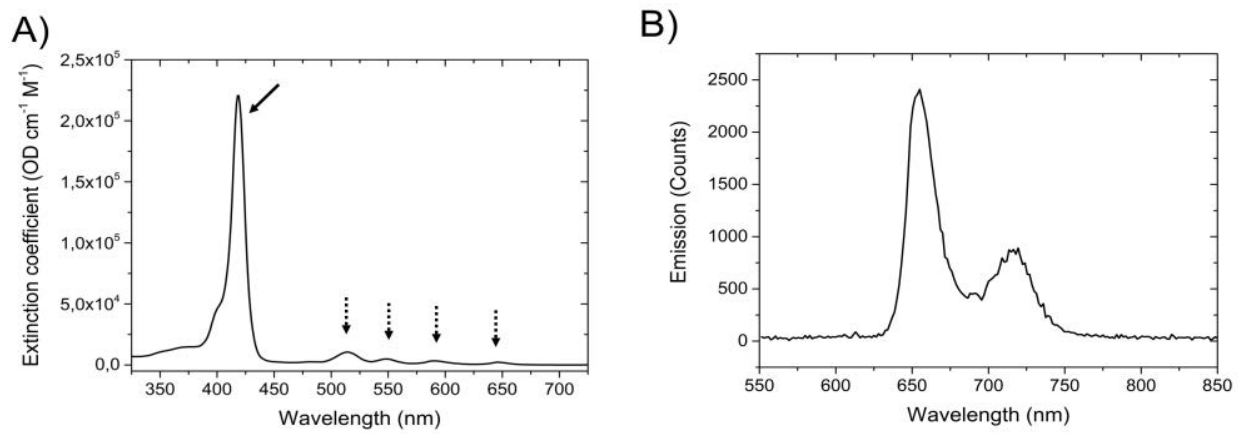

Figure 2. A) Typical absorption spectrum of a proto-form porphyrin with the Soret band (solid arrow) at around $420 \mathrm{~nm}$ and the four lower Q-bands (dashed arrows) at longer wavelengths. B) Emission spectrum of a proto-form porphyrin showing two emission peaks at around $650 \mathrm{~nm}$ and $720 \mathrm{~nm}$. Excitation at $419 \mathrm{~nm}$. Adapted from Arja et al. ChemistryOpen 2018;7;495-503, with permission.

The emission spectrum of an unmetallated porphyrin (proto-porphyrin) shows typically two emission peaks at around $650 \mathrm{~nm}$ and $720 \mathrm{~nm}$ (Figure 2B). Metal complexes of porphyrins have slightly blue-shifted emission peaks showing around $615 \mathrm{~nm}$ and 665 nm. ${ }^{4,5}$

Owing to their optimal structural elements of planar, aromatic structure with the possibility for metal insertion, as well as the photophysical and chemical properties resulting from the highly conjugated chromophore, porphyrinoids are found to carry out several life fundamental tasks in living organisms. Metalloporphyrins found in animals, including humans, play a vital part in the respiratory system of body, being responsible for the oxygen transportation through blood. Hemoglobin protein, found in red blood cells, contains four iron-coordinating porphyrin molecules as prosthetic groups. This iron-porphyrin complex called heme is responsible for the red color of blood, and, even more importantly, is the key to the mechanism of the oxygen transportation as each iron ion can temporarily coordinate an oxygen molecule as its sixth ligand for its later release. Other types of heme can be found in hemoproteins such as myoglobin, catalases, cytochromes and heme peroxidase, where they act as oxygen storage or have a catalytic activity. ${ }^{6}$

Another abundantly present porphyrinoid is the pigment chlorophyll found in plants and bacteria. Chlorophylls are magnesium coordinating chlorins incorporated in thylakoid membranes of chloroplasts where they function to harvest light energy and to convert it into chemical energy, as well as to produce molecular oxygen. ${ }^{6}$ 
The above-mentioned chemical and physical properties and the fascinating biological functions of porphyrins and the related compounds have evoked the interest of scientists in numerous fields, including catalysis chemistry, material science of solar energy and sensors, fluorescent probes, drug development and medicine. Figure 3 summarizes some possible applications for compounds containing porphin structure and there is no difficulty in finding illustrative examples for each application area in published literature.

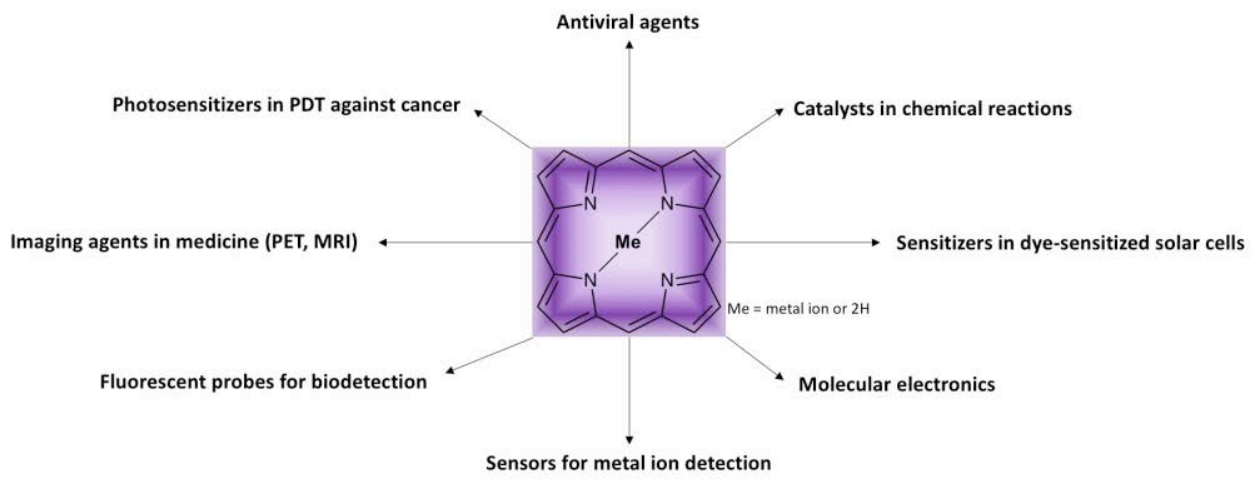

Figure 3. Areas of possible applications for porphyrins.

Iron-metallated porphyrins have successfully been used as biomimetic oxidation catalysts of peroxidase substrates ${ }^{7}$, while a ruthenium porphyrin complex has shown high catalytic activity in epoxidation of olefins and alcohols to ketones ${ }^{8}$. The potential of porphyrins being used as sensitizers in dye-sensitized solar cells to harvest light energy and convert it into electrical energy has been inspired by the photosynthesis and is under constant research for development and optimization. ${ }^{9}$ Owing to their metal complexation properties porphyrins have been evaluated as sensors for trace metal detection, where the altered optical spectra of porphyrins upon binding a metal ion can be used as a positive detection read-out to identify for example the presence of toxic heavy metals. ${ }^{5,10}$ Porphyrins are also utilized as luminescent probes for biodetection, where their affinity for various biological structures together with the strong optical signature serves for visualization and study of the biological targets and processes. ${ }^{11} \mathrm{In}$ medicine, porphyrinoids are used for both diagnosis and for therapy. Porphyrins are attractive scaffolds for imaging agents where they are used as probes in fluorescence microscopy imaging due to their inherent light absorbing-emitting properties. When featuring a radioisotope, porphyrins can be used as positron emission tomography (PET) tracers ${ }^{12}$, or when they are complexed with the paramagnetic gadolinium(III) ion they can be used as contrast agents in magnetic resonance imaging (MRI). ${ }^{13}$ The therapeutic use of porphyrinoids includes the utilization of these tetrapyrrolic structures for photodynamic therapy (PDT) to kill cancer cells and for photodynamic inactivation of bacteria. ${ }^{13}$ Heme and other related porphyrins have shown a promising inhibition effect on some of the most threatening viruses to human beings, i.e. hepatitis $\mathrm{C}$, hepatitis $\mathrm{B}$ 
and HIV. ${ }^{14}$ The possibility of combining both the therapeutic and the diagnostic properties in the same molecule makes porphyrins a fitting scaffold for synthesizing theranostic agents for medicinal use.

\subsection{Porphyrin synthesis}

Synthesis of porphyrins is a challenging yet inspiring task. The formation of the porphin core, nevertheless so stable, is complicated by the fact that, despite the methodology chosen for the synthesis, competing side reactions always dramatically decrease the yields and significantly complicate the purification process. This is especially true when the target porphyrin possesses low symmetry.

The modern history of porphyrin synthesis begins in 1929 when Hans Fischer publishes his work on using dipyrromethene salts in organic acid solutions for producing numerous classical naturally occurring porphyrins, although scanty in yields. ${ }^{15}$

Porphyrin synthesis can be roughly divided into four categories: monopyrrole tetramerization, $[2+2]$ route, $[3+1]$ route and synthesis from open-chain tetrapyrrolic intermediates. The synthetically most straight-forward method for gaining porphyrins is monopyrrole tetramerization where suitable pyrrole and aldehyde are reacted together for cyclisation followed by oxidation (Figure 4). The method was first developed by Rothemund ${ }^{16}$ and further modified by Adler and Longo ${ }^{17}$. In these early approaches the starting pyrrole and aldehyde were condensed together in refluxing organic acids in the presence of atmospheric oxygen for aromatization. It was the first time in the history of chemistry when synthetic porphyrins became accessible via a simple reaction. The method has of course it limitations, the biggest of them concerning the symmetry issue, making the reaction viable only for highly symmetrical porphyrins. Moreover, the harsh reactions conditions used do not allow for any sensitive substituents on the becoming porphyrin. Some major improvements on monopyrrole tetramerization have much later been made by Lindsey ${ }^{18}$ and his group. Instead of using carboxylic acid solvents under heating, his method applies highly diluted solutions of pyrrole and aldehyde in dichloromethane in the presence of a catalytic amount of a Lewis acid at room temperature. The reaction is of one-pot two-step type, where the condensation is followed by the oxidation with an organic oxidant, usually 2,3-dichloro-5,6-dicyano1,4-benzoquinone (DDQ) or p-chloranil. The mild conditions tolerate a lot of functional groups, making the variation of porphyrins easily achieved. Nevertheless, the symmetry problem still remains and, for that, the monopyrrole tetramerization is really suitable only for porphyrins made up of one single type of pyrrole and aldehyde. Moreover, the pyrrole must be symmetrical about its $C_{2}$ symmetry axis in order to avoid formation of several regioisomeric porphyrins. 


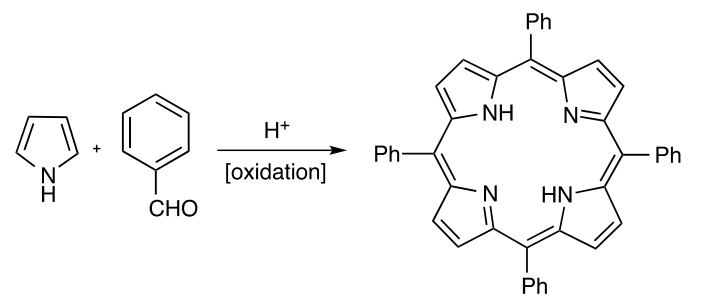

Figure 4. Porphyrin synthesis using monopyrrole tetramerization.

The remaining three categories for methodologies of porphyrin synthesis utilize preprepared pyrrolic intermediates of different lengths and can be categorized therefore as either the $[2+2]$ route, the $[3+1]$ route or the synthesis from open-chain tetrapyrrolic intermediates.

The [2+2] approach makes use of dipyrrolic building blocks, such as dipyrromethanes (or dipyrranes), their oxidized counterpart dipyrromethenes, or less commonly dipyrroketons ${ }^{19,20}$ (Figure 5). Dipyrromethenes dominated the first part of the history of the $[2+2]$ route due to their stable nature and the easiness to produce and isolate them as their hydrohalide salts. A famous illustration of this type of porphyrin synthesis is by Hans Fischer who produced deuteroporphyrin IX ${ }^{15}$, paving the way to the Nobel Prize award in 1930. The reaction conditions, however, for this type of porphyrin synthesis involved boiling dipyrromethenes in formic acids or organic acid melts at extremely elevated temperatures and are subsequently unsuitable for any elaborate substituents on dipyrromethenes. Dipyrromethanes were for a long time considered too unstable to be suitable for use in porphyrin synthesis. Their tendency to open up into fragments and to the starting molecules in acidic environment and to reform with a different substitution pattern, a process called scrambling, may jeopardize the formation of only one regioisomerically pure porphyrin. Dipyrromethanes are also sensitive to oxidation, requiring that more care is to be taken when storing them for longer periods. MacDonald's [2+2] approach of porphyrin synthesis using dipyrromethanes, published in $1960^{21}$, broke the long existing distrust into these dipyrrolic intermediates and showed that under mild, controlled conditions the method is highly useful allowing for a vast range of peripheral substituents and for the possibility for endless combinations of these building blocks. The Lindsey group has done a great developmental work on the synthesis and modification of dipyrromethanes and their subsequent use in porphyrin synthesis. ${ }^{22}$ Depending on whether large quantities of dipyrromethane are needed or a highly specific substitution pattern is sought, there are a couple of very effective methods for producing these intermediates. ${ }^{22}$ The one-flask reaction, using pyrrole as the solvents and either trifluoroacetic acid (TFA), $\mathrm{BF}_{3} \cdot \mathrm{O}(\mathrm{Et})_{2}$ or $\mathrm{InCl}_{3}$ as the catalyst, is usually suitable for most of synthetic requirements. ${ }^{23,24}$ The large excess of pyrrole minimizes the risk for formation of longer pyrrolic intermediates, whereas the remaining pyrrole can easily be purified by distillation and reused. 
Different meso-substitution patterns on the becoming porphyrin require different extent of modification of the including dipyrromethanes at the pyrrolic $\alpha$-positions, which entails acylation and/or reduction of either one or both of them.
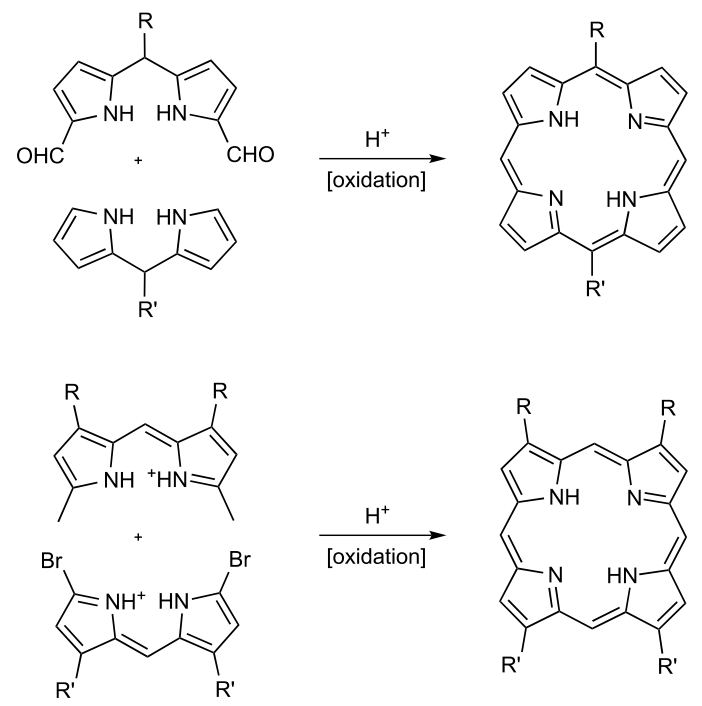

Figure 5. Porphyrin synthesis from the [2+2] approach using dipyrromethanes (upper panel) or dipyrromethenes (lower panel).

By extending dipyrromethanes with another methine group and another pyrrole adjacent to it, following the methodologies analogous to dipyrromethane formation, a tripyrrolic intermediate tripyrromethane (also called tripyrrane) is produced. Tripyrromethanes can undergo acid catalyzed condensation reactions with properly functionalized monopyrrolic building blocks in the [3+1] route, yielding porphyrins with the possibility to very highly asymmetrical substitution patterns (Figure 6 upper panel). ${ }^{25}$

An even more precise methodology for highly substituted porphyrins with low or no symmetry employs open-chain tetrapyrrolic intermediates bilanes or bilenes (Figure 6 lower panel). ${ }^{19,26,27}$ In this approach the major part of the work is put on the synthesis of the tetrapyrrolic intermediate as it must be built from a step-by-step sequence of reactions using pyrrole and methine group surrogates, often acyl group donors. As always, bridging of one pyrrolic side to another via a one-carbon linkage requires careful planning and suitable protecting groups for desired regioselectivity. Moreover, the inherent problem with scrambling of pyrrane intermediates when using acidic conditions, may cause the formation of recombined products. 

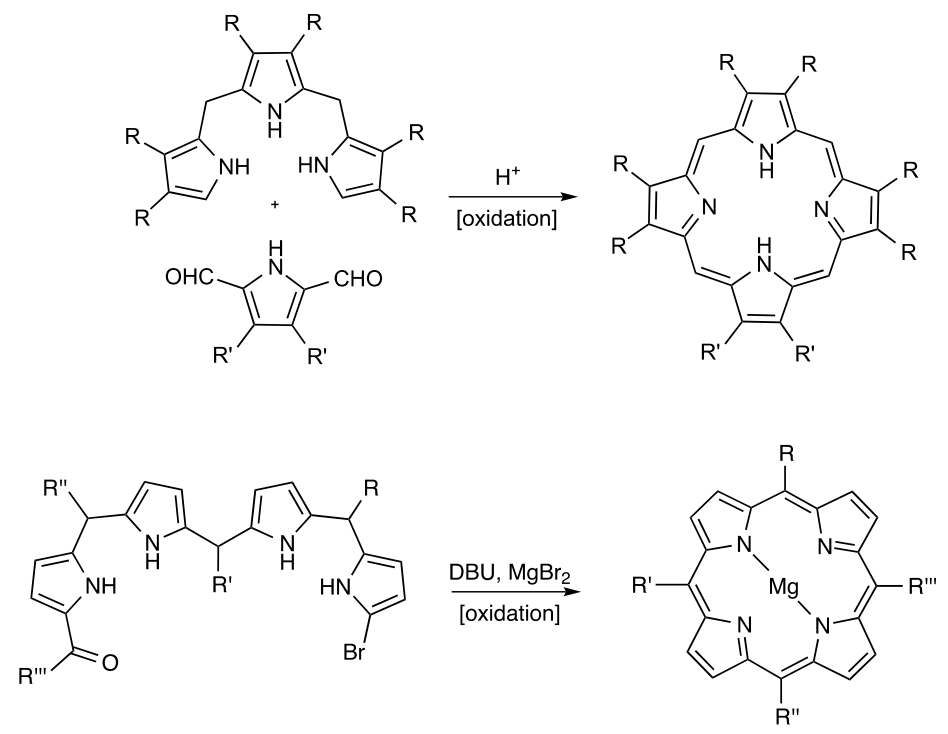

Figure 6. Porphyrin synthesis using the [3+1] approach (upper panel) or from an open-chain tetrapyrrolic intermediate, bilane (lower panel).

All the above-mentioned categories of porphyrin synthesis have their advantages and disadvantages, and which approach is chosen depends on the nature of the target porphyrin. Mature porphyrins can further be modified in a plethora of various reactions, expanding the possibility to functionalize these interesting macrocycles past their formation. The almost endless possibilities of the synthesis and organic chemistry of porphyrins is summarized in modest four hundred pages of Volume 1 in The Porphyrin Handbook by Kadish, Smith and Guilard. ${ }^{19}$

\subsection{Photodynamic therapy}

Photodynamic therapy (PDT) is a minimally invasive therapy that combines a photoactive drug, i.e. a photosensitizer (PS), and radiation with light of a specific wavelength to initiate radical reactions that destroy cancer tissue or other pathological cells. The two components of PDT, the photosensitizer and the light, are nontoxic by themselves. Upon co-localizing them, however, the toxicity is created as the photosensitizer in its electronically excited state interacts with the nearby molecular oxygen generating cytotoxic singlet oxygen. ${ }^{28}$

The photophysical and photochemical principles behind PDT are summarized in Figure 7. Shortly after administration of PS to a patient, it would accumulate in the diseased tissue, which, in case of a theranostic agent, can be confirmed by an appropriate diagnostic technique. The PS in its singlet ground state is excited to its singlet excited state by a light of an appropriate wavelength. Through a mechanism called intersystem 
crossing, excited singlet PS is converted to excited triplet PS, meaning that the spin of the excited electron changes to now be parallel to the spin of the electron in the ground state. A prerequisite of PS in PDT is a high intersystem crossing probability that would lead to a large population of PS in its triplet excited state. ${ }^{28,29}$ The triplet excited state is relatively long-lived (microseconds) compared to the singlet excited state, due to the fact that relaxation of the triplet excited state back to the singlet ground state through emission is a spin-forbidden process. PS in its excited triplet state can therefore undergo photochemical reactions underlying the PDT effect. These reactions are categorized as Type I or Type II. In the Type II pathway, the excited triplet of PS interacts with molecular oxygen that is one of the few molecules that exist as triplet in its ground state. ${ }^{30}$ By transferring its energy to molecular oxygen, PS generates excited singlet oxygen that is a strongly oxidizing radical species undergoing a series of cell-damaging reactions that would finally lead to cell death.

In the Type I pathway, the excited triplet PS interacts directly with biomolecular substrates in the cell, e.g. cell membrane, proteins or DNA. The PS donates an electron or a proton to reactive functional groups of various substrates, that in turn can react with oxygen, generating reactive oxygen species (ROS), such as hydroxyl radical $\left(\mathrm{OH}^{*}\right)$ and peroxyl radicals $\left(\mathrm{ROO}^{*}\right)$. Different types of radical chain-reactions will eventually damage the cell to the degree it must go into cell death. ${ }^{31}$ Depending on the particular PS used and where in a cell it accumulates, either Type I, Type II or both of the pathways may take place.

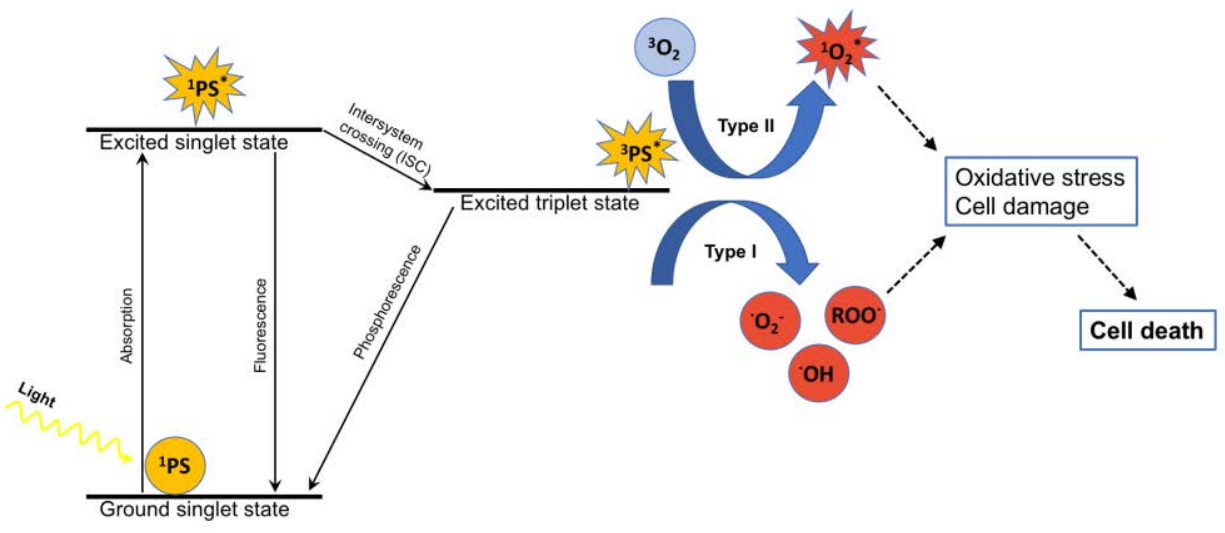

Figure 7. Photophysical processes involved in photodynamic therapy. Starting with PS absorbing a photon, several steps later two types of photochemical pathways (I and II) lead to cell death. 
Due to the high reactivity and short half-life of singlet oxygen and the ROS generated by the photosensitization, the damage they create is limited within the radius of a cell. ${ }^{32}$ One of the main advantages of PDT is the possibility for dual selectivity. PDT can be made selective by restricting the light exposure only to the area of body that needs to be treated. Besides that, photosensitizers are designed to display sufficient selectivity for cells of malignant tissue over healthy cells. Continuous work is being done on developing molecules that live up to the criteria for an ideal PS.

The shortcomings of PDT are associated with the selectivity of PS for diseased tissue and the accessibility of the light to the tumor location. If the PS is not selective enough and accumulates in other parts of the body where it lingers for a substantial time period, the patient experiences undesired side effect of light sensitivity and must avoid the exposure to direct sun light. ${ }^{33}$ As the light needed to excite PS has relatively short penetration depth in the biological tissue, the malign cells killed by PDT should ideally be located in easily accessible areas of body, such as skin and linings of the inner organs and soft tissue. ${ }^{34}$ Advanced instrumentation of clinically oriented light delivery systems, consisting of lasers and fiber optics, can be used to treat internal tumors. However, the equipment is expensive and may not be readily available. ${ }^{35}$

\subsubsection{Photosensitizers}

For a chemical compound to be considered as a PS, certain criteria need to be met. Characteristics of an ideal PS are derived from the demands of the PS to undergo the photophysical and -chemical process underlying the PDT effect, as well as ensuring the right location for the therapy. An optimal PS must be photoactive in the process of generating singlet oxygen and other reactive oxygen species upon excitation. Therefore, it must have a high quantum yield of triplet formation at its exited state through the spinforbidden ISC, with sufficiently high triplet energy. ${ }^{29}$ The PS needs to be effective at converting the ground state triplet molecular oxygen to the radical singlet oxygen, in other words, to have a high singlet oxygen quantum yield. Moreover, the toxic effect of the PS should occur only upon irradiation and the PS must show low or no dark toxicity.

In order for the PDT processes to be effective, high dosage of light with an appropriate wavelength needs to reach the PS in the target tissue. The absorption of the PS needs thus to have a high absorption at the wavelengths within a range designated as "the therapeutic window". The therapeutic window of the light used in PDT usually spans from $600 \mathrm{~nm}$ to $800 \mathrm{~nm}$ and is determined at the lower end by the decreased tissue penetration due to the scattering and absorption of the light by endogenous chromophores. The higher end of around $800 \mathrm{~nm}$, however, is set after the fact that these photons do not have enough energy for the triplet PS to convert ground state oxygen to its excited singlet state. ${ }^{36}$

Finally, the ideal PSs need to display advantageous biodistribution and pharmacokinetics, with high selectivity for cancer cells and high cellular uptake in order to increase the specificity of the treatment. The molecules of PS need to be metabolically 
stable in order to remain in cancer cells for sufficiently long time for the photo-excitation procedure to be carried out. ${ }^{31}$ At the same, the pharmacokinetic clearance from the rest of the body after the treatment should be rapid to avoid side-effects such as prolonged photosensitivity of skin. ${ }^{35}$ The aspects of biodistribution, bioavailability and pharmacokinetics of PDT dictates designing a PS structure of right polarity, solubility and with appropriate side chain functionalities and targeting modalities. Despite the countless efforts made, it is difficult to predict the behavior of PSs in such complex systems as a human body.

\subsubsection{Porphyrins as photosensitizers}

Porphyrins and porphyrin-related compounds have for long been known to possess photodynamic properties and have since the early 1990s been used in clinic as photosensitizers to treat cancer. ${ }^{37,38}$ In fact, the majority of compounds studied as PS or used in clinics for PDT are based on naturally occurring tetrapyrrolic macrocycles i.e. porphyrins, chlorins and bacteriochlorins (Figure 8). Depending on the degree of saturation about the porphin core, these porphyrinoids exhibit slightly different photophysical properties, with fully unsaturated porphyrin showing its highest absorption band just above $400 \mathrm{~nm}$ and two to four smaller secondary absorption bands between 500 and $700 \mathrm{~nm}$. Chlorins, having one less double bond, exhibit a significant increase in one of the secondary absorption bands at around $650 \mathrm{~nm}$, and bacteriochlorins with two less double bonds display the highest absorption band at around $770 \mathrm{~nm} .{ }^{36}$ Synthetically, however, porphyrins are the easiest to make and have proven to be most stable upon storage and robust during chemical derivatizations..$^{39-41}$ 

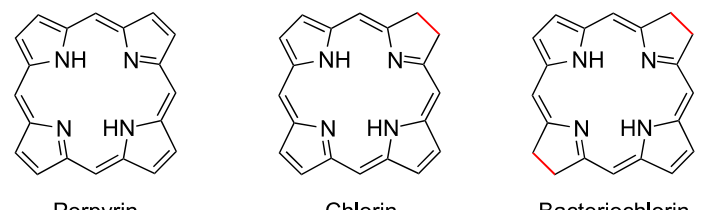

Porpyrin

Chlorin

Bacteriochlorin
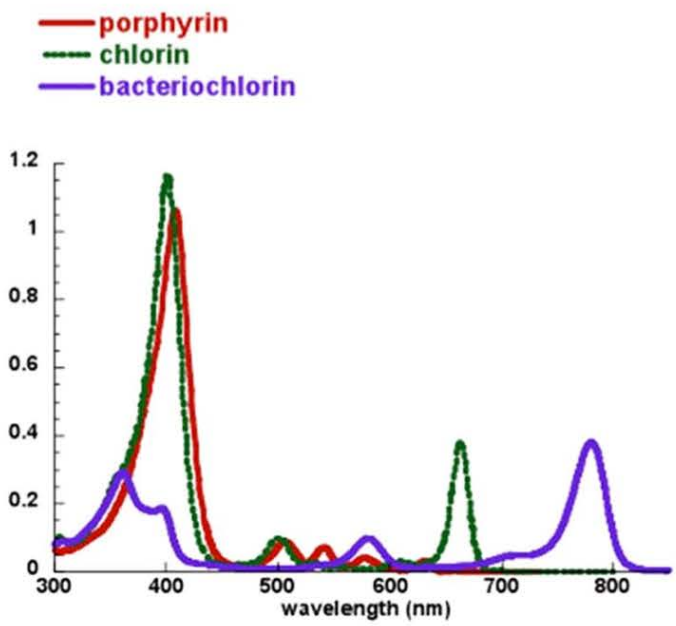

Figure 8. Structures and typical absorbance spectra of porphyrinoids. Adapted from Abrahamse et al. Biochemical Journal 2016;473;347-364, with permission. ${ }^{36}$

The development of porphyrin-based PSs for the use in PDT has gone through different stages, where focus on tackling a specific type of shortcoming has helped to evolve three generations of PSs. The first generation porphyrin-based PS was a purified form of the complex mixture of hematoporphyrin derivatives $(\mathrm{HpD})$ that was the first PS to receive the regulatory approval for clinical use in 1990s and has been sold under the name of Photofrin ${ }^{38}$ (Figure 9).

The strive after PSs with a water-soluble and well-defined structure with a higher absorption of near-infrared (NIR) light and better tumor-localizing ability eventually led to the second generation of porphyrin-based PSs ${ }^{36}$ (Figure 10). The synthetic strategies of the second generation porphyrin-based PSs covered a series of modifications on the previously synthesized PSs structures. Modified chromophores were used for enhanced absorption, while various side chains were tested for improved solubility and biodistribution. ${ }^{38}$

The third generation of porphyrin-based PSs have been developed with the focus on further improving the specificity of the treatment by increasing cancer cell selectivity over healthy cells. In this regard, the principles of targeted drug delivery via conjugation of porphyrins to targeting modalities, have been utilized. Small biologically active molecules, such as carbohydrates, amino acids, peptides, nucleotides and lipids, have 
been tethered to porphyrin-based PSs in hope of achieving pronounced tumor localizing properties (Figure 11). ${ }^{29,36}$

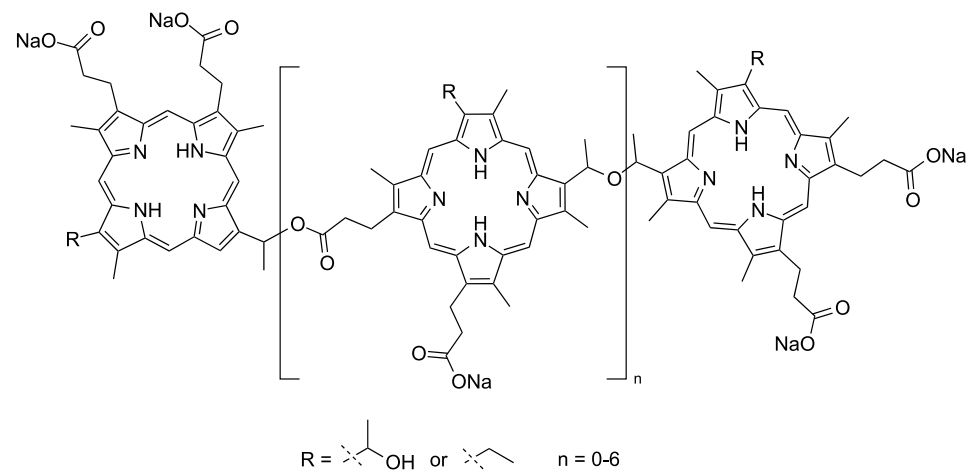

Figure 9. Structure of the first generation of porphyrin-based photosensitizers, Photofrin.

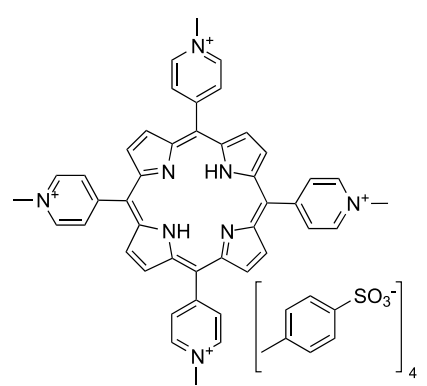

$5,10,15,20$-Tetrakis(1-methylpyridinium-4-yl)porphyrin tosylate

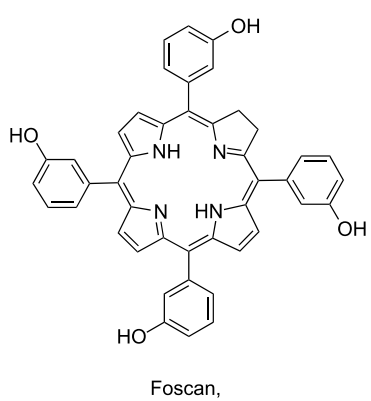

m-tetrahydroxyphenylchlorin

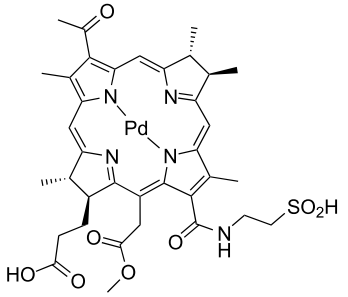

TOOKAD Soluble, WST-11 (bacteriochlorin)

Figure 10. Structures of a selection of the second generation porphyrin-based photosensitizers. 


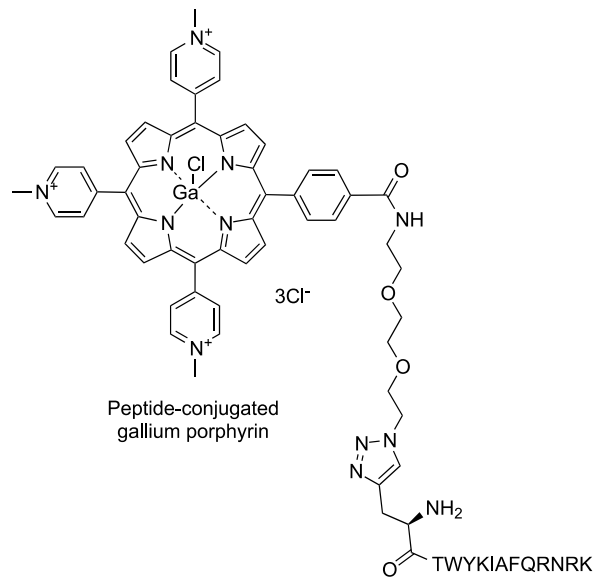

Figure 11. Structure of a third generation porphyrin-based photosensitizer featuring a peptide as a targeting moiety. ${ }^{42}$

Yet another feature of porphyrinoids is the possibility for metalation of the central tetrapyrrolic structure. Porphyrin core often holds a coordinating metal ion that can either be exactly inserted into the cavity, lying on the same plane as the coordinating inner nitrogens, or be slightly elevated forming a pyramidal coordination geometry to the porphyrin nitrogens. It has been found, that coordination with diamagnetic metal ions allows the porphyrin to retain its photosensitizing properties whilst paramagnetic metal ions quench the effect. ${ }^{31,43-45}$ Thus, suitable metal ions for coordination of porphyrins for PDT include $\mathrm{Zn}^{2+}, \mathrm{Pd}^{2+}, \mathrm{In}^{3+}, \mathrm{Sn}^{4+}, \mathrm{Lu}^{3+}, \mathrm{Al}^{3+}, \mathrm{Si}^{4+}, \mathrm{Ga}^{3+}$.

\subsubsection{Targeting strategies}

Porphyrins show inherent propensity of tumor tissue enrichment that has been ascribed to their amphiphilic nature that facilitates binding to various blood-circulating proteins and the subsequent transportation and uptake into malignant cells. ${ }^{12,46}$ This general tendency can, however, further be improved by means of rationally designed synthesis guided by the knowledge of alterations in cancer cell physiology. A hallmark of most types of cancer is fast and uncontrolled proliferation of cancer cells. As a consequence, cancer cells are in desperate need for a high and steady supply of nutrients, in particular, carbohydrates, fatty acids and amino acids, in order to synthesize essential biomolecules. ${ }^{47}$ The altered metabolism of cancer cells and the changes in the expression of various receptors can be taken advantage of when designing PSs for targeted cancer therapy.

Boyed by the knowledge of a specific cancer cell line and/or neoplastic conditions in general, ligation of PSs to molecular ligands recognizing specific cell surface receptors, facilitates uptake and accumulation of the drug into the cancer cells. Using such targeting modalities has been proven successful in many studies. For example, the antiHER2 monoclonal antibody targeting the HER2 epidermal growth factor receptor, that 
is overexpressed on breast cancer cells, successfully increases cancer cell selectivity of its porphyrinoid conjugates. ${ }^{48}$ Similarly, small peptides, e.g. the dodecapeptide by Bryden et. al. having affinity for the $\alpha_{6} \beta_{1}$-integrin that is upregulated in various cancers ${ }^{42}$ have been demonstrated to fulfill their function to improve cancer cell selectivity.

Concerning other classes of compounds, literature has numerous examples of small organic molecules with affinity for specific receptors overexpressed in various malignant tissues. 4-arylaminoquinazolines show high affinity for the growth factor receptors EGFR and VEGFR and have therefore served the targeting role in PSs for PDT. ${ }^{49}$ Many tumor cell lines, including ovarian, colorectal, endometrial, breast, lung carcinomas and metastases, exhibit upregulation of folate receptors (FA), in particular FA- $\alpha^{50}$, which has made conjugation of folic acid an attractive targeting strategy. Based on the premise of the increased expression of FA- $\alpha$ in malign cells, Gravier et al. conjugated a folic acid moiety to FDA-approved PSs used in clinic, mtetrahydroxyphenylchlorin or Foscan, and witnessed a two-fold increase in the accumulation of the conjugate in tumor cells as compared to Foscan alone. ${ }^{51}$ Furthermore, the tumor-versus-healthy cell selectivity improved significantly.

Carbohydrates, being the primary source of energy for fast-growing and proliferating cells, make an attractive tool for improving tumor localizing properties of PSs. Cancer cells, in general, have due to their up-regulated metabolism higher consumption of glucose, a phenomenon known as the Warburg effect. ${ }^{52}$ In addition, different cancer cell-lines over-express receptors for different carbohydrates ${ }^{13}$ that can be utilized for selective targeting of a specific type of malign tissue via functionalization of PSs with mono- and oligosaccharides. ${ }^{53-55}$ The topic on carbohydrates being exploited in cancer drug delivery and the detailed explanations for the causes laying as the ground to it will be discussed in the next section.

\subsection{Carbohydrates}

Carbohydrates are a class of molecules with the general formula $\mathrm{C}_{\mathrm{x}}\left(\mathrm{H}_{2} \mathrm{O}\right)_{\mathrm{y}}$ explaining their name as hydrated carbons. Alternative names for simple carbohydrates are sugars or saccharides. Functionally, carbohydrates can be described as polyhydroxy aldehydes or ketones, although they primarily exist as their cyclic hemiacetals or acetals due to the intramolecular cyclization reaction. The biologically most prevalent structures for monomeric sugars are six-carbon molecules that form either 5- or 6-membered rings. The cyclization yields monosaccharides that upon condensation reactions with other monosaccharides, called glycosylation, build oligosaccharides (2-10 molecules of monosaccharides) or polysaccharides. Some well-known disaccharides include maltose, consisting of 2 glucose units, sucrose, consisting of a glucose and a fructose, and lactose, made of glucose and galactose. ${ }^{56}$ 
Carbohydrate chemistry is made exceedingly complex because the seemingly similar molecules of monosaccharides possessing a very high degree of asymmetry suddenly behave completely differently both in synthetic chemistry and in biological environment. With every $\mathrm{CH}(\mathrm{OH})$ unit in a molecule a stereogenic centre is introduced, leading to $2^{\mathrm{n}}$ stereoisomers for an acyclic form of a monosugar containing $\mathrm{n}$ stereogenic centers. All these asymmetric centers are assigned (R) or (S). Furthermore, cyclization of the acyclic form to the cyclic form produces a new asymmetric center at $\mathrm{C} 1$ and two stereoisomers - anomers - can be formed, labelled $\alpha$ - and $\beta$-anomer (Figure 12).

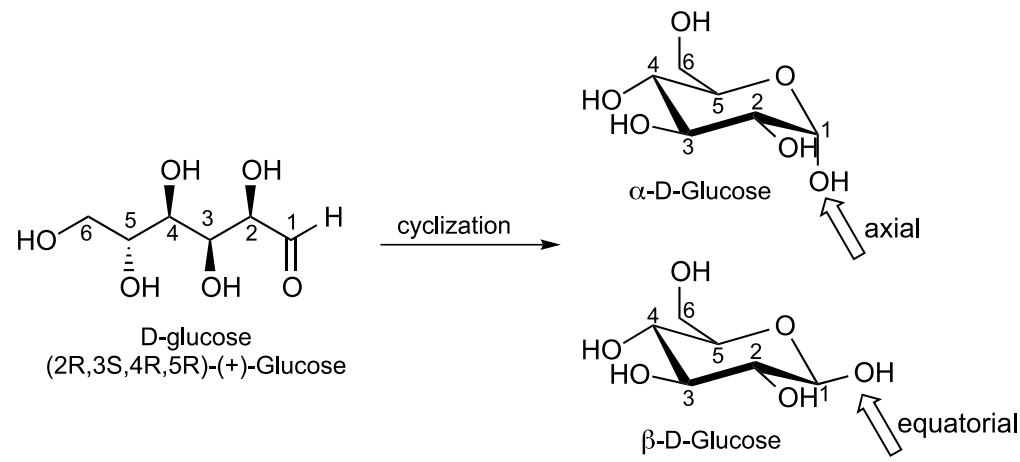

Figure 12. Ring closure of acyclic monosaccharides produces diastereomeric $\alpha$-and $\beta$-anomers at $C-1$. The example illustrates cyclization of D-glucose.

The D- and L-description of sugars provides information about the configurational stereochemistry of a given sugar, based on the direction of the hydroxyl group at the last stereocenter in a drawn Fischer projection. ${ }^{57}$ The reaction of a cyclic sugar at $\mathrm{C} 1$ with a nucleophile, for example an alcohol, under acidic conditions transforms the hemiacetal to an acetal that is called a glycoside. Glycosides have vital roles in biological systems and the glycosidic linkage conjugates carbohydrates to a plethora of organic and bioorganic molecules and macromolecules, including other sugars, proteins and lipids.

\subsubsection{Carbohydrates in cancer and healthy cells}

The role of sugars in nature cannot be overestimated. The monosaccharide glucose is the most important energy source for cells. After it is taken up into a cell, it is metabolized in a series of enzyme catalyzed reactions, termed glycolysis, citric acid cycle and oxidative phosphorylation, releasing energy in form of ATP that cells can exploit for a variety of cell functions. ${ }^{6}$

Besides the fueling role, carbohydrates perform other important tasks in living organisms, such as making up the mechanical support in form of cellulose and chitin, and being a component in protective barriers of slime and mucus. ${ }^{58}$

Carbohydrates are covalently linked to proteins and lipids, forming glycoproteins and glycolipids that are incorporated into cell membranes where they play an essential role 
in cell recognition and cell signaling. Receptors for various carbohydrates are therefore also expressed on the surfaces of cells in order to match the signal carrying sugars. Here the importance of the stereochemical complexity of carbohydrate structure and chemistry comes clear, as the subtle changes in the configuration of a monosaccharide unit may affect its interaction with cell membrane proteins. This gives the biological systems the means to utilize the huge family of carbohydrates to the endless tasks of signaling and recognition.

Inspired by their ubiquitous presence and vital role in biological systems, carbohydrates make an important focus for synthetic and medicinal chemists, as well as cell biologists. Using synthetic carbohydrates for biochemical and biological studies can reveal useful information about processes taking place on the cellular and biomolecular level. As mentioned above, carbohydrates are successfully used as targeting modalities in PDT for cancer therapy. This potentiality results from the increased metabolism of carbohydrates in malign cells as compared to benign cells, which engages upregulated expression of carbohydrate-specific receptors on malign cell membrane and higher glycolytic rate in cytosol..$^{59}$ The phenomenon was first studied by Warburg in 1956 in "The origin of cancer cells". ${ }^{52}$ In fact, it has been shown that both the influx rate of glucose molecules into some cancer cells and the rate of glycolysis to harvest the energy stored in glucose is up to 30 -fold greater than in normal cells. ${ }^{59}$ The enhanced glucose transport into cancer cells is facilitated by upregulation of transporter proteins for glucose in the plasma membrane, namely GLUT1 and, in some cases, also GLUT3, GLUT12 and SGLT1. Besides the stored energy, glucose is also used as a carbon source and as a precursor for synthesis of necessary biomolecules including lipids and nucleic acids.

The overabundance of transporter proteins for carbohydrates in cancer cells can be taken advantages of when designing target-specific photosensitizers for PDT. In a study by Tanaka et al. conjugation of glucose at four sites on a highly fluorinated chlorin, yielded a water-soluble PS, $\mathrm{H}_{2}$ TFPC-SGlc (Figure 13A), that, when compared to its nonglycosylated counterpart, showed a significantly higher cellular uptake and improved cancer cell selectivity both in vitro and in vivo. On the contrary, the cellular uptake of the glycosylated and non-glycosylated PS into benign cells was on a comparable level. The results could be correlated to the degree of expression of glucose transporters on the used cell lines, measured by the Western blot and RT-PCR analysis. ${ }^{54}$ 


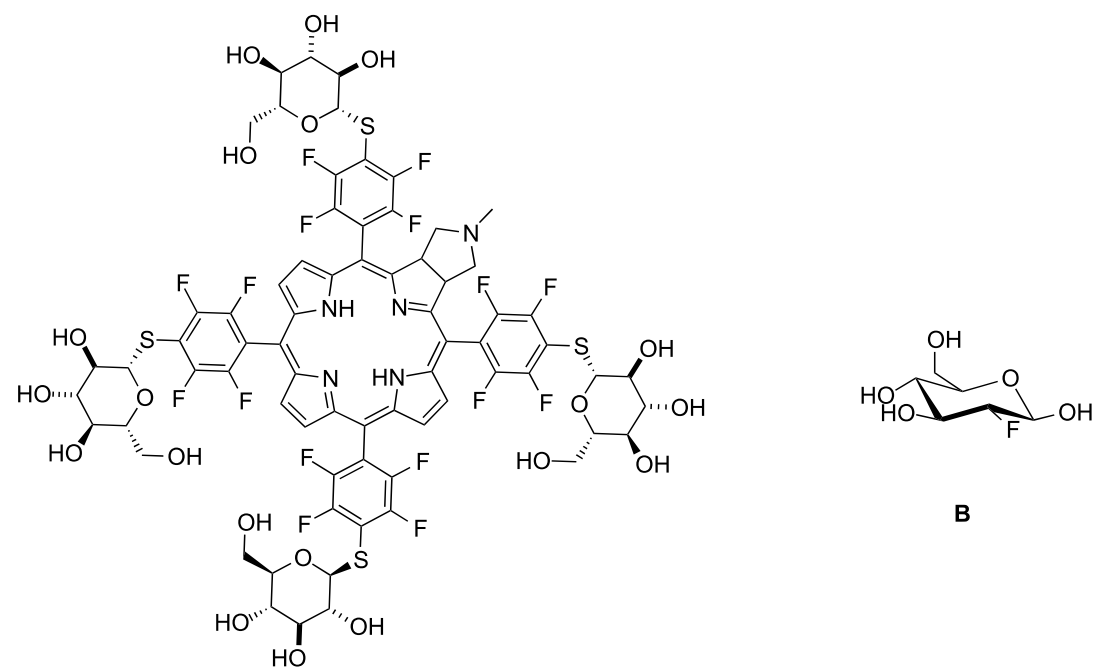

A

Figure 13. A) Structure of tetraglucosylated chlorin, $\mathrm{H}_{2}$ TFPC-SGlc, that showed superior cancer cell selective and accumulating properties as compared to the corresponding non-glucosylated chlorin. ${ }^{54}$ B) Structure of 2-fluoro-2-deoxy-D-glucose (FDG).

Numerous other examples can be found in the literature, where the glycosylation strategy is used in attempts to improve tumor-specific interactions of PSs and the subsequent PDT. Besides glucose, other carbohydrates have been used, such as galactose, mannose and lactose, and different lengths and types of linkage units have been tested to investigate their role in cellular uptake, chemical stability and photocytotoxicity. ${ }^{53-55}$

The special characteristics of glucose metabolism in cancer cells have made possible for the well-known and widely-utilized cancer diagnostics by positron emission tomography (PET), where an ${ }^{18}$ F-radio-labelled derivative of glucose - 2-fluoro-2deoxy-D-glucose (FDG) (Figure 13B) - is used to visualize tumor tissue. The method is based on the preferential accumulation of FDG into cancer cells due to the above described factors. Moreover, the FDG molecule, lacking a hydroxyl group at C2 cannot go through the glycolytic sequence in the normal manner, but is halted after the first phosphorylation step and gets metabolically trapped in the cells. This metabolic trapping retains the PET probe in the target tissue for a sufficiently long time for the PET scans to be done and also enhances the contrast to the background. ${ }^{59}$ The same principle as behind the PET imaging can be used in therapy to increase cancer cell affinity of FDGconjugated drugs and to prolong their retention inside the cells. ${ }^{60}$ 


\subsection{Protein misfolding and amyloid disease}

Besides carbohydrates, another essential class of biological macromolecules in all living organisms are proteins. Proteins take part in almost every biochemical event that happens on the cellular level. They act as catalytic enzymes, as transporters and storage modalities, they participate in various recognition processes as antibodies and in signaling pathways as messengers. Proteins also make up the structural components on both the cellular level and on the whole-body scale, where they provide support and mechanisms for motion. ${ }^{58}$

Proteins are heteropolymers made up of a set of twenty different amino acids linked together via amide bonds, also called peptide bonds, constituting their primary structure i.e. the polypeptide chain. Proteins need, however, to adopt a higher-level structure in order to carry out their designated purposes in the biochemical environment. After they are synthesized on ribosomes, polypeptides start their folding process through the secondary structural elements of $\alpha$-helices and $\beta$-strands, the tertiary structure of a completely folded monomeric protein and finally, if applicable, into the quaternary structure as a complex of several tertiary proteins. The protein folding goes through a multitude of equilibrium and thermodynamically controlled conformational states that are governed by both the intrinsic amino acid sequence and by complex quality control mechanisms, such as interaction with chaperons and degradation. ${ }^{61}$ Each protein normally folds into a single three-dimensional structure that is determined by the minimal free energy $(\Delta G)$. The question how the transition from a completely unfolded primary structure into the particular conformation of functional native protein is made, is still not entirely answered. As already mentioned, the information for its stable threedimensional structure is coded in a protein's amino acid sequence and it can be deciphered by passing the unstable unfolded protein through a free energy landscape of possible conformations. The relationship between a protein structure during the folding process and its free energy can be illustrated as a funnel where the freedom of choice for possible structural conformations of the protein decreases the more the protein adopts its native-like structure. At the same time the protein becomes more stable with the lower free energy (Figure 14). 


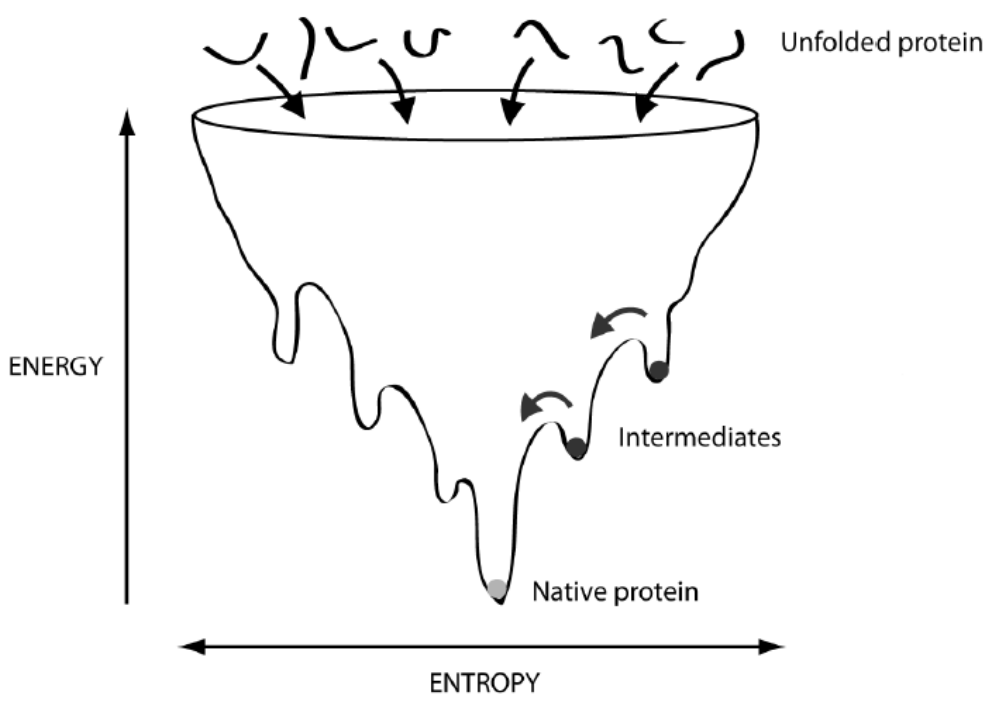

Figure 14. Illustration of the protein folding process as a funnel of energy and entropy. Adapted from Klingstedt 2013, with permission. 62

When the normal folding process is disrupted, either by alterations in the primary structure or by failure of the quality control systems, the protein adopts an incorrect structure that often leads to the loss of its natural function. If, in addition, the degradation of the misfolded proteins does not work properly or the misfolding process is extensive, these misfolded proteins start to aggregate and deposit, forming nonfunctional and potentially damaging aggregates called amyloids. Although originating from misfolded or partly unfolded proteins, amyloid has a highly organized fibrillary structure. The structure of amyloid deposits is composed of bundles of straight fibrils that themselves are made of two or more protofilaments entwined around each other. In protofilaments the included polypeptide chains have been re-arranged into $\beta$-strands that run perpendicular to the long axis of the fibril, the organization called the cross- $\beta$ structure. The cross- $\beta$ structure of protofilaments characterizes amyloid fibrils irregardless of the precursor proteins. The amyloid formation is characterized as nucleation-dependent polymerization and the process involves several sequential steps as illustrated in Figure 15. First the functional native protein is turned into the corresponding misfolded monomers that interact with each other via hydrophobic interactions and hydrogen bonds to form oligomers during the so-called lag phase. These oligomers function as seeds where the polymerization can proceed on. During the upcoming growth phase, the oligomers grow rapidly into protofibrils that form fibers and further extensive amyloid aggregates at the saturation phase. ${ }^{62,63}$ The time-scale for the course of these events varies a lot being different for in vitro and in vivo processes and for different precursor proteins. 


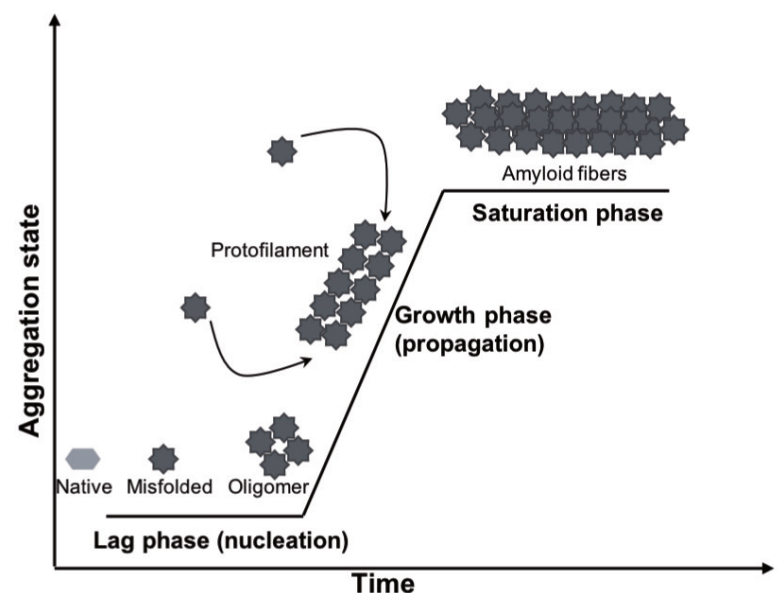

Figure 15. Schematic illustration of nucleation-dependent amyloid formation.

Similarly to the normal folding of a polypeptide into a functioning protein, the process of protein misfolding can be described on a schematic energy landscape funnel. Figure 16 uses the highly amyloidogenic $A \beta$ peptide as an example to illustrate the dynamic and complex processes of self-aggregation of misfolded proteins going through a multitude of energetic and conformational states to reach the macroscopic state of plaque. ${ }^{64}$ The figure also demonstrates the fascinating fact that, depending on the aggregation path taken, a single polypeptide chain can give rise to several different intermediate aggregate states and result in morphologically varying mature protein aggregates. ${ }^{65}$

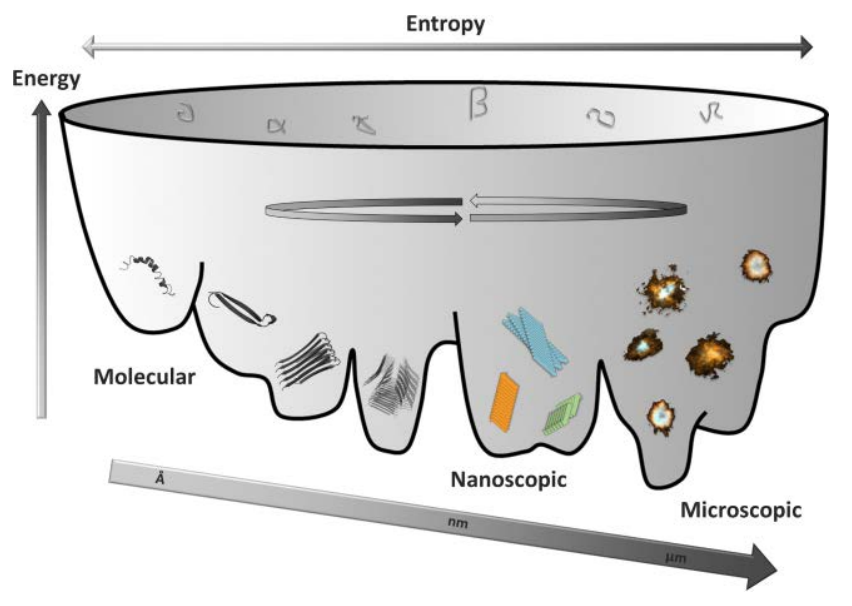

Figure 16. Energy landscape of polypeptide aggregation into a multitude of structurally different final aggregate states. Adapted from Fändrich et al. J. Intern. Med. 2018;283;218-237. 64 
Protein aggregation is associated with many devastating diseases of which a great part are neurodegenerative. From over 30 currently known peptides and proteins that form amyloid deposits, more than the double number of different diseases are derived. The most well-known protein aggregation diseases include progressive and neurodegenerative conditions such as Alzheimer's disease (AD), Parkinson's disease, Creutzfeldt-Jakob's disease and Huntington's disease.$^{61} \mathrm{In} \mathrm{AD}$, deposits of two different proteins are found: neuritic plaque of amyloid $\beta$-peptide $(\mathrm{A} \beta)$ formed extracellularly and intracellularly deposited neurofibrillary tangles of hyperphosphorylated tau protein. ${ }^{66}$ In Parkinson's disease the proteinaceous deposits of $\alpha$-synuclein, the Lewy bodies, are built up in neuronal cells, while Creutzfeldt-Jakob's disease involves the infectious prion protein that accumulates in brain. ${ }^{61}$

To date, no curative methods are available to treat the amyloidosis. Both for scientific research and clinical use effective molecular tools are necessary for studying the origin and development of these disorders. Amyloidospecific ligands for detecting and studying protein aggregates have a great importance in the field of protein aggregation as the early-stage and asymptomatic diagnosis of amyloid diseases still is a challenge.

The molecular dyes Thioflavin $\mathrm{T}$ and Congo red have historically been used to stain and study protein aggregation. The detection is based on the interaction of these dyes with the repetitive pattern of the cross- $\beta$ structure in amyloid aggregates. ${ }^{67}$ Today, there is a plethora of existing ligands for $A \beta$ aggregates, most of them using fluorescence as the means for detection. ${ }^{68}$ Optical imaging, especially imaging using near-infrared fluorescent (NIRF) probes, has been recognized as well-exploitable method for studying $A \beta$ aggregation. The method owes its high usability to low cost, possibility for real time detection and high resolution. Furthermore, there is no need for hazardous radioactive isotopes as in PET imaging. ${ }^{69}$ The existing ligands for detecting amyloid $\beta$ aggregates include, inter alia, Thioflavin $\mathrm{T}$ and its derivatives, Congo red, stilbene-type of compounds, curcuminoids and BODIPY-derivate probes. ${ }^{68}$ Lately, a novel class of luminescent conjugated oligothiophene ligands has been developed, and proven their superiority to the other amyloid ligands in many regards, including what comes to their selectivity and sensitivity. ${ }^{70-77}$

\subsection{Luminescent conjugated oligothiophenes}

Conjugation of monomeric thiophene molecules into chains of two to around twenty thiophene units yields conjugated oligothiophenes. The word oligomer is derived from the Greek oligo- meaning "a few" and -mer meaning "parts". In organic chemistry the term oligomer is used for molecules consisting of repetitive units where the exact number of units, as well as the total structure of the molecule, is known as opposed to a polymeric material where a mixture of molecules of varying lengths of basically unlimited number of monomers is present. Another definition of oligomeric compounds is that the compound changes its properties upon adding or removing monomers, 
whereas for a polymeric material slight changes of the lengths of polymers do not affect its properties. ${ }^{78}$

Thiophene is a sulfur containing aromatic heterocycle. In agreement with the reactivity of its nitrogen equivalent pyrrole, thiophene can undergo various electrophilic substitution reactions. The substitutions take primarily place at its 2- and 5-positions, also called $\alpha$-positions, that are more reactive than the remaining $\beta$-positions. On this basis, polymerization and oligomerization of thiophene links the monomers via their $\alpha$ positions rendering lineal molecular chains (Figure 17). These oligomers are highly conjugated with alternating single and double bonds stretching throughout the molecule where the aligned p-orbitals make it possible for the movement of delocalized $\pi$ electrons. The extensive conjugation of oligothiophenes gives rise to some interesting characteristic properties of this type of molecules. Conjugated thiophenes are good at absorbing and emitting light which makes them useful chromophores for various applications. The luminescence from these molecules is effectively used as a method of detection of various targets that oligothiophenes bind to, thereby the name luminescent conjugated oligothiophenes or LCOs. These conjugated systems can also transport electrical charges and are therefore used in conducting materials for the applications of electronic devices, for example light-emitting diodes (LED), solar cells and field effect transistors (FET). ${ }^{79}$

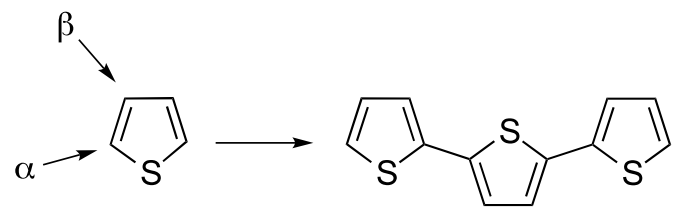

Figure 17. Oligomerization of a thiophene molecule via $\alpha$-positions renders conjugated oligothiophenes, exemplified here by trimerization.

There is rotational freedom around the single bonds connecting thiophene units in an LCO. The thiophene monomers can either lay in the same plane relative to each other or they can be twisted out of this plane to a different extent as illustrated in Figure 18A. The rotation along the single bonds changes the overlap of the p-orbitals in the conjugated system, thus affecting the $\pi$-electron flow and the total effective conjugation. The more planar the LCO is, the longer the effective conjugation and vice versa. ${ }^{80}$ The conjugation length is reflected in the shifted absorption and emission wavelengths and can be used to follow the conformational changes of LCOs upon interacting with various target structures and with each other. ${ }^{81,82}$ In a completely planar LCO the conjugation is the longest giving rise to emission spectrum at longer wavelengths. The conformational twisting, however, shortens the conjugation which results in a blue-shifted emission spectrum as illustrated in the schematic emission spectra in Figure 18B. 
A)

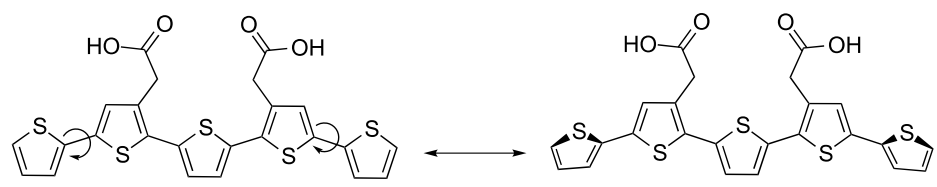

B)

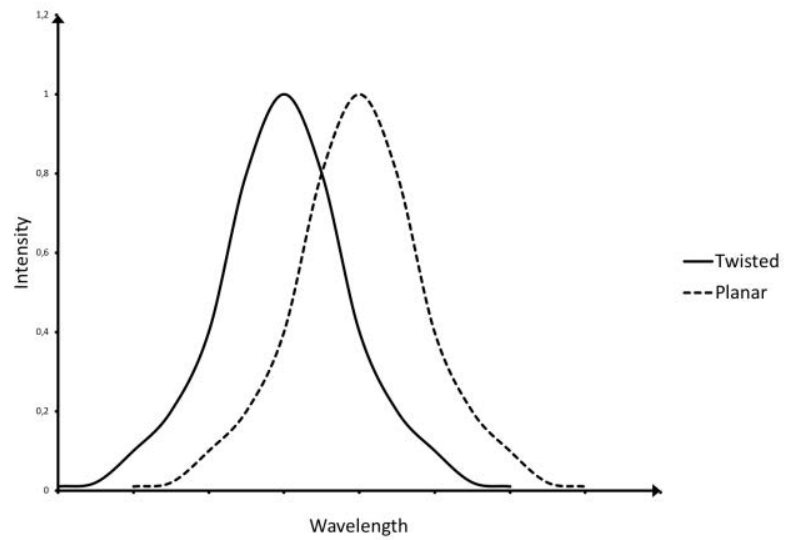

Figure 18. Rotational freedom around the thiophene-connecting single bonds entails twisting of an LCO backbone (A) and shift of the emission spectrum (B).

Development of LCOs in Nilsson group at Linköping university has with great success resulted in optimized synthetic methodologies towards numerous thiophene-based molecules making up an extensive molecular library. ${ }^{75,70}$ These compounds are based on oligothiophene backbone of various lengths, ranging usually from three to eleven monomer units, and featuring a number of different side chains and functional groups at distinct positions. LCOs have the eminent property to be able to bind to amyloid protein aggregates and visualize these biochemical structures by the intense characteristic fluorescence upon excitation. The high affinity for amyloid protein deposits over unaggregated proteins, together with the signature emission triggered by the conformational changes in the thiophene backbone, makes these compounds attractive probes for detecting and characterizing misfolded proteins both in vitro and in vivo. ${ }^{74}$ Seemingly slight modifications in LCOs' structure, involving either change in length of the backbone or addition or positional movement of side chains, can result in amyloidophilic probes with varying preferential binding affinity and distinct optical signature for the plethora of different protein aggregates, such as A $\beta$ plaque, neurofibrillary tangles of tau protein and cerebral A $\beta$ angiopathy (CAA). ${ }^{71,72,76,83}$ Moreover, one and the same LCO can be used for discriminating between several types of amyloid proteins due to the protein-specific changes in optical readouts that can be assimilated to certain target structures. As an example, the anionic thiophene tetramer HS-68 with a distinct regiochemical composition (Figure 19A), can be successfully used to optically distinguish between A $\beta$ plaque and tau neurofibrillary tangles. ${ }^{72}$ The same LCO can also reveal the age-dependent development of morphotypes of these 
protein aggregates in brain tissue sections from transgenic mice as illustrated in Figure 19B where fluorescence microscopy images of $A \beta$ plaque from $A D$ mice at different ages are shown. The study shows likewise that subtle structural modifications of HS-68 render analogous probes with impaired properties for detecting polymorphic protein aggregates, indicating a strong structure-activity relationship of LCOs' ability to function as fluorescent amyloid probes.

A

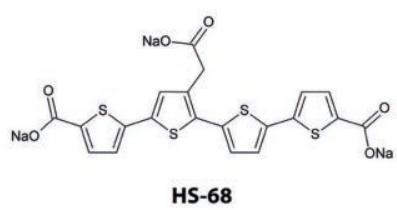

B

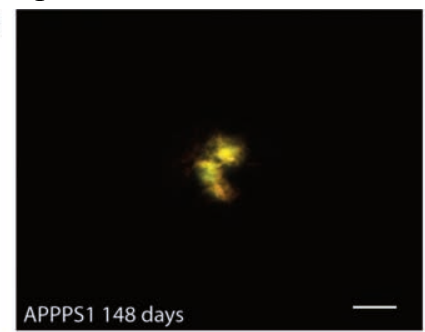

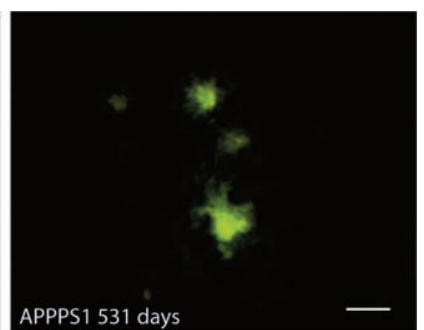

Figure 19. Chemical structure of the amyloidophilic anionic LCO, HS-68 (A) and fluorescence microscopy images of its staining on $A \beta$ aggregates in the brain tissue slices of transgenic mice at different ages (B). Adapted from Klingstedt et al. Chemistry 2015;21; 9072-9082, with permission. 72

The LCOs have shown to be effective probes even for systemic amyloidosis. The negatively charged heptameric LCO hFTAA did, for example, successfully detect amyloid deposits, that were Congo red negative, in patient tissue samples by its intense fluorescence even at very low quantities, demonstrating its superior sensitivity. ${ }^{84}$ Moreover, besides their main application area of detecting disease associated proteinaceous amyloid deposits, the LCOs can be used to detect and study other types of structure-regular biomaterials. The extracellular matrix components of bacterial biofilms, curli and cellulose, can be simultaneously monitored in real time in situ using hFTAA. ${ }^{85}$ Engaging positively charged pHTEA instead, gives the means to spectrally distinguish cellulose, hemicellulose and lignin in the complex material of biomass. ${ }^{86}$

\subsection{Bioorganic materials}

The preceding chapters have cast light on how small organic compounds can be used to detect biomolecular targets upon interacting with them. These ligands can in some cases carry out therapeutic tasks by affecting their targets' structure or function. The interactions between the biomolecule and its ligand can sometimes, however, be utilized in constructing new materials. Doping synthetic polymers with naturally occurring compounds renders materials with biocompatible features. ${ }^{87,88}$ Nevertheless, one can also combine small organic molecules or nanoparticles with polymeric biomolecules, such as peptides or polysaccharides, to give rise to materials of well-defined structure and specific optical, electronic or biological properties that make the material attractive for a multitude of applications. ${ }^{89-91}$ Biomolecules, such as proteins, polysaccharides, nucleic acids and lipids, often occur in nature as highly ordered supramolecular architectures. $^{92,93}$ The propensity to spontaneously, or upon an initiation, self-associate into organized assemblies of various structures even in vitro makes these biomolecules 
attractive candidates for making new materials. ${ }^{94}$ As an example of useful supramolecular self-assemblies, in the Stupp group novel filamentous materials are designed resulting from self-assembly of glycoconjugated peptide amphiphiles. These structures have shown potential as improved biomimetics for heparin and sulfated heparan. ${ }^{95}$ The well-defined architecture of these nanostructured materials is made up of filaments of lipophilic core and hydrophilic surface featuring sulfated carbohydrates. The multivalent interactions of carbohydrates with the target proteins ensures the biomimetic effect. In such biological applications the peptide supramolecular assemblies can simulate the function of designed proteins. ${ }^{96}$

Development of optoelectronic biomaterials combines the biocompatibility with highly versatile electronic and optical qualities. ${ }^{97}$ The term optoelectronic properties of a material implies that an electric input can transduce an optical output of the material, and vice versa. ${ }^{98}$ Such qualities of the material come in use in devices with photoelectric or photovoltaic effects, photoconductivity, stimulated emission, radiative recombination and photoemissivity. ${ }^{99}$ While biomolecular assemblies are suitable for constructing the mechanical structure of a material with the wanted soft-matter qualities and biocompatibility, they seldom intrinsically possess the optoelectronic properties. ${ }^{100,101}$ The protein bacteriorhodopsin is an example of a biomolecule with an inherent optoelectronic function owing to the presence of its cofactor retinal. ${ }^{102}$ Bacteriorhodopsin is therefore of extreme interest to material science. ${ }^{103,104,105}$ Majority of protein or peptide monomers must, nevertheless, be modified prior to the assembly into a functioning material. The modifications can be carried out by genetic alterations of protein primary structure and by covalently attaching functional groups or molecules of interest to the specific positions. ${ }^{106-108}$ An alternative is to combine, by assembly via intermolecular forces, an oligo- or polymeric biomolecule with the guest compound having the complementing characteristics to yield the well-structured material with optoelectronic properties. ${ }^{90,109}$ This approach takes advantage of complementary physical properties of the associating partners, such as electrostatic interactions, hydrogen bonding, van der Waals forces and other types of hydrophobic interactions, as well as steric aspects. In this way the covalent coupling chemistry to the oligomeric units can be avoided which, in case of sensitive biomolecules, such as peptides, proteins and polysugars, prevents the problems with using organic reagents and solvents. Furthermore, using self-assembly via intermolecular forces between the different components of a material allows for a greater freedom of finetuning the resulting properties of the material. With respect to the ratio of the assembling components and alterations in reaction conditions, such as temperature, $\mathrm{pH}$, additives and ultrasound, variations in certain properties can be obtained. ${ }^{110}$ Keeping the components separated also makes it easier to structurally modify them prior the assembly. Thus, applying this approach in material design could provide the means to produce well-structured biocompatible soft-materials with desirable biological and optoelectronic properties. 


\section{Research aim}

The general aim of this thesis lies in designing and synthesizing multimodal porphyrinbased conjugates with distinct molecular units that should possess properties for hetero multi-functionality in a number of bioapplications. Our hypothesis is whether we can functionalize porphyrin scaffold with other biologically and optically interesting molecules to obtain conjugates with combined and superior properties compared to the parent porphyrin.

We consequently aimed to synthesize porphyrin-oligothiophene conjugates with improved properties as fluorescent amyloid ligands, and examine their amyloid binding and photophysical behavior.

Buoyed by the pre-existing knowledge of oligothiophenes interacting with synthetic peptides, we also wanted to investigate if porphyrin-oligothiophene conjugates in combination with peptides could be utilized to generate self-assembled bioorganic materials with distinct chiroptical properties and dynamic structure.

Finally, we strived to design multimodal theranostic agents for a potential application in photodynamic therapy towards malign diseases. This aim entailed synthesizing carbohydrate functionalized porphyrins with the properties for diagnosis, therapy and targeted drug delivery coming from the distinct molecular modalities. 


\section{Design and synthesis of oligothiophene porphyrin hybrids (OTPHs)}

\section{(Paper I, Paper II and Paper III)}

In Paper I and II the LCOs are conjugated to porphyrin moieties in order to create novel amyloid ligands featuring two distinct optical moieties, the molecules coined oligothiophene porphyrin hybrids or OTPHs. The conformation dependent interactions between the porphyrin and the LCO moiety of the conjugates can be monitored by emission and excitation spectral characterization, as well as fluorescence lifetime imaging (FLIM) techniques. These conformation-induced optical signatures do, in turn, indirectly reflect on the structure and morphology of the proteinaceous deposits the ligands are bound to. The LCO-porphyrin conjugates engaged in these studies are based on the well-known and -utilized anionic pentameric LCO pFTAA that has marked itself as an excellent probe for detecting and visualizing misfolded protein aggregates, such as $A \beta$ plaques and tau fibrillary tangles.

In Paper III these OTPHs are used with respect to material science where the OTPHpeptide interactions, that give rise to spontaneous self-assembly into higher-ordered structures with induced chiroptical properties, are studied.

\subsection{Molecular design}

By combining an LCO and a porphyrin in a covalently bound conjugate the respective building blocks were prepared separately in a way they would feature an appropriate functional site for the upcoming coupling reaction. For that, the synthesis of both of the building blocks would involve a certain degree of asymmetry and orthogonally protected functional groups. The criteria for the chemical structures of the final conjugates were determined by the general coveted properties of the target compound as described in Table $\mathbf{1 .}$

Table 1. Structure function relationships of LCO-porphyrin conjugates.

\begin{tabular}{|l|l|}
\hline Desired properties & Chemical structure \\
\hline $\begin{array}{l}\text { Conjugates are nearly or completely water } \\
\text { soluble to be compatible with biological } \\
\text { environment. }\end{array}$ & LCO and porphyrins have hydrophilic groups. \\
\hline $\begin{array}{l}\text { Conjugates have conformational flexibility } \\
\text { between the building blocks to allow for } \\
\text { alternating interactions between molecular } \\
\text { moieties as well as between the probe and the } \\
\text { target. }\end{array}$ & $\begin{array}{l}\text { Spacer molecule is used to tether LCO to } \\
\text { porphyrins. }\end{array}$ \\
\hline
\end{tabular}




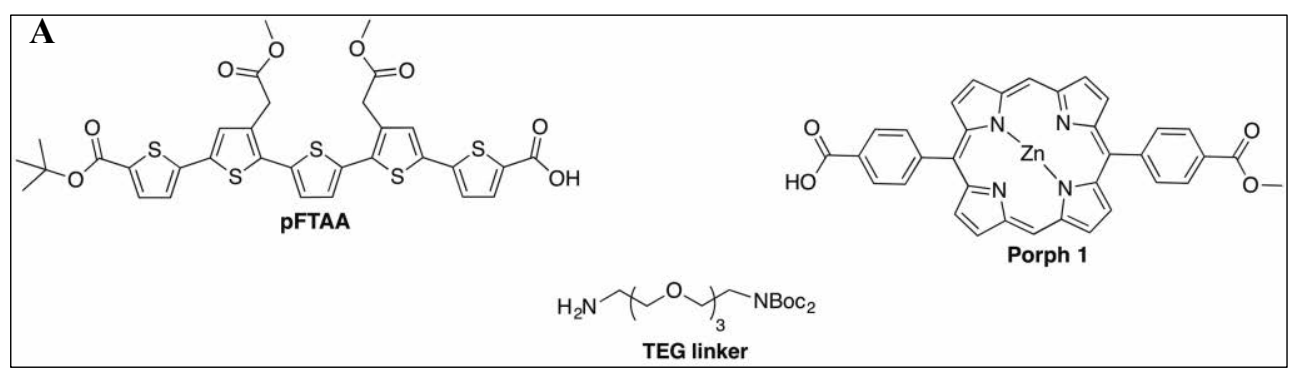

B
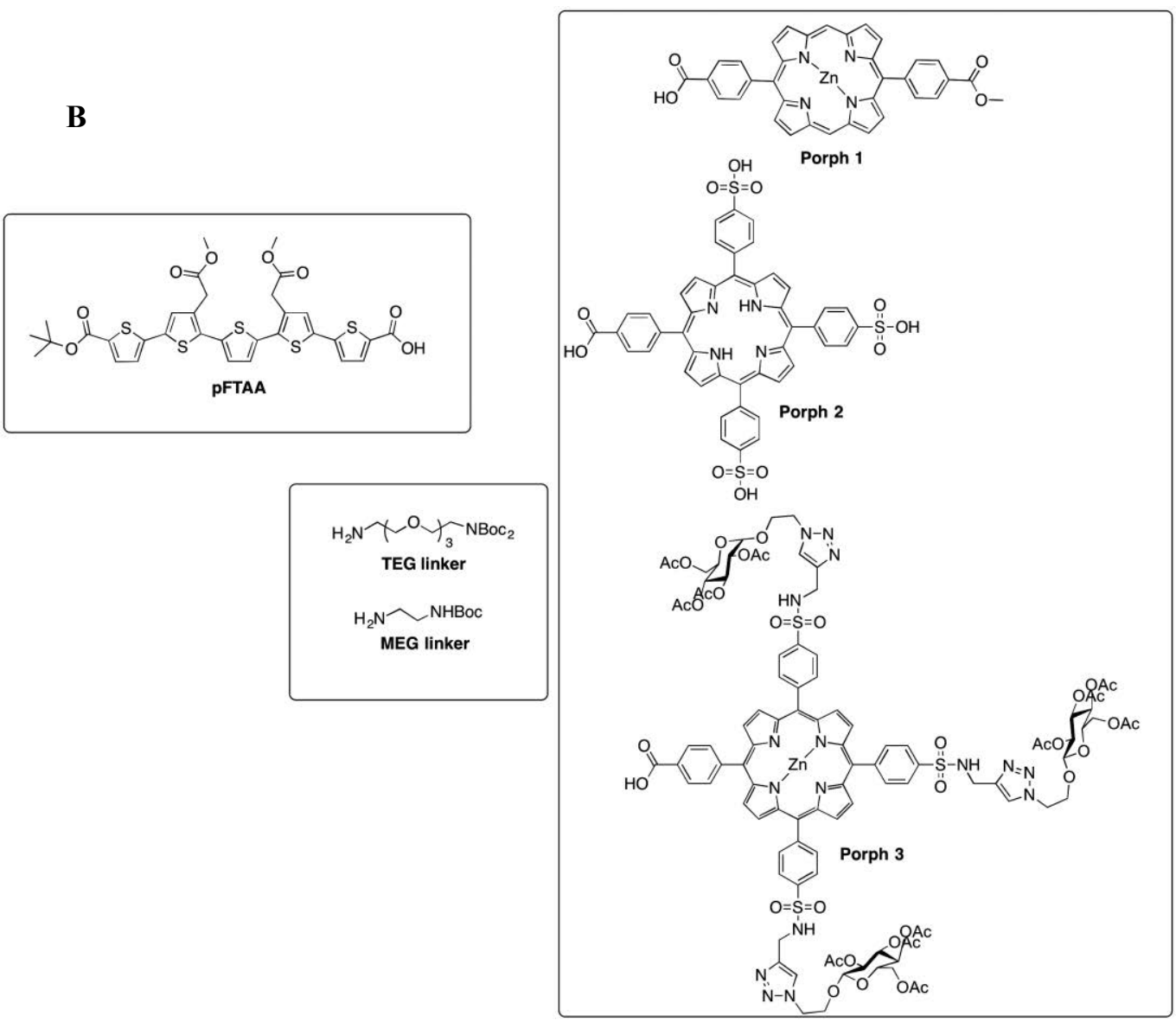

Figure 20. Synthetic building blocks necessary for producing OTPHs. A) The synthetic constructs for OTPH1 in Paper I pioneering the design of OTPHs. B) Molecular moieties necessary for producing OTPH1 - OTPH4.

Considering the points laid out above, three different building blocks were synthesized (Figure 20). Firstly, the asymmetric pFTAA with three ester protected carboxylic acids 
and one free carboxylic acid at $\alpha$-position; then porphyrins with several protected polar side chains or functional groups and one free carboxylic acid as the coupling site; and finally, orthogonally functionalized spacer molecules for linking the LCO to porphyrins. The amide bond formation was chosen as the means of coupling between the building blocks. The first OTPH synthesized, pFTAA-porph that was later renamed to OTPH1, was the basis for Paper I and comprises the distinct molecular moieties obtained through a convergent synthetic approach (Figure 20A).

In order to study the effect of the porphyrin moiety of an OTPH and the spacing between the two different optical moieties on its amyloidophilic and optical properties, further development of such conjugates was carried out. In Paper II a broader set of OTPHs were synthesized using pFTAA as the LCO but varying the length of the linker and the nature of the porphyrin moiety (Figure 20B).

In the following sections a more detailed description and reasoning behind the synthesis of the different building blocks and the final OTPH conjugates are brought out.

\subsection{Synthesis of the LCO moieties}

The history of using LCOs as fluorescent dyes for purposes of detection and studying protein deposition, and even cells, at Linköping reaches over a decade. The research in this area has gone hand-by-hand with the chemical development of LCOs through method optimization and structural modifications. The first conjugated thiophene molecules that were used to stain proteinaceous structures were polymeric. ${ }^{82}$ The luminescent conjugated polythiophenes (LCPs) come often from simple one-step polymerization reactions where either a single monomer or a short oligomer is elongated under oxidative conditions with $\mathrm{FeCl}_{3}$ for up to 24 hours giving homo- and heteropolymers, respectively. The formed polydispersed material is purified by repetitive precipitations and centrifugations. In this manner the anionic polythiophene acetic acid PTAA and the zwitterionic tPTT are synthesized as illustrated in Scheme 1.

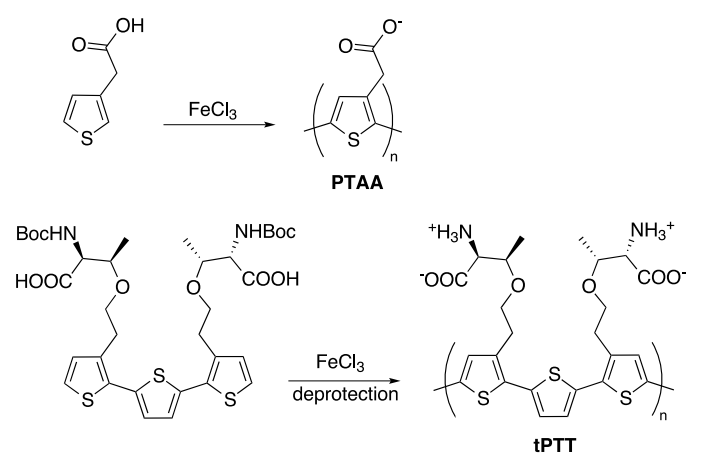

Scheme 1. Synthesis of luminescent polythiophenes, LCPs, through Fe(III)-polymerization.

For the synthesis of LCOs a more refined and, with that, a more complex and timeconsuming methodology is required. For the well-defined structures of LCOs a step-by- 
step synthesis to the final molecule from a monomeric thiophene unit is carried out. After the years-long experience and numerous optimizations, a general synthetic route consisting of consecutive brominations and Suzuki coupling reactions has evolved. Depending on the degree of symmetry and the nature of side chains on the final LCO, the total synthesis also contains a varying number of protection-deprotection steps. A pervading consideration in the synthesis of LCOs, regardless of the exact structure, is the ever complex-growing purification as the chain length increases and the solubility decreases.

The synthesis of the symmetrical pentameric LCOs can be exemplified by synthesis of a pentamer called pHTAA as illustrated in Scheme 2. If the LCO is made asymmetric, for example in order to conjugate it to another molecule, the synthesis needs be divided into a greater number of steps for singly addressable reactions at either side of the chain.

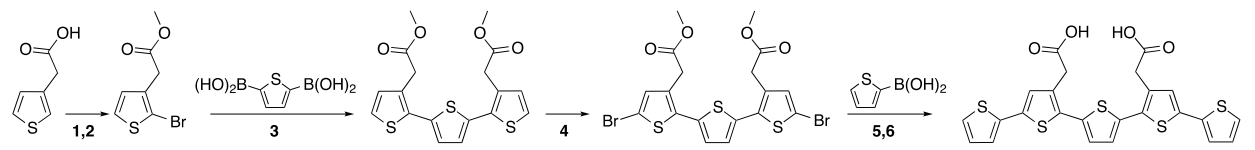

Scheme 2. General synthesis of a symmetric pentameric LCO contains the following reactions: 1. protection 2. bromination 3. Suzuki coupling 4. dibromination 5. Suzuki coupling and 6 . deprotection.

For the study of LCO-porphyrin conjugates, asymmetric LCOs with orthogonally functionalized scaffolds were to be used. The LCO used in OTPH1- OTPH4 was the asymmetric pFTAA derivative depicted previously in Figure 20, the synthesis of which proceeded according to the synthetic scheme below (Scheme 3). The synthesis starts, similarly to the synthesis of symmetrical pFTAA $^{75}$, with 3-thiopheneacetic acid $\mathbf{1}$ that is methylated with methyl iodide in the presence of weakly basic cesium carbonate. The corresponding methyl ester is subjected to monobromination with the equivalent amount of N-bromo succinimide (NBS) yielding methyl-2-bromo-3-thiopheneacetate $\mathbf{2}$ in good yield. The regioselectivity of the bromination can be explained by the inductive effect from the $\beta$ alkyl substituent on the forming intermediate. The monobrominated thiophene monomer is reacted with 2,5-thiophenebisboronic acid in a palladium catalyzed cross coupling reaction to yield the symmetric trimer $\mathbf{3}$. From an in-house screening study among several palladium catalysts and varying conditions, the most suitable combination was found to be 0.01 equivalent of commercially available PEPPSI-IPr catalyst with potassium carbonate base in toluene-methanol solvent at 80 ${ }^{\circ} \mathrm{C}$. The reaction is high-yielding producing the trimer in around $70-80 \%$.

From now on, the synthesis of the asymmetric pFTAA differs somewhat from the synthesis of the symmetric equivalent. ${ }^{70,111}$ In order to obtain the LCO with one protected and one free carboxylic acid substituent, the fourth and the fifth thiophene unit were added to the growing oligomer one at a time. Monobromination of the trimer with NBS yields compound $\mathbf{4}$ that in next step undergoes Suzuki coupling to 5carboxythiophene-2-boronic acid under the similar conditions as described above. The 
formed tetramer is, without any prior purification, subjected to tert-butylation on the carboxylic acid with t-butyl-2,2,2-trichloroacetimidate in the presence of catalytic amount of $\mathrm{BF}_{3} . \mathrm{OEt}_{2}$, yielding tetramer 5 . The procedure of bromination and the Suzuki coupling reaction is then repeated in order to install the fifth thiophene unit, only this time the carboxylic acid is kept free to obtain the partially protected pFTAA precursor 7.

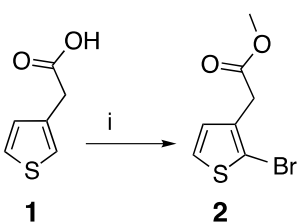<smiles>O[B]c1ccc([B]O[GaH])s1</smiles>

2
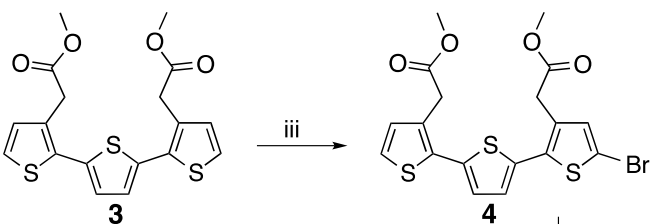

$\left.\mathrm{HOOC}^{\mathrm{S}}\right\rangle^{-\mathrm{B}(\mathrm{OH})_{2}}$<smiles></smiles>

Scheme 3. Synthesis of the asymmetric pFTAA precursor. General conditions and reagents: i) 1 . $\mathrm{CH}_{3} \mathrm{l}$, $\mathrm{Ce}_{2} \mathrm{CO}_{3}$, DMF, r.t.; 2. NBS, DMF, $-14^{\circ} \mathrm{C}$ to $0{ }^{\circ} \mathrm{C}, 60 \%$; ii) PEPPSI-IPr, $\mathrm{K}_{2} \mathrm{CO}_{3}, \mathrm{MeOH}$ :toluene, $80{ }^{\circ} \mathrm{C}, 88 \%$; iii) NBS, DMF, $-14{ }^{\circ} \mathrm{C}$ to $0{ }^{\circ} \mathrm{C}, 70 \%$; iv) PEPPSI-IPr, $\mathrm{K}_{2} \mathrm{CO}_{3}$, MeOH:toluene, $80{ }^{\circ} \mathrm{C}$; v) t-butyl-2,2,2trichloroacetimidate, $\mathrm{BF}_{3} . \mathrm{OEt}_{2}$, $\mathrm{THF}$, r.t. $84 \%$ over two steps; vi) $\mathrm{NBS}, \mathrm{DMF},-14^{\circ} \mathrm{C}$ to $0{ }^{\circ} \mathrm{C}, 93 \%$; vii) PEPPSI-IPr, $\mathrm{K}_{2} \mathrm{CO}_{3}, \mathrm{MeOH}$ :toluene, $80{ }^{\circ} \mathrm{C}, 77 \%$.

The catalyst of choice for the Suzuki reaction - PEPPSI-IPr - has ligands that are based on N-heterocyclic carbenes (NHC) (Figure 21). Unlike the palladium catalysts with the classical phosphine-based ligands, the steric and electronic properties of the NHC-based ligands are kept apart, as the bulky aryl groups are not directly attached to the carbene atom. This allows for the independent adjustments of the steric and electronic properties of the ligands and therefore the optimization of the catalyst for faster and higher-yielding cross coupling reactions. ${ }^{12}$ In the synthesis of LCOs, the PEPPSI-IPr-catalyzed Suzuki 
coupling reactions often go to completion in half an hour. Furthermore, the catalyst is shelf-stable and requires no prior activation.

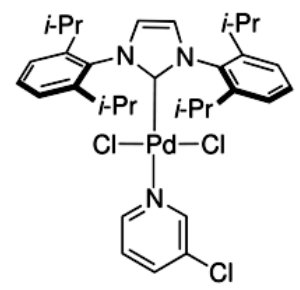

Figure 21. [1,3-Bis(2,6-Diisopropylphenyl)imidazol-2-ylidene](3-chloropyridyl)palladium(II) dichloride (PEPPSI-IPr)

\subsection{Synthesis of the linker}

In Paper I only one type of linker was used, namely tetraethyleneglycol-based linker functionalized with one free and one protected amino group, suitable for orthogonal amide coupling reactions to the LCO and the porphyrin moieties, respectively. In Paper II, in addition to the previously used linker, a commercially available monoethyleneglycol-based linker was used to evaluate the spacing effect on the conjugates' behavior. The linkers were named TEG (13) and MEG, respectively, and are depicted in Scheme 4 and Figure 22.

Synthesis of the TEG linker (13) started with monotosylation of tetraethyleneglycol 8 to create asymmetry and to yield $\mathbf{9}$ in the expectedly low yield (Scheme 4). The tosylate was substituted for azide, giving compound 10, and the second tosylation was carried out on the remaining hydroxyl group leading to 11. The tosylate of $\mathbf{1 1}$ was substituted for diBoc-protected amino group with di-tert-butyl-iminodicarboxylate in 12. Finally, the azide was reduced to free amine via the Staudinger reduction using triphenylphosphine, yielding TEG linker 13.

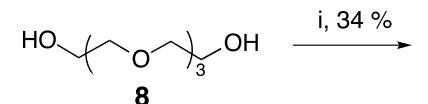

8

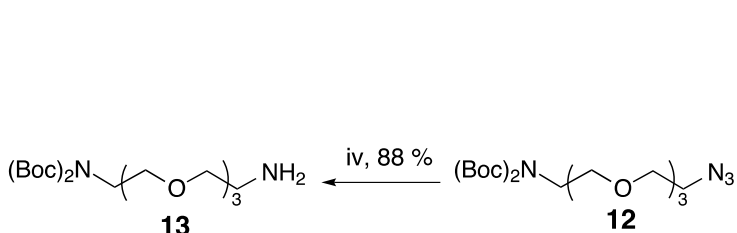

13

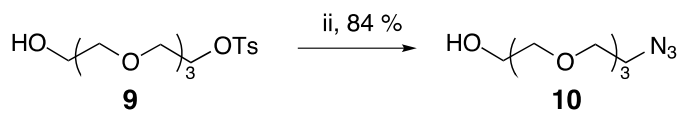

12

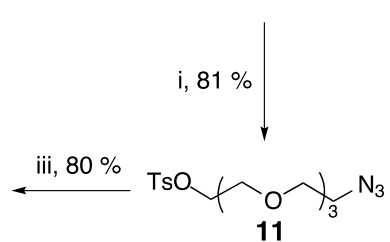

11

Scheme 4. Synthesis of the TEG linker. General conditions and reagents: i) $\mathrm{TsCl}, \mathrm{Py}, \mathrm{O}^{\circ} \mathrm{C}$ to r.t.; ii) $\mathrm{NaN}_{3}$, DMF, $60{ }^{\circ} \mathrm{C}$; iii) $\mathrm{NH}(\mathrm{Boc})_{2}, \mathrm{~K}_{2} \mathrm{CO}_{3}, \mathrm{THF}, 70^{\circ} \mathrm{C}$; iv) 1. $\mathrm{PPh}_{3}, \mathrm{THF}, 60^{\circ} \mathrm{C} ; 2 . \mathrm{H}_{2} \mathrm{O}$ 
To study the effect of a greater proximity between the LCO and the porphyrins, the shorter MEG linker was used (Figure 22).<smiles>NCCNC(=O)c1ccccc1</smiles>

Figure 22. Chemical structure of monoethyleneglycol based linker, MEG.

\subsection{Synthesis of porphyrins}

A summarized background to the general porphyrin synthesis is given in Chapter 1.2. Porphyrin synthesis. As mentioned earlier, the synthetic aim of the porphyrin moieties was to produce compounds with polar peripheral substituents and with an accessible carboxylic acid site for subsequent conjugation via amide bond formation. Because of the high lipophilicity of the porphyrin core, moderately polar substituents make the handling of porphyrins easier during reactions and purifications, due to improved solubility in most solvents. Porphyrin synthesis involves, as described in greater details in previous sections, a final condensation-oxidation step that in most of the cases produces very low yields of the target porphyrin accompanied with a high amount of byproducts and unreacted starting material. If organic oxidants are used, such as pchloranil or DDQ, the crude mixture gets even more complex. Subsequently, for the sake of a somewhat easy isolation and purification, the synthesized porphyrin should not be too polar, nor contain any charged groups.

For our very first OTPH conjugate prior to Paper I, fruitless attempts were made to produce porphyrin $\mathbf{1 4}$ in Scheme 5 in reasonably large quantities and with a workable procedure. Due to the acidic reaction conditions, any acid labile carboxylic acid protection group was ruled out.

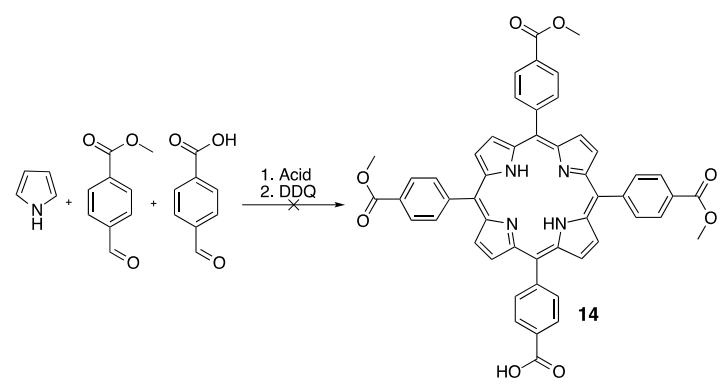

Scheme 5. Attempt to synthesis of a porphyrin with orthogonally protected carboxylic acid groups.

Instead of monopyrrole tetramerization, we adopted the [2+2] approach. An elegant, oxidant free synthesis of dimeso-substituted zinc(II) porphyrins has been published by the Lindsey group. ${ }^{113}$ For that dipyrromethane (DPM) 15, featuring a methyl ester, was synthesized using $\mathrm{InCl}_{3}$ as the Lewis acid catalyst in a large excess of pyrrole according to Laha et. $\mathrm{al}^{24}$ (Scheme 6). The procedure allows for a gram-scale synthesis of DPMs 
with no detectable scrambling. Part of $\mathbf{1 5}$ was hydrolyzed to free acid DPM $\mathbf{1 6}$ to form the first half of the becoming porphyrin. For the second half, an electrophilic DPM with suitable leaving groups was prepared by first formylating 15 via the Vilsmeier-Haack reaction using phosphoryl chloride and $\mathrm{DMF}^{114,115}$, yielding 17 . The dialdehyde was then converted to bisimino DPM 18 constituting the activated DPM partner for the pending condensation reaction. The porphyrin formation occurred under relatively mild conditions in boiling ethanol with $\mathrm{Zn}(\mathrm{OAc})_{2}$ acting both as Lewis acid, as well as coordinating force for the nitrogen ligands. The reaction is clean, with only one porphyrin species to isolate from a simple crude mixture. The formed porphyrin was NHS-activated on the free acid rendering $\mathbf{1 9}$, ready for amide coupling.

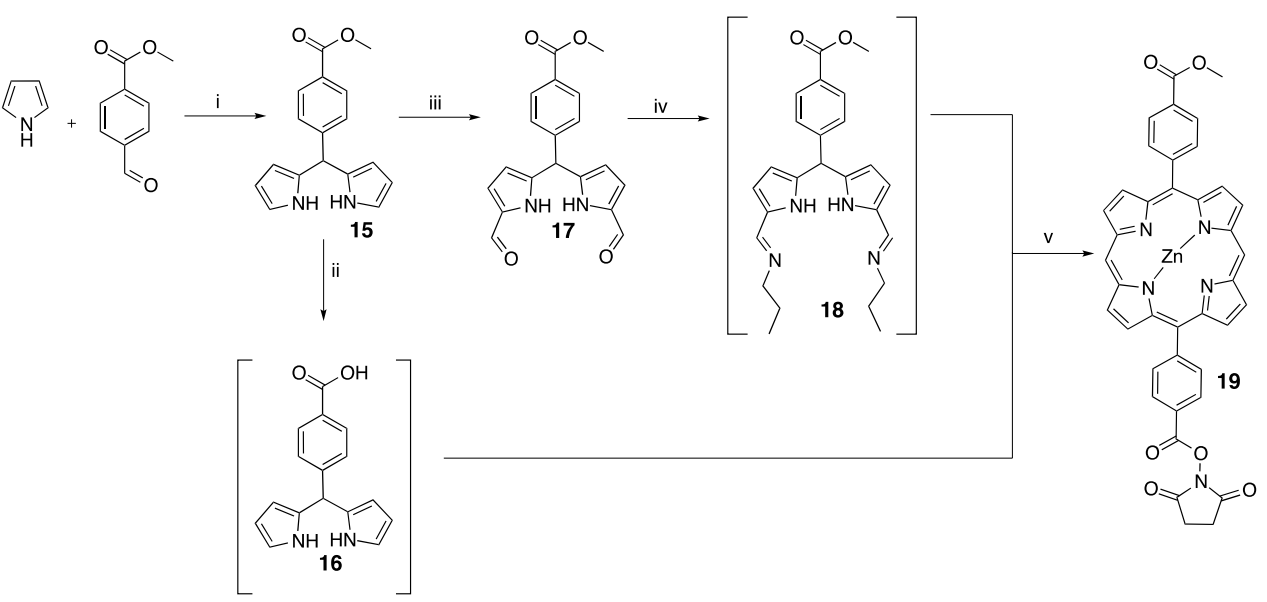

Scheme 6. Synthesis of Porph1 (19). General conditions and reagents: i) $1 . \operatorname{lnCl} l_{3}$, r.t. 2. $\mathrm{NaOH}$, r.t. $88 \%$; ii) $\mathrm{NaOH}$ (aq), THF, r.t. quant. iii) 1. $\mathrm{POCl}_{3}$, $\mathrm{DMF}, 1,2$-dichloroethane, $0{ }^{\circ} \mathrm{C}$ to $35^{\circ} \mathrm{C} ; 2$. $\mathrm{K}_{2} \mathrm{CO}_{3}, \mathrm{H}_{2} \mathrm{O}, 0{ }^{\circ} \mathrm{C}$; $66 \%$; iv) propan-1-amine, THF, r.t. quant. v) $1 . \mathrm{Zn}(\mathrm{OAC})_{2} * 2 \mathrm{H}_{2} \mathrm{O}$, EtOH, reflux; 2. NHS, EDC, DIPEA, DMF, r.t. $16 \%$. Adapted from Arja et al. Front. Chem. 2018;6;391. ${ }^{116}$

The porphyrin formation using a bis(imino)-DPM together with a DPM is a facile way to produce trans-AB porphyrins, such as $\mathbf{1 9}$. The reaction is free of any Bronsted acid that would cause scrambling of DPMs. The usage of $\mathrm{Zn}(\mathrm{OAc})_{2}$ has probably other mechanistic roles than just being the reaction-catalyzing Lewis acid. As mentioned above it has some coordinating function to the DPMs thus forcing the two DPMs in close proximity, reported also by Taniguchi et. al. ${ }^{113}$ The resulting porphyrin is metallated with zinc(II), that in many cases eases the following purification. The porphyrin usually formed from $\mathbf{1 6}$ and $\mathbf{1 8}$ has a free carboxylic acid, that together with the presence of uncoordinated inner nitrogens renders a zwitter ionic compound. However, by protecting the nitrogens, only the acid functionality had to be considered during silica chromatography. 
The possibility for aerobic oxidation of the porphyrinogen to fully oxidized porphyrin at relatively low temperatures is ascribed to the presence of propylamino substituents at 5- and 15-positions on the porphyrinogen (structure b in Figure 23). Zinc-coordinated propylamino substituents being good leaving groups, as compared to the usually present hydrogen atoms, readily leave to produce dihydroporphyrin $\mathbf{c}$ that undergoes facile oxidation with molecular oxygen yielding mature porphyrin $\mathbf{d}$.

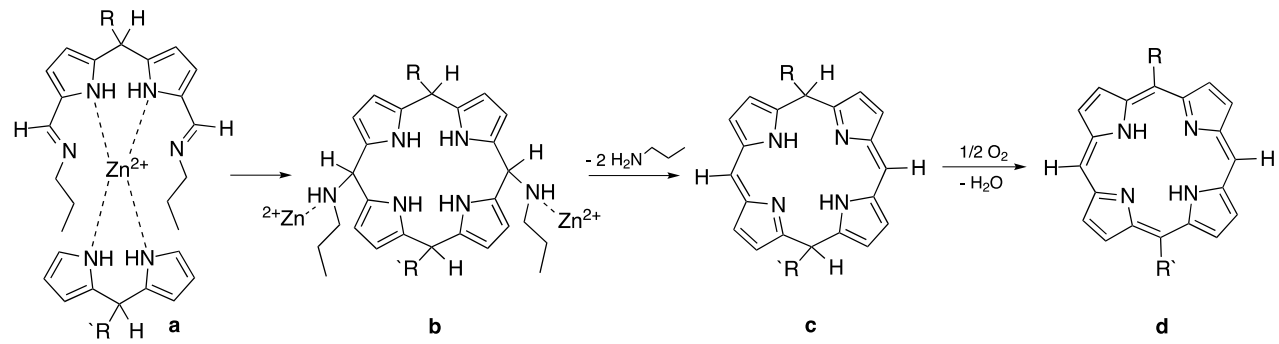

Figure 23. Aerobic oxidation of 5,15-bisamino porphyrinogen formed from [2+2] condensation of a bis(imino)substituted DPM with a DPM.

For the synthesis of tetrameso-substituted porphyrins of high symmetry, the most convenient method still remains monopyrrole tetramerization, with the condition of absence of any charged substituents on the porphyrin. In Paper II OTPH3 and OTHP4 comprise porphyrins featuring the element of tetraphenylporphyrin (TPP). An alternative to producing highly functionalized porphyrins from porphyrin condensation reaction is to synthesize a simple porphyrin and functionalize it thereafter. For this purpose, a fairly symmetrical methyl mono(p-carboxy)tetraphenylporphyrin (MepcTPP) 20 was synthesized (Scheme 7). 20 is easily accessible using the Lindsey method of a one-pot two-step reaction of pyrrole, benzaldehyde and methyl 4formylbenzoate under $\mathrm{BF}_{3} \cdot \mathrm{OEt}_{2}$ catalysis followed by DDQ oxidation. Fascinatingly, a modification of the reaction using $0.1 \mathrm{M} \mathrm{NaCl}$ solution in the reaction medium improved the isolated yield of the target porphyrin to $19 \%$, which is a two-fold increase of the yield as compared to the reaction without any salt. ${ }^{117}$

Porphyrin 20 was chlorosulfonated in neat chlorosulfonic acid in an electrophilic aromatic substitution, where the acid-deactivation of the porphin ring resulted only in chlorosulfonated phenylic para-positions. This unpolar intermediate is sufficiently stable for purification from excess of acid through water extraction in DCM, while the sulfonyl chlorides then are easily hydrolyzed to sulfonic acids in warm water. The elegance of the method lies in avoiding getting the polar sulfonated porphyrin in an inseparable mixture of strong polar acid, e.g. $\mathrm{H}_{2} \mathrm{SO}_{4}$.

The ester was deprotected under basic conditions with sodium hydroxide yielding porphyrin 21 as the precursor for Porph 2 in Figure 20. 


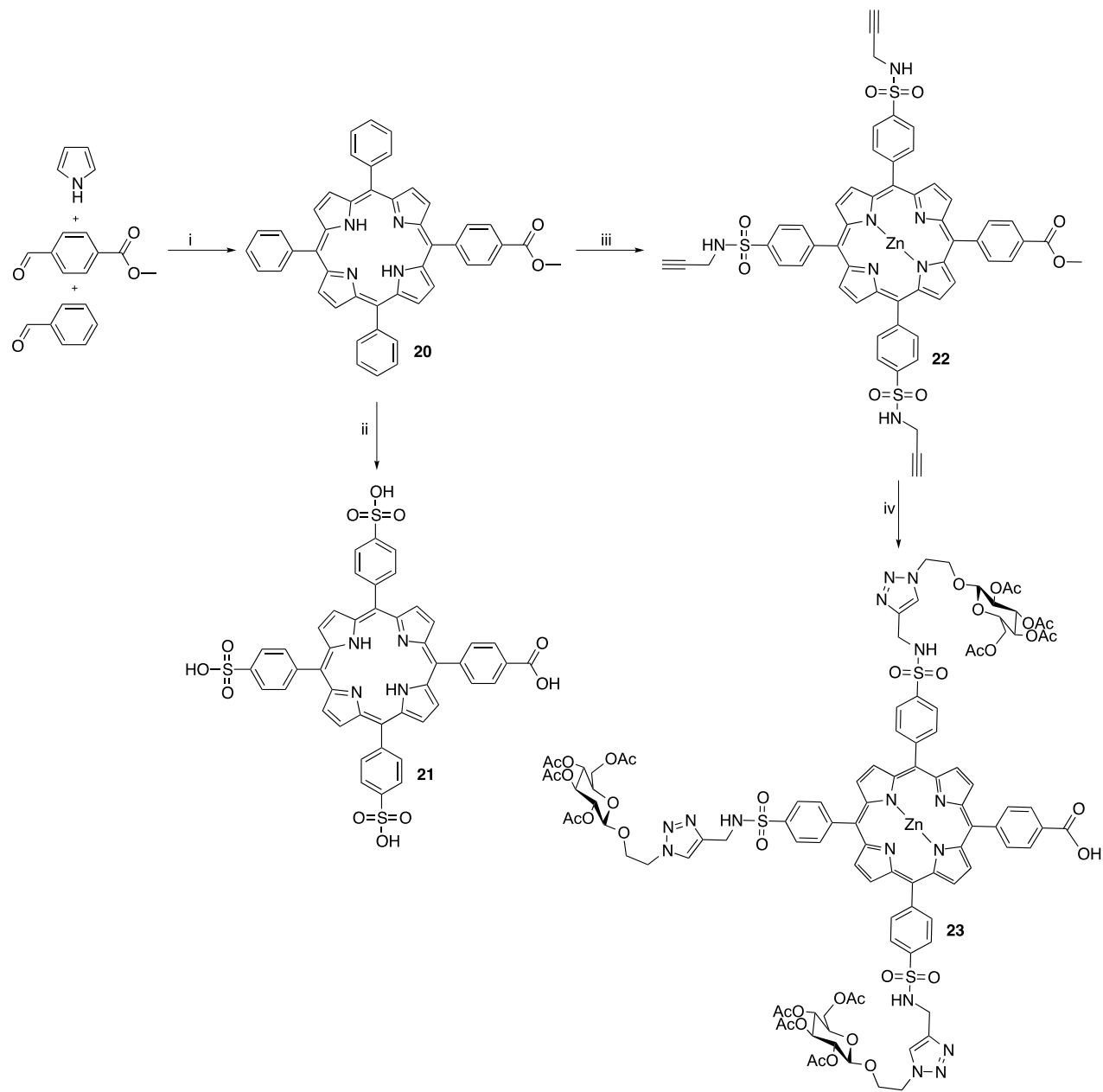

Scheme 7. Synthesis of porph2 (21) and porph3 (23). General conditions and reagents: i) 1 . $\mathrm{BF}_{3} \cdot \mathrm{OEt}_{2}$, $\mathrm{NaCl}, \mathrm{DCM}$, r.t. 2. $\mathrm{DDQ}$, r.t. 3. TEA, r.t. $19 \%$; ii) $\mathrm{HSO}_{3} \mathrm{Cl}$, r.t. iii) 1 . $\mathrm{H}_{2} \mathrm{O}, 80^{\circ} \mathrm{C}$; 2. $\mathrm{NaOH}$, r.t., quant. iv) 1 . Propargylamine, DIPEA, DMF, r.t. 2. $\mathrm{Zn}(\mathrm{OAC})_{2} * 2 \mathrm{H}_{2} \mathrm{O}, \mathrm{DCM}, \mathrm{MeOH}$, r.t., $40 \%$ over 2 steps; iv) 1 . LiCl, DMF, $\mathrm{MW}, 160{ }^{\circ} \mathrm{C}, 77 \%$. 2. 2-azidoethyl- $\beta$-D-glucoside $24, \mathrm{CuSO}_{4}$, sodium L-(+)-ascorbate, THF, t-BuOH, $\mathrm{H}_{2} \mathrm{O}$, $\mathrm{MW}, 85^{\circ} \mathrm{C}, 59$ \%. Adapted from Arja et al. Front. Chem. 2018;6;391. 116

Reaction with the chlorosulfonated intermediate is not restricted to water but can be conducted with any suitable nucleophile, by so creating a convenient method for rapidly functionalizing the otherwise so inert and robust tetraphenyl porphyrin. For an OTPH featuring glycosylated porphyrin building block Porph 3 (Figure 20), glycoconjugation with glucose was planned on three sites of the porphyrin. Therefore, the high-yielding and exclusively regioselective copper(I)-catalyzed alkyne-azide cycloaddition (CuAAC) ${ }^{114,115}$ was chosen for the coupling reaction. 20 was therefore chlorosulfonated and in the next step reacted with propargyl amine to yield terminal alkynyl functionalized porphyrin that upon metalation with zinc(II) yielded compound $\mathbf{2 2}$. The 
complexation with zinc(II) was done in preparation for the upcoming click reaction where initial studies showed that the catalytic copper otherwise would insert into the porphyrin cavity. The yield over these three steps was $40 \%$.

Porphyrin 22 now carries two different types of handles for selective site-specific conjugation reactions. The alkynes are to be used in $\mathrm{CuAAC}$ reaction to azidoglucoside 24 (Figure 24) whereas the ester-protected acid is meant to undergo amide coupling to the LCO moiety via a linker. The ester was therefore hydrolyzed to the free acid using the mild and selective Krapcho demethylation ${ }^{116,117}$ under microwave irradiation ${ }^{118,119}$ which left the sulfonamide bonds untouched.

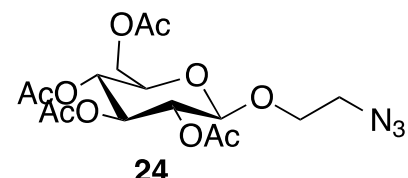

Figure 24. Structure of per-acetylated 2-azidoethyl- $\beta$-D-glucoside.

The glycosylation protocol used Sharpless' copper(I) catalyzed modification of the Huisgen 1,3-cycloaddition ${ }^{120}$ under microwave activation. The conditions were adapted from Maillard and co. ${ }^{121}$ offering a mild and highly efficient conjugation in only 5 minutes of reaction time at $85{ }^{\circ} \mathrm{C}$ in a sealed vial under microwave irradiation. The isolated yield of glycosylated porphyrin $\mathbf{2 3}$ was $59 \%$.

\subsection{Conjugation of LCO to porphyrins}

For conjugation of the LCO unit to the porphyrins, two different sequence orders are possible. By carefully considering the various available protecting-deprotecting options, we chose to first connect the linkers, TEG or MEG, to the LCO and then to conjugate the LCO-linker units to the porphyrins. Two amide coupling methods were used, namely HATU-mediated amide bond formation and EDC-NHS activation of the carboxylic acid partner. Which one of these was used depended on the structure and polarity of the coupling partners and whether it was desirable to purify and store the activated acid. With this in mind, Porph1 underwent EDC catalyzed NHS activation, rendering porphyrin 19 in Scheme 6, that could be purified on silica and stored in freezer.

Scheme 8 shows the general conditions for coupling of LCO 7 to TEG linker $\mathbf{1 3}$ and to the MEG linker, using HATU amide coupling reagent in DMF. Compounds $\mathbf{2 5}$ and $\mathbf{2 6}$ were obtained in fair yields. The tert-butyl carbamate protection groups on the amines were removed by treatment in TFA:DCM, 4:1, and the free amines $\mathbf{2 7}$ and $\mathbf{2 8}$ were amide coupled to NHS-activated porphyrin 19 according to Scheme 9 and Scheme 10, respectively. The basic ester hydrolysis yielded the final deprotected conjugates OTPH1 and OTPH2. A general observation from these syntheses was the remarkably poorer solubility of OTPH2 and its preceding compound containing the shorter linker, 
as compared to OTPH1. The observation could possibly be explained by the greater aggregation propensity of conjugates where the structurally similar molecular moieties are in the immediate vicinity of each other. Furthermore, the tetraethyleneglycol moiety adds to the greater polarity of OTPH1.

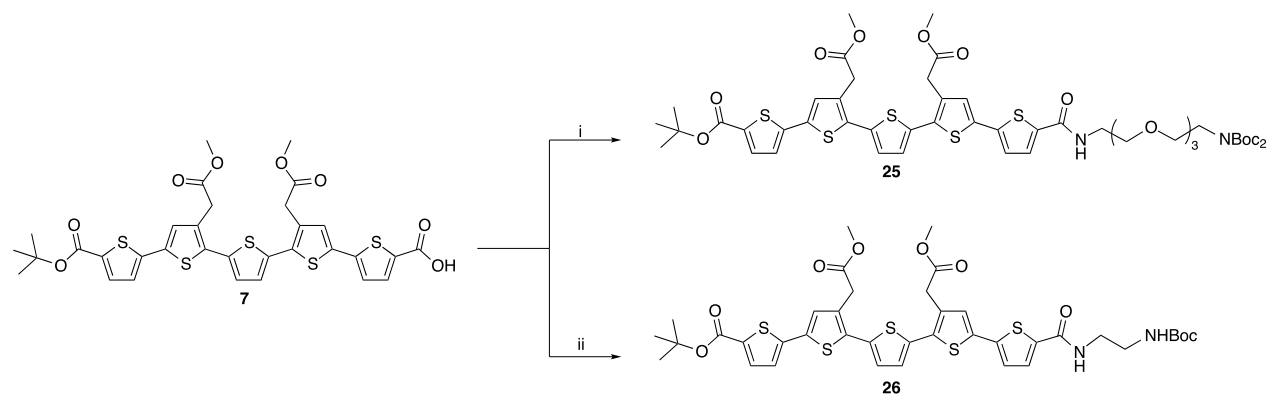

Scheme 8. General conditions and reagents: i) TEG-linker 13, HATU, TEA, DMF, r.t., $59 \%$; ii) ethylene mono-Boc diamine (MEG), HATU, DIPEA, DMF, r.t. 58 \%. Adapted from Arja et al. Front. Chem. 2018;6;391. ${ }^{116}$
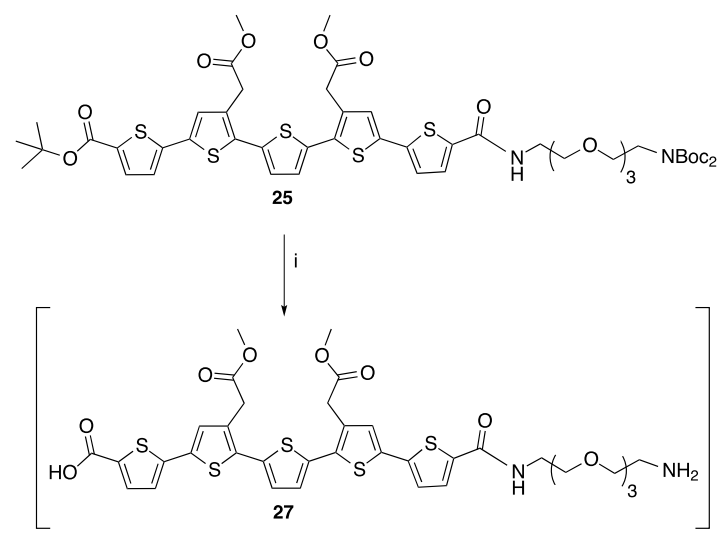
19 , ii

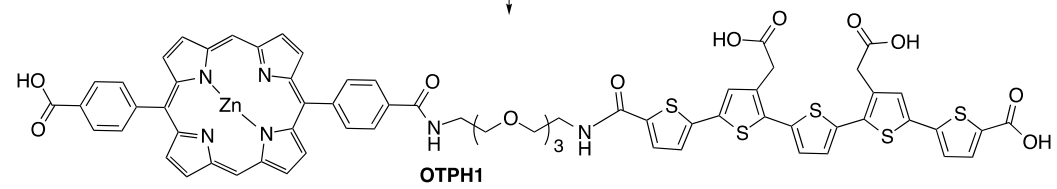

Scheme 9. General conditions and reagents: i) DCM:TFA, 4:1, r.t. ii) 1, DIPEA, DMF, r.t., $60 \%$; 2. $\mathrm{NaOH}$, $\mathrm{H}_{2} \mathrm{O}$, dioxane, reflux; 3. Dowex; 73 \%. Adapted from Arja et al. Front. Chem. 2018;6;391. 116 

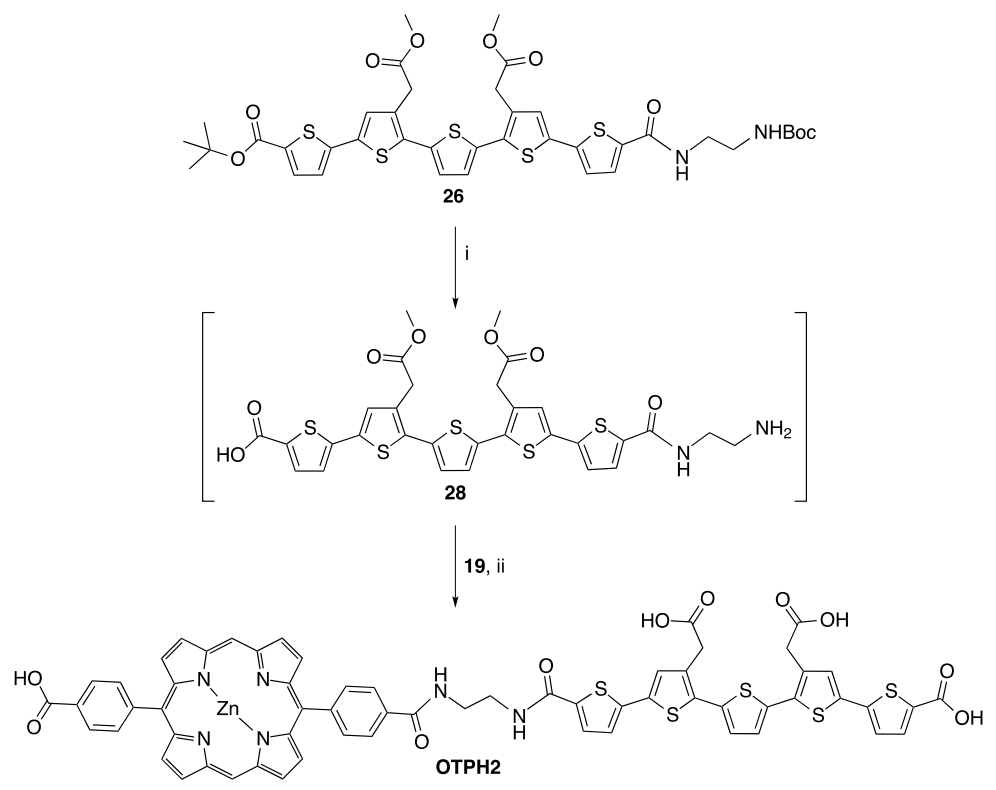

Scheme 10. General conditions and reagents: i) DCM:TFA, 4:1, r.t. ii) 1, DIPEA, DMF, r.t.; 2. $\mathrm{NaOH}, \mathrm{H}_{2} \mathrm{O}$, THF, r.t. 3. Dowex; 29 \%. Adapted from Arja et al. Front. Chem. 2018;6;391. 116

The synthesis of OTPH3 and OTPH4 involved conjugation of the free amine LCOTEG 27, derived from 25, to porphyrins 21 and 23, respectively, as illustrated in Scheme 11. Following HATU-mediated amide coupling reaction, ester hydrolysis and metalation with zinc(II) rendered OTPH3 in good yield. For glycosylated OTPH4, amide coupling was likewise followed by treatment with aqueous sodium hydroxide in order to deprotect the methyl esters on the LCO as well as the acetates on the sugars. 


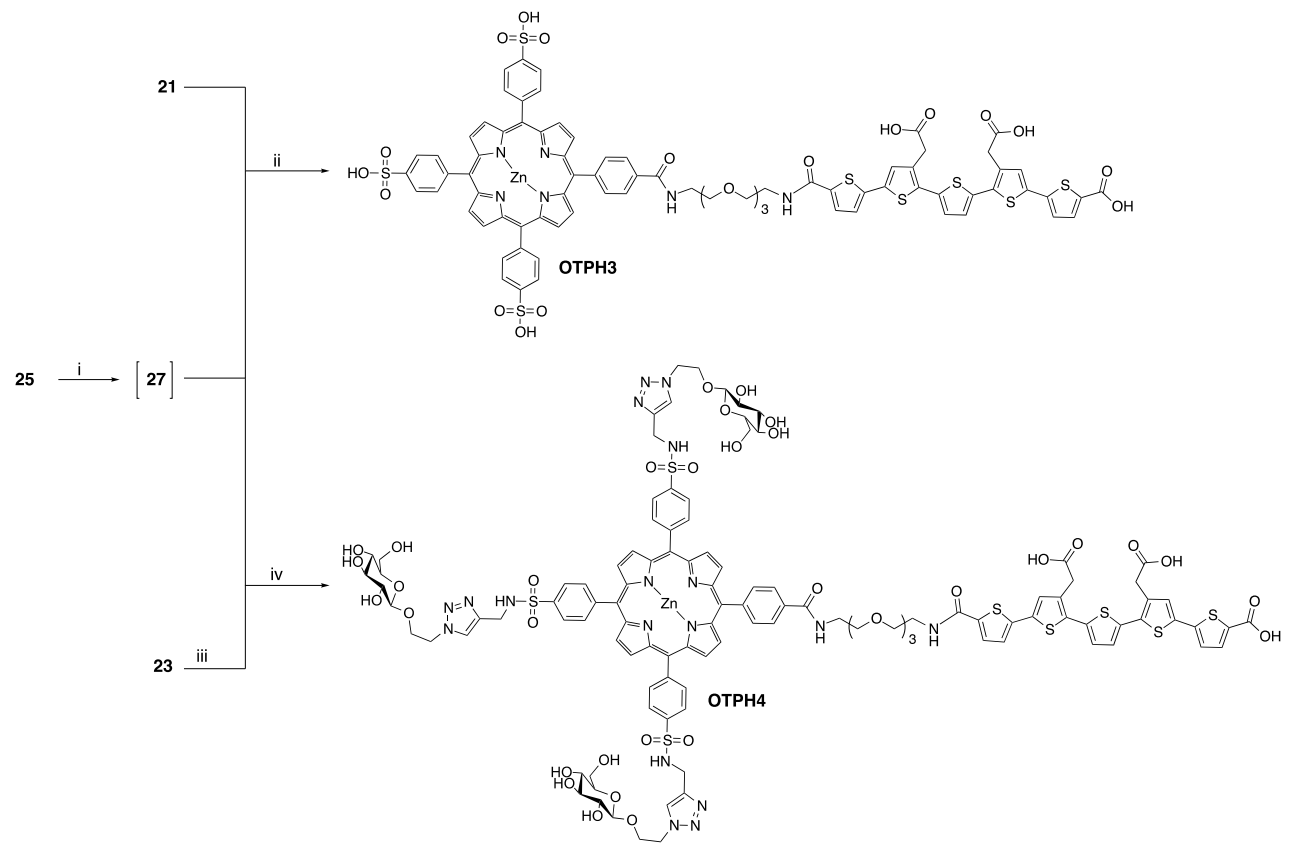

Scheme 11. General conditions and reagents: i) DCM:TFA, 4:1, r.t. ii) 1. HATU, DIPEA, DMF, r.t. 2. NaOH, $\mathrm{H}_{2} \mathrm{O}$, THF, r.t. 3. $\mathrm{Zn}(\mathrm{OAC})_{2} * 2 \mathrm{H}_{2} \mathrm{O}$, r.t. 65 \%; iii) $\mathrm{NHS}$, EDC, DMF, r.t. iv) 1. DIPEA, DMF, r.t. 2. $\mathrm{NaOH}, \mathrm{H}_{2} \mathrm{O}$, THF, r.t. 3. Dowex; 19 \%. Adapted from Arja et al. Front. Chem. 2018;6;391. 116 


\section{Oligothiophene porphyrin hybrids as fluorescent probes}

\section{(Paper I and Paper II)}

Both oligothiophenes and porphyrins have separately been used as fluorescent probes for bioapplications, but only a few conjugates between these molecules have been utilized for such purposes. The optical and electronic interplay of these molecular moieties is, however, more widely being taken advantage of in the field of optoelectronics and photovoltaics. ${ }^{122,123}$ Examples of polymeric thiophene-porphyrin conjugates and complexes can be found in literature, where the interactions of these structural moieties give rise to optical readouts for detecting bacteria ${ }^{124}$ and eukaryotic cells $^{125}$, or where such compounds are used for photodynamic inactivation of bacteria ${ }^{126}$ and fungi ${ }^{127}$.

\subsection{Paper I}

As mentioned earlier, chemically well-defined LCOs have been used as fluorescent probes for detecting and studying misfolded protein aggregates, and the diseases associated with such aggregates, for more than ten years. In Paper I, we aimed to further develop LCO-based ligands by combining them with an additional light-active molecule in hope to enhance their performance on detecting and visualizing $A \beta$ amyloid fibrils and plaque. For that, the anionic thiophene pentamer pFTAA was conjugated to Porph1 to render OTPH1, at the time of publication called p-FTAA-porph.

The optical characterization of the compound clearly indicated the presence of two different optical moieties. In addition to the typical broad absorption of pFTAA between 350 and $450 \mathrm{~nm}$, a much more intense Soret band at around $420 \mathrm{~nm}$, as well as two secondary Q-bands between 500 and $600 \mathrm{~nm}$, could be observed in the spectra (spectra shown in Paper I). Also, the emission spectra of OTPH1 exhibited contributions from both of the molecular moieties. For the free probe in solution, the broad emission from 500 to $600 \mathrm{~nm}$ corresponds to the pFTAA moiety and the peaks at 600 and $645 \mathrm{~nm}$ for the porphyrin. Noticeably, the emission from the oligothiophene moiety in the conjugate appears moderately quenched when compared to pFTAA alone (Figure 25).

Upon binding to recombinant A $\beta$ 1-42 amyloid fibrils in solution the overall emission intensity of the conjugate increases, with a signature emission of the amyloid-bound pFTAA moiety showing a double peak at $515 \mathrm{~nm}$ and $545 \mathrm{~nm}$. The enhanced fluorescence is particularly evident at the porphyrin emission peaks. Nevertheless, when compared to pFTAA alone bound to A $\beta$ fibrils, the pFTAA moiety in conjugate does not show the increase in emission intensity to the same extent (Figure 25) 

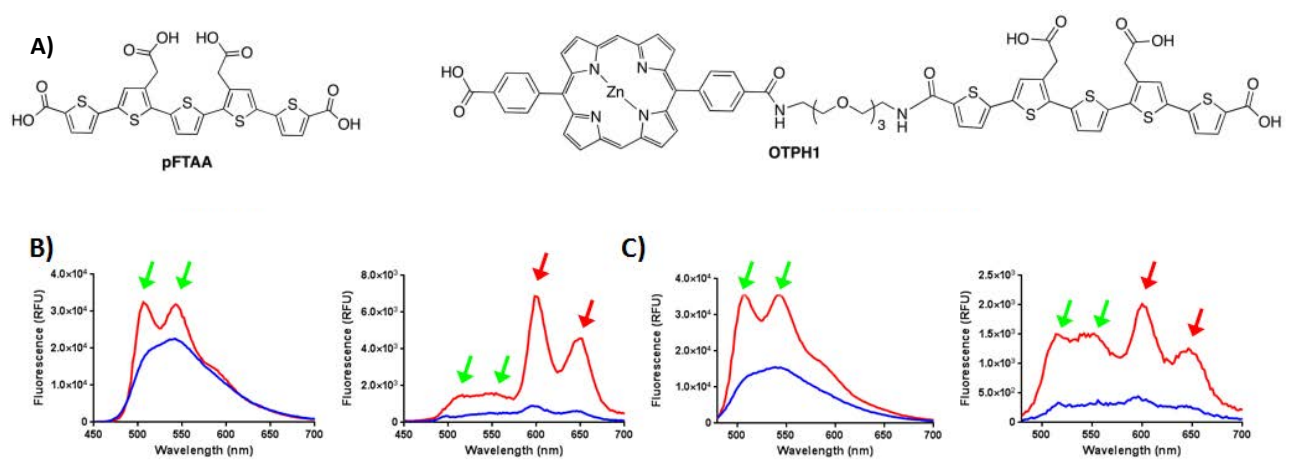

D)

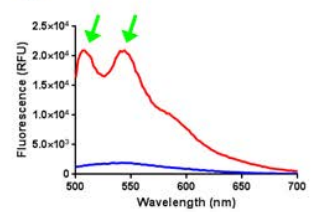

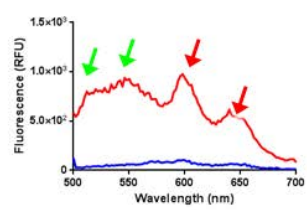

E)
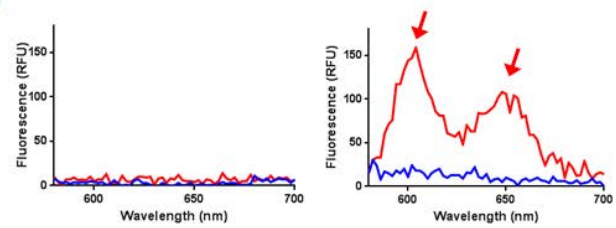

Figure 25. A) Chemical structures of pFTAA and OTPH1. B-E) Emission spectra of $300 \mathrm{nM} \mathrm{pFTAA} \mathrm{(left)}$ or $300 \mathrm{nM}$ OTPH1 (right) in PBS (blue) or mixed with $10 \mu \mathrm{M}$ recombinant $\mathrm{A} \beta$ amyloid fibrils in PBS (red). Excitation at $425 \mathrm{~nm}$ (B), $440 \mathrm{~nm}$ (C), $480 \mathrm{~nm}$ (D) or $560 \mathrm{~nm}$ (E), respectively. Emission peaks assigned to the pFTAA moiety are indicated with green arrows, whereas emission peaks associated with the porphyrin moiety are indicated with red arrows. Adapted from Arja et. al: Enhanced Fluorescent Assignment of Protein Aggregates by an Oligothiophene-Porphyrin-Based Amyloid Ligand. Macromol. Rapid Commun. 2013 Vol. 34 (9) pp. 723-730. Copyright Wiley-VCH Verlag GmbH \& Co. KGaA. Reproduced with permission. 128

In general, OTPH1 shows a lower fluorescence intensity than pFTAA when bound to A $\beta$ 1-42 amyloid fibrils, indicating that OTPH1 might be less sensitive than pFTAA for identification of minor amounts of amyloid. Nonetheless, OTPH1 shows an enhanced spectral range compared with pFTAA and may therefore function as a probe for improved spectral assignment of heterogeneous protein aggregates.

In Paper I we could also observe that OTPH1 shows selective and specific staining of immune-positive $A \beta$ deposits so the aggregates can be identified and visualized by the intense fluorescence. The specific binding ability of pFTAA to A $\beta$ deposits was therefore retained despite the ligated porphyrin unit. Furthermore, the emission of OTPH1 bound to $A \beta$ aggregates had a varying spectrum at different positions on the plaque, a phenomenon not characteristic to pFTAA alone (Figure 26). When studying individual $\mathrm{A} \beta$ deposits by combining two different excitation wavelengths (405 and 560 $\mathrm{nm}$ ), plaques stained with pFTAA show a uniform emission spectral profile, whilst OTPH1 stained plaques unveil location-dependent spectral diversity. The observed spectral heterogeneity of plaque-bound OTPH1 derives most likely from different conformation dependent routes for fluorescence quenching and FRET, which depend on the varying morphology within an $\mathrm{A} \beta$ plaque. 

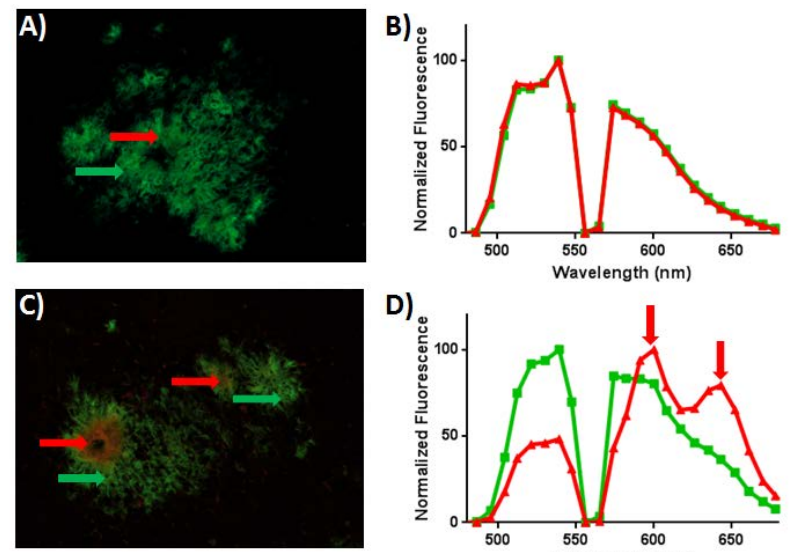

Figure 26. Fluorescence images of pFTAA (A) or OTPH1 (C) stained A $\beta$-deposits in a brain tissue section from a transgenic mouse with AD pathology. Emission spectra of pFTAA (B) or OTPH1 (D) bound to A $\beta$ deposits. The green and red spectrum correlates to areas of the deposits as indicated with green and red arrows in $\mathbf{A}$ and $\mathbf{C}$. The images and the spectra were collected using a combination of two excitation wavelengths, 405 and $560 \mathrm{~nm}$. Adapted from Arja et. al: Enhanced Fluorescent Assignment of Protein Aggregates by an Oligothiophene-Porphyrin-Based Amyloid Ligand. Macromol. Rapid Commun. 2013 Vol. 34 (9) pp. 723-730. Copyright WileyVCH Verlag GmbH \& Co. KGaA. Reproduced with permission. ${ }^{128}$

For an even greater versatility of OTPHs as amyloid probes, fluorescence lifetime imaging microscopy (FLIM) can be employed. In Paper I we also demonstrate mapping of the heterogeneous nature of these plaques using FLIM on OTPH1-stained amyloid deposits. In Figure 27 FLIM images of pFTAA stained (A) versus OTPH1 stained (B) aggregates are depicted, revealing that, unlike pFTAA alone, the pFTAA-porphyrin conjugate is able to distinguish between the core and the peripheral amyloid structures of $A \beta$ proteinaceous deposits. 

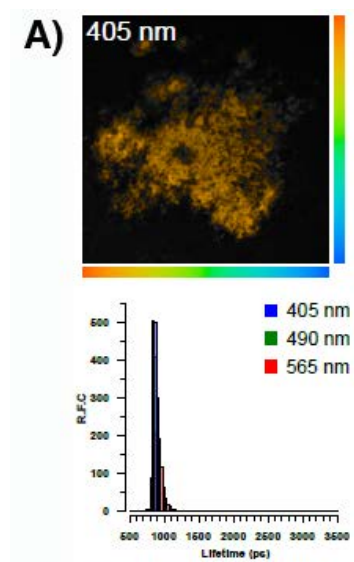
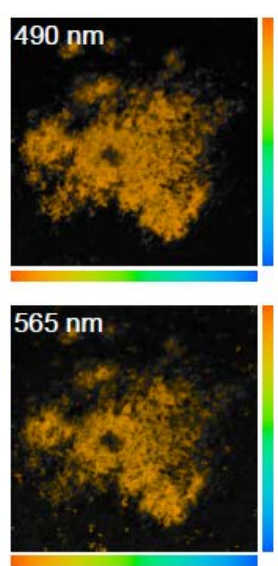

B)
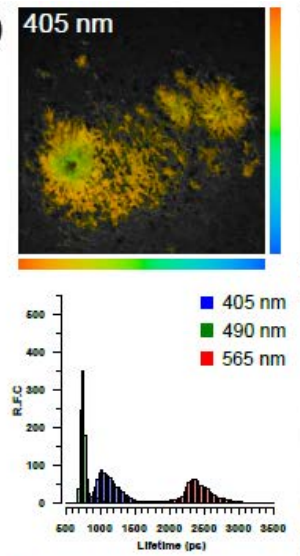
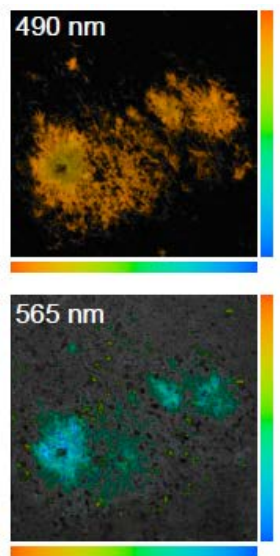

Figure 27. A) Fluorescence lifetimes of pFTAA stained $A \beta$-deposits in a brain tissue section from a transgenic mouse with Alzheimer's disease (AD) pathology. B) Fluorescence lifetimes of OTPH1 stained $A \beta$-deposits in a brain tissue section from a transgenic mouse with $A D$ pathology. The fluorescence lifetimes were collected with excitation at 405, 490 and $565 \mathrm{~nm}$, and the color bar in A and B represent life times from 500 ps (orange) to 3500 ps (blue). The images in A and B are color coded according to the representative life time. Adapted from Arja et. al: Enhanced Fluorescent Assignment of Protein Aggregates by an Oligothiophene-Porphyrin-Based Amyloid Ligand. Macromol. Rapid Commun. 2013 Vol. 34 (9) pp. 723-730. Copyright WileyVCH Verlag GmbH \& Co. KGaA. Reproduced with permission. ${ }^{128}$

\subsection{Paper II}

With the encouraging results from both the design and synthesis, as well as the photophysical and amyloidophilic properties of OTPH1 in Paper I, we now proceeded to broaden the subset of OTPHs in our molecular probe library. In Paper II, pFTAA was conjugated to three other porphyrin-based molecules, producing ОTPH2, ОTPH3 and OTPH4 (Figure 28) according to the synthetic routes in in the previous chapter. Together with OTPH1 they were optically characterized and evaluated as fluorescent probes for detecting misfolded protein aggregates.

Our aim was to study the effects of structural modifications of the porphyrin moiety and of the spacer between the LCO and porphyrin, for the optical and electronic interactions between the two distinct optical elements when using OTPHs as amyloid ligands. 

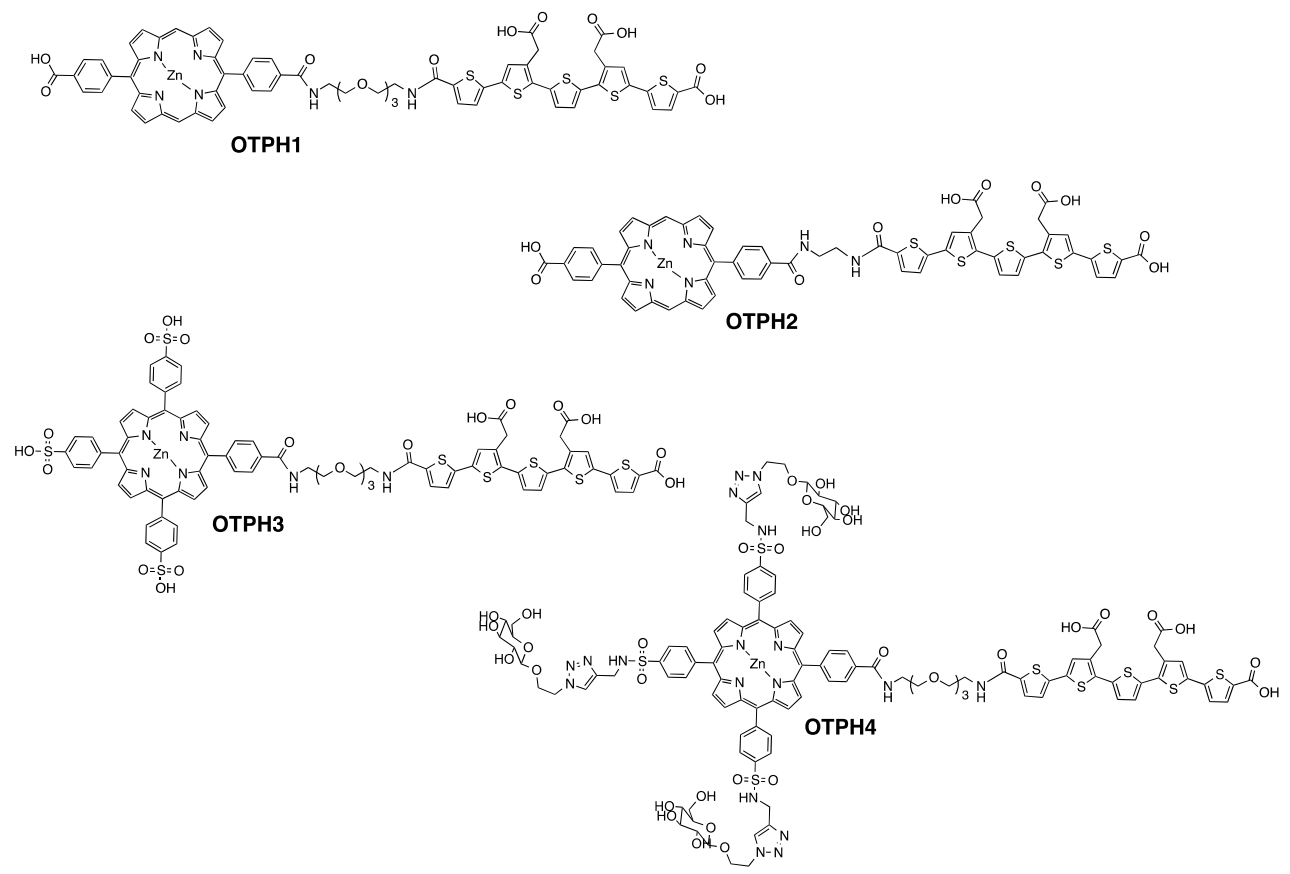

Figure 28. Chemical structures of OTPHs.

Optical characterization of OTPHs in solution confirmed the presence of two distinct optical modalities. The absorption spectra of OTPHs display, besides the broad pFTAA absorption between 300 and $500 \mathrm{~nm}$, the considerably higher porphyrin absorption Soret band at $420 \mathrm{~nm}$ for OTPH 1 and OTPH2, and at $430 \mathrm{~nm}$ for OTPH3 and OTPH4, as well as two secondary Q-bands between 550 and $610 \mathrm{~nm}$. The tetrameso-phenyl substitution pattern of OTPH3 and OTPH4, as compared to dimeso-phenyl of OTPH1 and OTPH2, was evident from the slightly red-shifted absorption of these porphyrin moieties. The same red-shifted trend was even noticed for the porphyrin emissions that moved from 600 and $650 \mathrm{~nm}$ for OTPH1 and OTPH 2 to 620 and $670 \mathrm{~nm}$ for OTPH 3 and OTPH4. The expected emission intensity for the pFTAA moiety at $550 \mathrm{~nm}$ was considerably decreased for the hybrid molecules 1 and 2 and absent for 3 and 4, which strongly indicates quenching interaction from the porphyrins.

All the OTPHs in this study show selective and specific staining for $A \beta$ deposits in brain tissue sections from transgenic mice with $\mathrm{AD}$ pathology. The thorough investigation of the fluorescence images and the emission spectra of the stained protein aggregates reveal interesting details that can be ascribed to the distinct structural elements and differences between these conjugates. Similarly to the results in Paper I, the heterogeneous morphology of the protein deposits can be clearly visualized with all the oligothiopheneporphyrin conjugates, using the excitation at $561 \mathrm{~nm}$ to highlight the dense core and the excitation at 458 or $488 \mathrm{~nm}$ to visualize the diffuse exterior of the amyloid. The fluorescence comes from the porphyrins and from the oligothiophene, respectively. 
Using only the corresponding oligothiophene as the dye, does not provide the same detailed spectral assignment. (Figure 29).

In OTPH1 and OTPH2 the diphenyl porphyrins seem to interact with the LCO in a different manner than the tetraphenyl porphyrins in OTPH3 and OTPH4 do, as evident from the complete absence of the porphyrin emission and lacking of the characteristic double peaks of the typical amyloid bound oligothiophene emission when OTPH1 and OTPH2 are excited at 458 or $488 \mathrm{~nm}$. Quite so expectedly, even the length of the linker has an effect on the optical interplay between the porphyrin and the LCO in a plaque bound conjugate, exemplified with the lacking porphyrin double emission peaks for OTPH2 featuring the short monoethylene linker. (Figure 29)
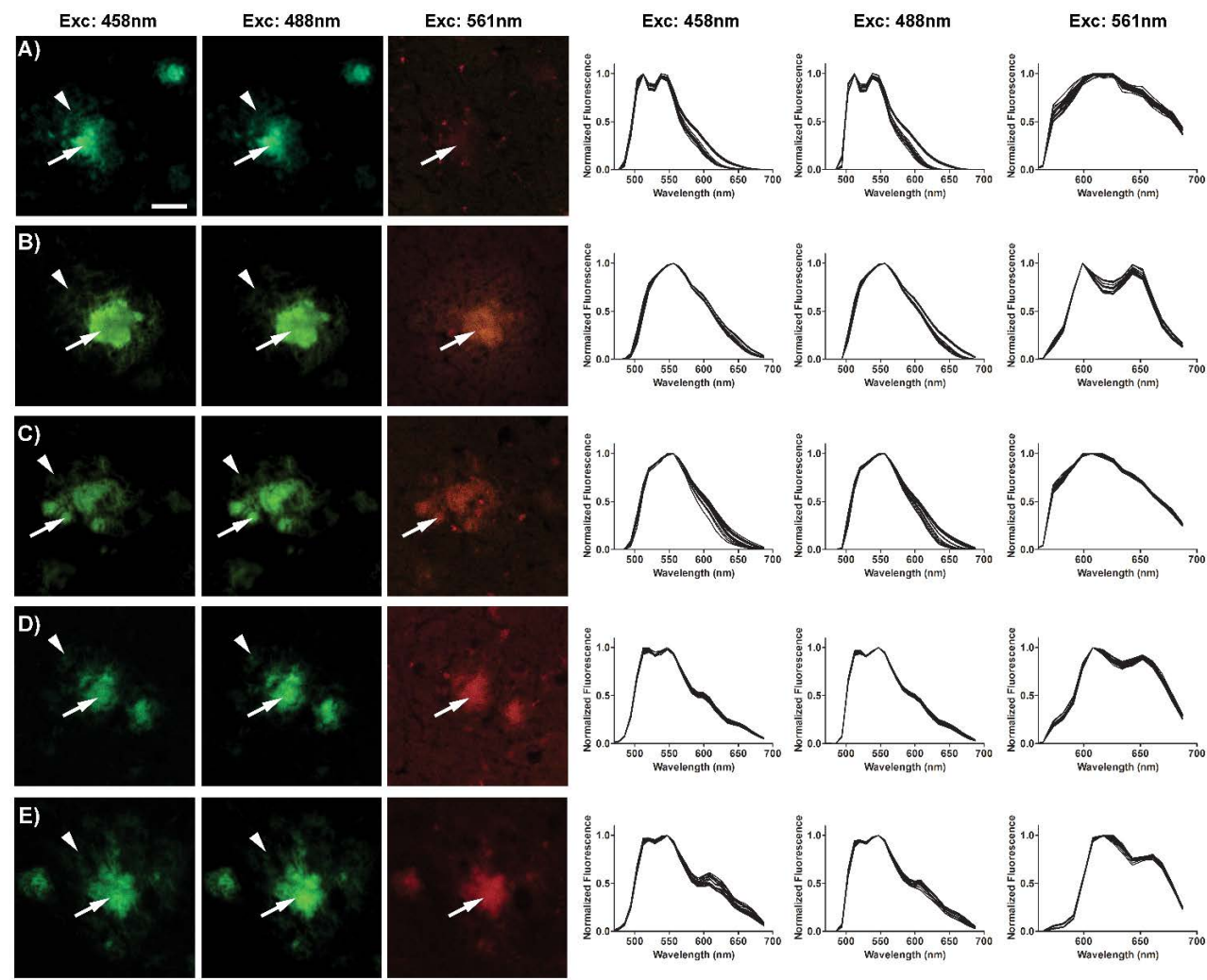

Figure 29. Fluorescence images (left panel) and emission spectra (right panel) of pFTAA- (A) and OTPHstained (B-E OTPH1-OTPH4, respectively) $A \beta$ deposits in brain tissue section from transgenic mice with AD pathology. Three different excitation wavelengths ( $458 \mathrm{~nm}, 488 \mathrm{~nm}$ and $561 \mathrm{~nm}$ ) were used for all of the ligands. The $A \beta$ deposits are composed of compact cores (white arrows) and a diffuse exterior (white arrow heads). Scale bar represents $20 \mu \mathrm{m}$. Adapted from Arja et al. Front. Chem. 2018;6;391, with permission. ${ }^{116}$ 
The results from the FLIM study of the OTPH-stained A $\beta$ deposits confirm the evidence for some structure - probe activity relations (Figure 30). When exciting the pFTAA moiety (at $490 \mathrm{~nm}$ ), OTPH1 and OTPH2 display fluorescence decay times shorter than that of pFTAA alone, while ОTРН3 and ОTPH4 show longer fluorescence decay times. All the decay time distributions differ from each other, assuring varying molecular and photophysical interactions between the probe and the target, as well as between the two distinct optical moieties of a probe. The FLIM images acquired with the excitation at $490 \mathrm{~nm}$ visualize both the core and the peripheral structures of the plaque.
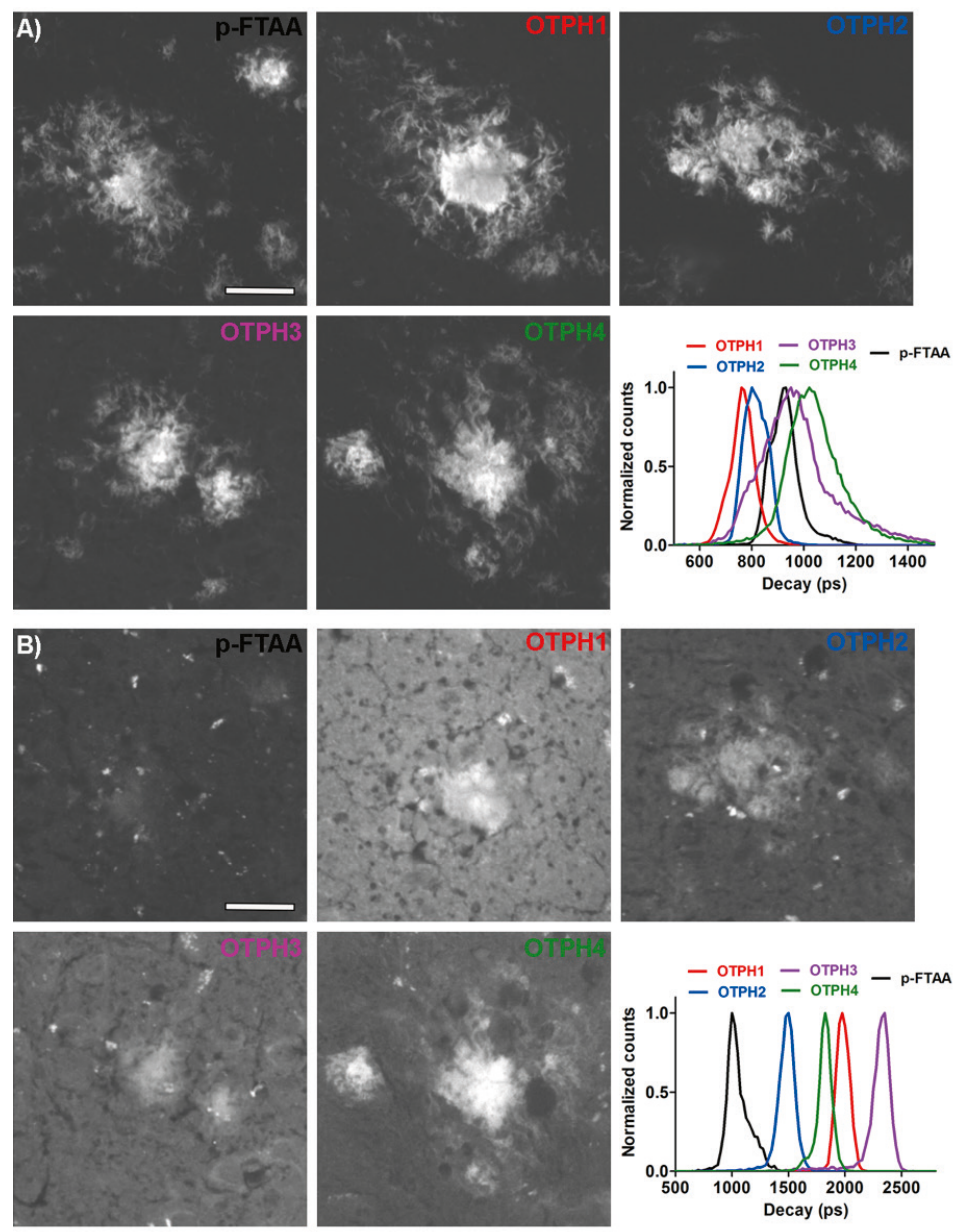

Figure 30. Fluorescence lifetime images and intensity-weighted mean lifetime distributions of pFTAAand $\mathrm{OTPH}$-stained $A \beta$ deposits in brain tissue section from transgenic mice with $A D$ pathology. A) Excitation at $490 \mathrm{~nm}$. B) Excitation at $561 \mathrm{~nm}$. Scale bar represents $20 \mu \mathrm{m}$. Adapted from Arja et al. Front. Chem. 2018;6;391, with permission. ${ }^{116}$

The same observations of strongly varying fluorescence decay times can be seen when exciting the porphyrin units of the OTPHs (at $561 \mathrm{~nm}$ ). The fluorescence decay times 
for the different porphyrins vary greatly, with the porphyrin moiety in OTPH2 having an average fluorescence decay time around $1500 \mathrm{ps}$ and the porphyrin moiety in OTPH3 around 2400 ps. The FLIM images now only highlight the central core of the amyloid plaque, the pattern already observed in Paper I.

In Paper II we finally present the results for OTPH4, featuring the glucosylated porphyrin, being utilized as a fluorescent chemosensor to distinguish between the agerelated morphotypes of $A \beta$ aggregates in brain tissue sections from transgenic mice with $\mathrm{AD}$ pathology. The glycosylation with the quintessential monosaccharide glucose provides a dye for optical discrimination between misfolded protein plaque acquired from transgenic APPPS1 mice of different ages. For this purpose, both the assessment of emission spectra of the $A \beta$ plaque bound probe and fluorescence lifetime imaging can be successfully used (Figure 31). The differences in the spectral readouts from the probe-stained $A \beta$ aggregates upon aging of the transgenic mice depend with all probability on the morphological changes in the structure of the maturing amyloid plaque. The unglycosylated OTPH1 does not show this property of distinction between age-related morphotypes, which indicates the need for the presence of the glucose motifs on the porphyrin. In an earlier study by Nyström et. al, using a combination of two structurally similar LCOs, the anionic tetrameric qFTAA and the anionic heptameric hFTAA, provided the means to discriminate between $A \beta$ amyloid deposits from transgenic mice of different age using emission spectral assessment. ${ }^{74}$ Age-dependent changes in morphology of $A \beta$ aggregates have also been observed by using fluorescence imaging with HS-68, an LCO with altered spacing between the anionic sidechains. ${ }^{72}$ With OTPH4, we have synthesized a single molecule with two chromophoric modalities which enables to study the time-dependent structural changes in $A \beta$ aggregates in a progressing disease using both emission spectral assessment and FLIM. The necessity for the presence of the carbohydrates on the porphyrin moiety implies the existence of some interactions of carbohydrates with the amyloid deposit. The phenomenon is not new to the amyloid community as the similar type of interaction has been known for amyloid proteins and the endogenous polysaccharides glycosaminoglycans (GAGs). ${ }^{129}$ It is believed that GAG amyloid interactions are mediated via specific binding pockets on the amyloid aggregates. We speculate that the optical sensitivity of OTPH4 towards $\mathrm{A} \beta$ plaque maturing could originate from the similar interaction basis. 
A)

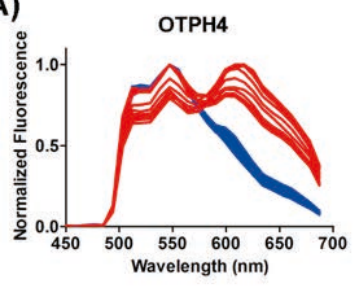

D)

- OTPH1 young APPPS1 mice - OTPH4 young APPPS1 mice

- OTPH1 old APPPS1 mice - OTPH4 old APPPS1 mice

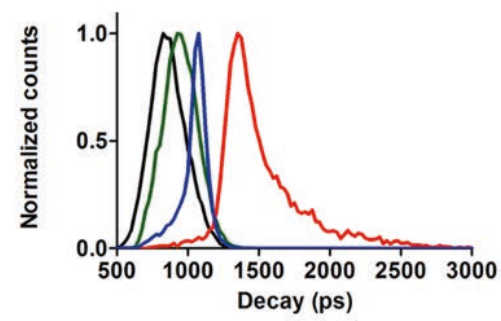

B)

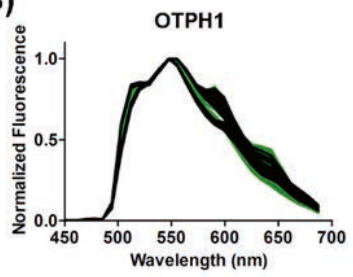

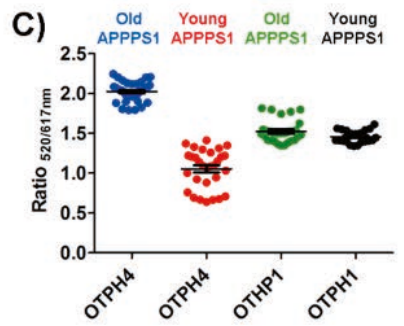

E)

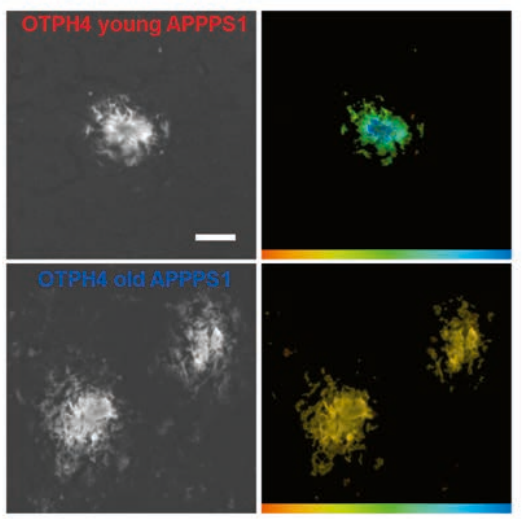

Figure 31. Spectral assessment (A-C) and fluorescence lifetime imaging (D-E) of OTPH1 and OTPH4 stained $A \beta$ deposits in brain tissue section from young (148 days) or old (533 days) APPPS1 transgenic mice with AD pathology. Adapted from Arja et al. Front. Chem. 2018;6;391, with permission. 116 


\section{Oligothiophene porphyrin hybrids in chiroptical bioorganic materials}

\section{(Paper III)}

Proceeding from the proteinacous targets for our synthetic organic ligands in Paper I and II, Paper III demonstrates a study on interactions of OTPH1 and OTPH3 with two synthetic peptides, with the focus on material science. In a previously published article by Selegård et al. reporting on synthesis of peptide-oligothiophene hybrid materials, non-covalent association of a cationic synthetic peptide and the anionic LCO pFTAA was observed. The structural arrangements were accompanied with induced chiroptical activity. ${ }^{130}$ OTPHs, featuring pFTAA and an additional molecular moiety with appealing structural and photophysical qualities in form of porphyrins, make attractive guest molecules for hybrid bioorganic materials. As described earlier, biomoleculebased materials offer great advantages of soft and static structure resulting from conformational flexibility of the biomolecular components. ${ }^{100,131-133}$ These materials display improved biocompatibility, suitable for biological and medicinal applications, and the synthetic advantage of self-assembly. Furthermore, the possibility to punctually alter the structure of the components on the molecular level gives the means to fine-tune the properties of the resulting material in a controlled manner. This gives direct means to adjust the final product for a specific applicational area. As an example, in a study by Dånmark et al. peptide-based hydrogels of varying viscoelasticity and temperature stability were produced. ${ }^{134}$ Four synthetic 28 amino acid long peptides had previously been produced and evaluated for parallel coiled-coil heterodimerization and self-sorting properties. $^{135}$ Now these peptides were covalently conjugated to a star-shaped polyethylene glycol scaffold and self-associated into highly branched networks of hydrogels. Further fine-tuning of the mechanical properties can in this case be done by addition of non-PEGylated peptide of a higher affinity to disassociate some of the coiled-coil structures in the network.

In our study two synthetic peptides, JR2K and KI bearing a net positive charge, were chosen to further investigate their potential in biomaterials with tunable properties. The primary sequences of these peptides are the following, JR2K being composed of 42 amino acids while KI consists of 21 amino acids:

\section{JR2K NAADLKK AIKALKK HLKAKGP VDAAQLK KQLKQAF KAFKRAG}

\section{KI KIAALKE KIAALKE KIAALKE}

Gray color indicates positively charged residues lysine $(\mathrm{K})$ and arginine $(\mathrm{R})$.

The synthesis of the peptides was done on an automated peptide synthesizer using fluorenylmethyloxycarbonyl (Fmoc) chemistry according to the previously described proceedures. ${ }^{135,136}$ Both peptides exist as random coils at neutral $\mathrm{pH}$. JR2K is designed 
to form a four-helix bundle heterodimer with a negatively charged peptide, while it does not homodimerize due electrostatic repulsions. ${ }^{136} \mathrm{KI}$, however, is meant to build coiledcoil heterodimers with complementary peptides and shows a marginal degree of homodimerization and folding at $\mathrm{pH} 7 .{ }^{135}$

In this study OTPH1, featuring carboxylic acid functionalized diphenyl porphyrin, and OTPH3, comprising sulfonate functionalized tetraphenyl porphyrin, were used together with the reference compounds P1, P3 and pFTAA (Figure 32). The detailed synthesis of the compounds is described in Chapter 3.

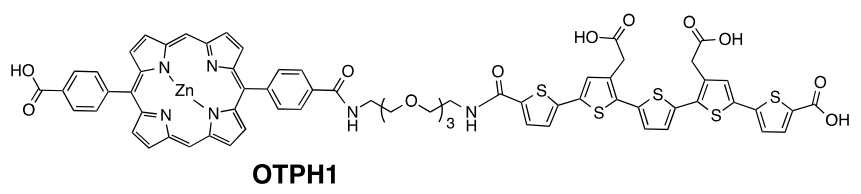

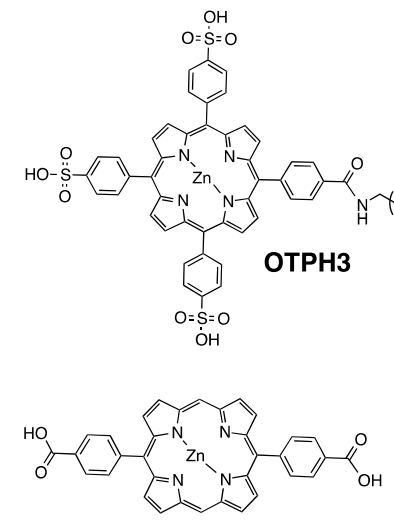

P1
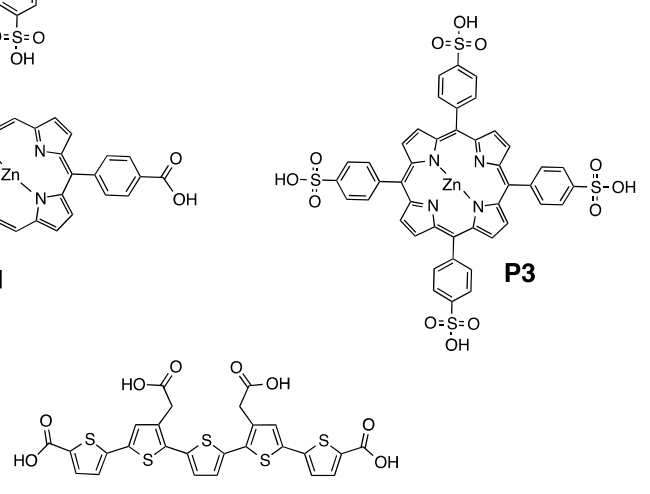

pFTAA

Figure 32. Chemical structures of OTPH1, OTPH3, PFTAA, P1 and P3.

Absorption and emission measurements of the peptide-ligand solutions did reveal small alteration of the spectral profiles due to possible interaction. A slight redshift in absorption and emission peaks for all the guest compounds mixed with JR2K (Figure 33) was registered. The most evident shift was observed for pFTAA-JR2K, which is in accordance with a previously published study. ${ }^{130}$ The redshifts in absorption and emission maxima may indicate that upon interaction with JR2K these probes adopt a more planar conformation resulting in a longer effective conjugation. In addition, increased emission was detected for OTPH1 and OTPH3 while interacting with JR2K. 
Possible interactions of the probes with KI could not be assigned in the same manner to the absorption-emission data.
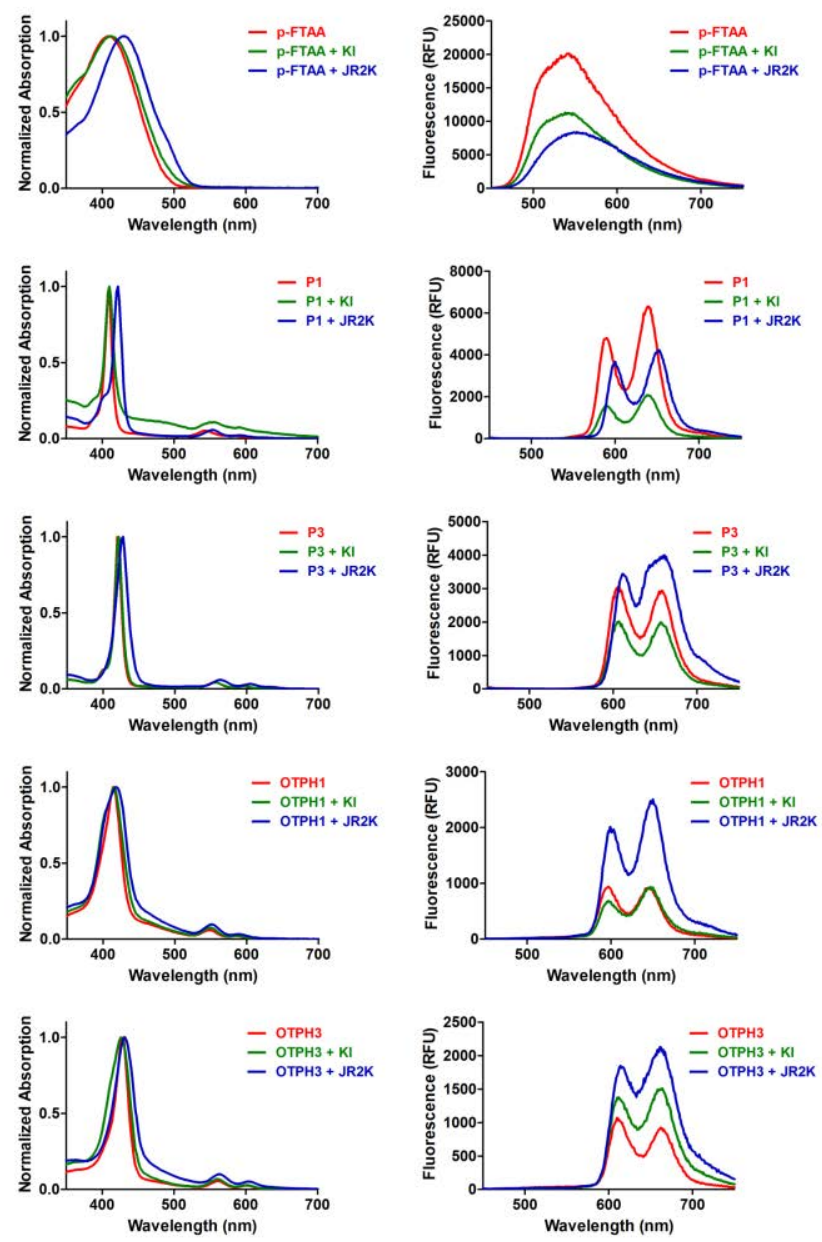

Figure 33. Absorption and emission spectra of pFTAA (first row), P1 (second row), P3 (third row), OTPH1 (fourth row) and OTPH3 (fifth row) alone in solution and mixed with peptides KI and JR2K.

To further investigate the possible interactions between the OTPHs and the peptides, circular dichroism (CD) measurements were carried out. CD is a common method to study different structural elements of proteins. Based on the phenomenon that chiral molecules absorb left-handed (L) and right-handed (R) circularly polarized light to different extent, structural changes and interactions of, for example, proteins and peptides can be investigated. A CD signal can be observed if a molecule is either intrinsically chiral, a molecule is covalently attached to a chiral center or a molecule is in an asymmetric environment. The last criterion results from a certain three- 
dimensional structure that the molecule adopts. ${ }^{137} \mathrm{CD}$ is measured as the difference of absorption $\Delta \mathrm{A}=\mathrm{A}_{\mathrm{L}}-\mathrm{A}_{\mathrm{R}}$, but is often converted to and reported as ellipticity $\theta$ in degrees, where the simple numerical relation $\theta=32.98 \Delta \mathrm{A}$ connects these two quantities. $\mathrm{CD}$ is measured as the function of wavelength and, as to proteins, one of the most often gained sort of information is about the secondary structure of the polypeptide chain indicated in the far-UV end of the spectrum. ${ }^{138}$

The usage of porphyrins as $\mathrm{CD}$ reporter groups is wide-spread thanks to their intense red-shifted absorbance and the ease of interaction with other molecules through $\pi-\pi$ stacking, via peripheral functional groups and via any coordinating metal ion in the porphyrin cavity. ${ }^{139}$ In many cases, achiral porphyrins are used to study chiral molecules, such as amino acids, that directly interact with the porphyrins through the stereocenter. ${ }^{140}$ Other cases demonstrate examples of $\mathrm{CD}$ on intrinsically chiral porphyrins to study enantioselective interactions ${ }^{141}$ with guest molecules or to perform asymmetric catalysis ${ }^{142}$.

In our study, we aimed to achieve an induced chirality of OTPH-peptide hybrid molecules resulting from adopted well-defined three-dimensional structures guided by electrostatic interactions between the cationic peptides and the anionic OTPHs. The separate components, the OTPHs and the reference compounds showed no CD signals, indicating their random solvation in the solutions. In the same manner, the peptides alone displayed the $\mathrm{CD}$ signals of random coil conformations. However, upon mixing the probes with the peptides in rations 1:1, induced chirality and $\alpha$-helical nature of the peptide could in a number of cases be observed by the spectropolarimeter. For JR2K, both OTPH1 and OTPH 3 made the peptide adopt the $\alpha$-helical secondary structure as recognized from the characteristic negative peaks at around $222 \mathrm{~nm}$ and $208 \mathrm{~nm}$ (Figure 34 upper panel). Nevertheless, a higher ratio of the two minima $\left(\theta_{222} / \theta_{208}\right)$ for the OTPH3-JR2K complex is indicative of a slightly different helical structure than for OTPH1-JR2K. JR2K peptide does gain an $\alpha$-helical structure even from interactions with porphyrin P3 and to a lesser extent with P1, as well as with pFTAA as already established in earlier published literature ${ }^{130}$. Furthermore, intense bisignate induced CD (ICD) signals are observed for the guest molecules at the expected wavelengths for their absorption, which proves their incorporation into higher-order complexes with the peptide. ICD signal of OTPH1 and $\mathrm{P} 1$ can be ascribed to the $\mathrm{B}_{\mathrm{x}}$ component of the Soret band, while the two sets of split signals of OTPH3 and $\mathrm{P} 3$ derive most probably from $\mathrm{B}_{\mathrm{x}}$ and $\mathrm{B}_{\mathrm{y}}$ components of the sulfonate porphyrin moiety as observed by Nezu et al. ${ }^{143}$ Interestingly, the patterns of the ICD signals for OTPH1 and OTPH3, with a negative Cotton effect at longer wavelengths and a positive Cotton effect at shorter wavelengths, are quite different from the corresponding porphyrins $\mathrm{P} 1$ and $\mathrm{P} 3$ that demonstrate the opposite Cotton effects of the sharp bisignate signal around the main porphyrin absorption band. This observation may suggest that, as compared to a free porphyrin, a pFTAA-conjugated porphyrin has a different mode of interaction with the peptide which can be explained by the intramolecular interactions within an OTPH as well as the competing oligothiophene-peptide interplay. 
The CD spectra of peptide KI together with OTPH1 and OTPH3 in ratios 1:1 demonstrate two distinct minima characteristic of $\alpha$-helical structure of the peptide (Figure 34 lower panel). This observation was particularly interesting as neither pFTAA alone nor the porphyrins P1 and P3 were able to initiate the folding of KI into an $\alpha$ helix. The ICD signal of the OTPHs associated with KI differed significantly from the ones of JR2K complexes. OTPH1-KI hybrid molecule shows a sharp split-type ICD signal of almost double the intensity compared to OTPH1-JR2K, while OTPH3-KI hybrid gives rise to two pronounced minima at $438 \mathrm{~nm}$ and $421 \mathrm{~nm}$ before intersecting the zero line to give a maximum at the shorter wavelengths. These results suggest that for $\mathrm{KI}$ a porphyrin-oligothiophene conjugate is necessary to adopt its $\alpha$-helical structure. Furthermore, varying the porphyrin moiety in OTPH affects the induced chiroptical properties of these self-assembled hybrid molecules.
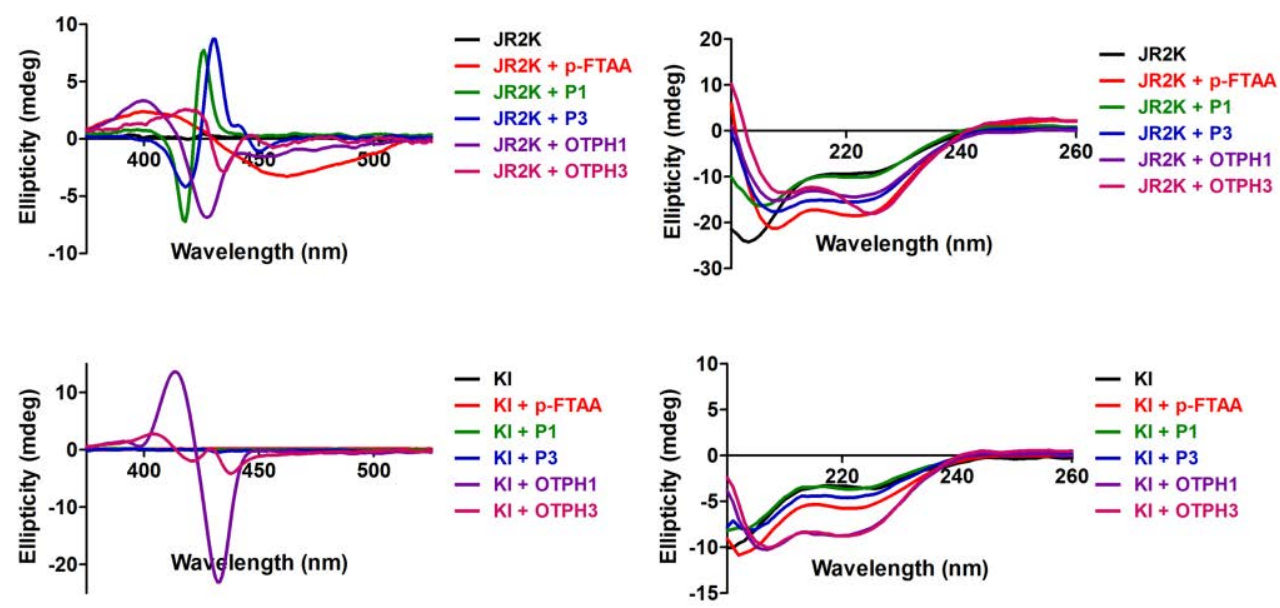

Figure 34. CD spectra of JR2K (upper panel) and KI (lower panel) alone and mixed with the ligands.

That CD signals for the ligands split around the expected absorption bands has been explained by electronic coupling of two or more chirally oriented chromophores, in our case either two ligands or a ligand and the peptide. The situation is known as exciton couplet and results from close proximity and appropriate orientation of the chiral chromophores so that their transition dipole moments can interact. ${ }^{139,144}$

Nezu et al. observed ICD of meso-tetrakis(p-sulfonatophenyl)porphyrin (TPPS) upon binding to random coil poly(L-lysine). ICD signal changed when the peptide adopted $\alpha$ helical structure at higher $\mathrm{pH}$. TPPS did not, however, initiate the folding process but could be used as an indicator for the conformational transformations of the peptide. ${ }^{143}$ TPPS inducing $\alpha$-helicity into a short peptide has been previously observed in another case, but this time the induced chirality of the porphyrin was minimal. ${ }^{145}$ In another study by Pasternack et al. helical biomolecules, e.g. ss and ds DNA, and a polypeptide, were used as templates for self-assembly of a set of metalloporphyrins, which induced 
intense CD signals for the surface-aggregated porphyrins. ${ }^{146}$ No structural alterations were observed for the polybiomolecules. With the OTPH-peptide hybrids we demonstrate spontaneous structural arrangements of two randomly organized components into well-defined three-dimensional architectures, where both the peptide and the guest molecules adopt their specific conformation, giving rise to distinct chiroptical properties. The necessity of the presence of the peptide as well as the OTPH for these transformations to happen is a convenient way to control the appearance of the structural and the optical qualities of possible functional materials composed of such hybrid molecules.

The structure of the self-assembled hybrid material between the peptides and the optoelectronic elements in our study was further investigated using dynamic light scattering (DLS) measurements (Figure 35). The analysis of the light scattering intensities and the correlation functions revealed that, individually, only P1 formed larger aggregates. For P3 and OTPH3, regrettably, no signals could be obtained which was explained with the most probable interference of the He-Ne laser $(632.8 \mathrm{~nm})$ by the absorption from these molecules. DLS of the samples of KI combined with pFTAA, P1 and OTPH1 did not indicate any aggregate formation either, while the combination with P3 and OTPH3 could not be assessed due to the absence of signals. For the hybridization with JR2K, only OTPH1 and OTPH3 of the considered molecules showed formation of larger assemblies, as indicated by very high scattering intensities. Interestingly, no signal suppression was evident for OTPH3 when combined with JR2K, which suggests an altered photophysical characteristics of the probe when present in the hybrid material.

The assemblies were visualized by scanning electron microscopy, revealing that JR2KOTPH1 produced spherical-like particles of approximately $100 \mathrm{~nm}$, whereas JR2KOTPH3 resulted in amorphous structures of about $200 \mathrm{~nm}$. 

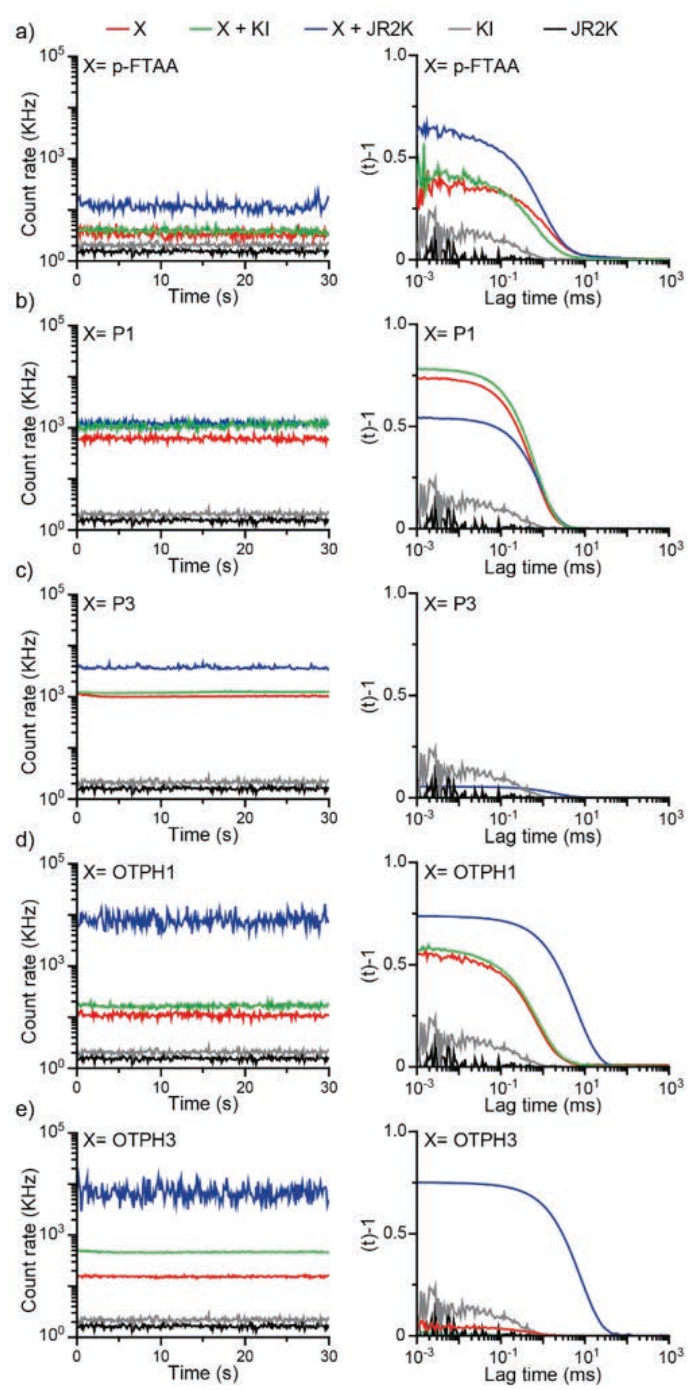

Figure 35. Scattering intensities (left panel) and resulting correlation functions (right panel) recorded by dynamic light scattering measurements of $30 \mu \mathrm{M}$ peptide (JR2 $\mathrm{K}$ in black and $\mathrm{KI}$ in gray), $30 \mu \mathrm{M}$ optoelectronic molecule (red) and the mixtures of peptide/optoelectronic molecule ( $\mathrm{KI}$ in green and JR2K in blue) in phosphate buffer (20 mM, pH 7.4). a) p-FTAA, b) P1, c) P3, d) OTPH1 and e) OTPH3. 


\section{Design and synthesis of fluoroglycosylated porphyrins}

\section{(Paper IV)}

In Paper IV we shifted our focus from proteinaceous targets to cell systems, and with that the question at issue became cancerous diseases rather than neurodegenerative disorders. Considering the well-established background of photodynamic therapy (PDT) towards cancer and porphyrins as highly potent photosensitizers, as described in greater detail in Chapter 1.3. Photodynamic therapy, our aim in this study was to design and synthesize porphyrin-based glycoconjugates that could be used as theranostic agents in malign diseases.

Our rationale behind the design of the target compounds strives to embrace as many of the criteria for an optimal therapeutic photosensitizer as possible, as well as providing the means for possible diagnosis. Porphyrins, having the inherent property of generating toxic oxygen radicals upon irradiation, were chosen consequently as the central structure of our photosensitizers. Furthermore, porphyrins make feasible fluorescent probes as they exhibit near infrared emission, thus enabling microscopy studies on subcellular and cellular level.

Despite the earlier observed general tendency of porphyrinoids to preferentially accumulate in cancer tissue ${ }^{12}$, an often-occurring shortcoming of the existing photosensitizers is their poor selectivity for cancer cells over healthy cells. This could potentially lead to poorer therapy and heavier side-effects. These shortcomings could be tackled by considering the concept of targeted drug delivery, an approach pharmacology and medicinal chemistry often turn to. There are various methods that aim for selective delivery and uptake of photosensitizers into cancer cells, as described in Chapter 1.3.3. Targeting strategies, and we decided to adopt the strategy of glycosylation of porphyrins. For fast and high-yielding glycosylation reactions on the porphyrin scaffold, click reaction was singled out as the optimal coupling reaction type. Three common monosaccharides, glucose, galactose and $N$-acetyl glucosamine, were chosen to be conjugated at three sites on a porphyrin scaffold (Figure 36A). The possibility of varying the nature of the attached monosaccharides could potentially aid the optimization of photosensitizer for a given target.

Finally, a fourth carbohydrate, 2-fluoro-2-deoxy-D-glucose (FDG), was chosen to occupy the fourth site on the tetrapyrrolic scaffold (Figure 36A). FDG, being a glucose analogue, is taken up to cells via GLUT transporters in the same manner as glucose, whereas its metabolism in the cells is haltered due to the absence of the hydroxyl group at C-2. FDG is therefore trapped inside the cytoplasm for considerably longer period of time as compared to normal glucose. ${ }^{59}$ Furthermore, by substituting the named hydroxyl 

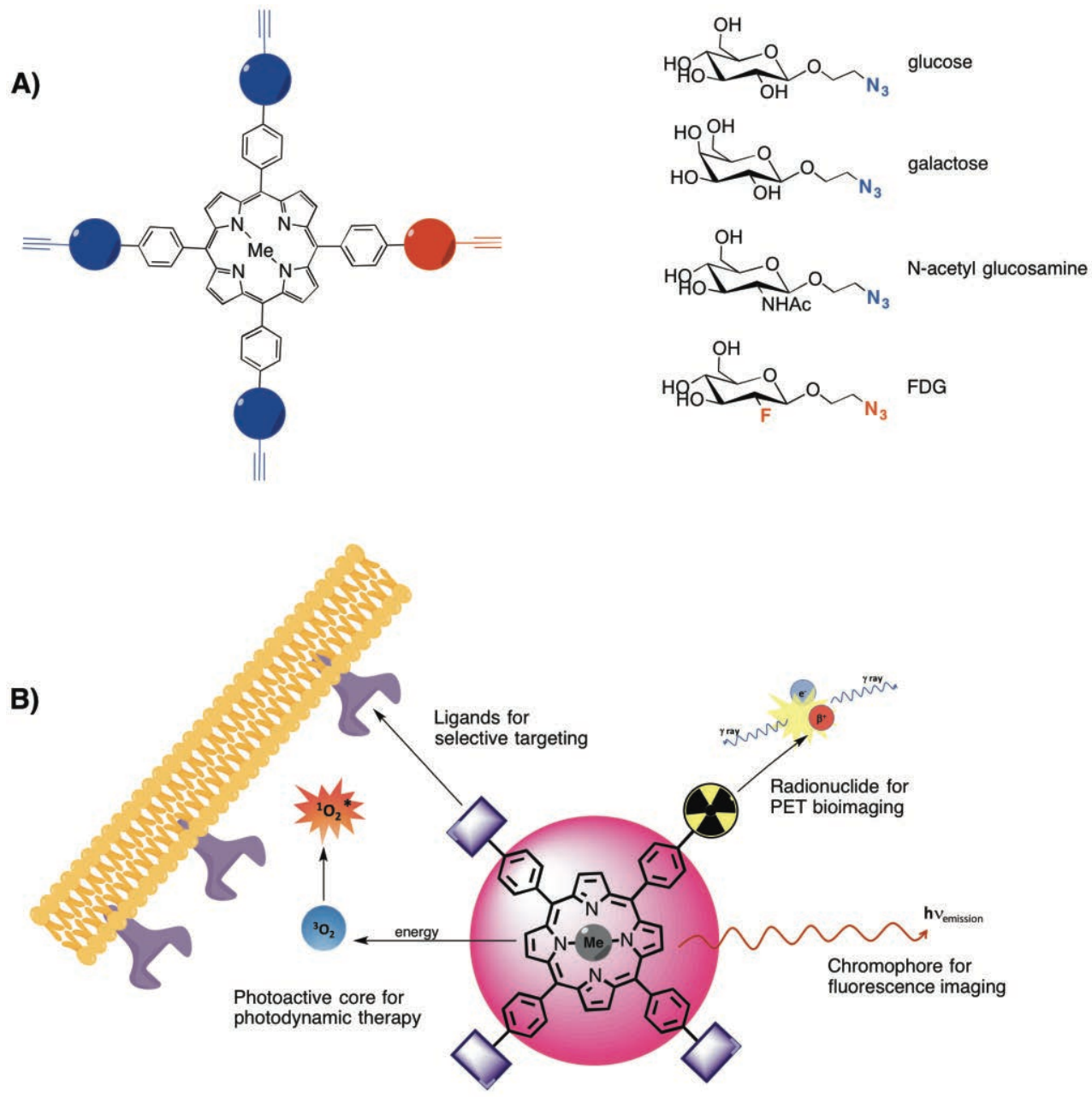

Multimodal theranostics

Figure 36. Schematic drawing showing A) the molecular design of fluoroglycosyated porphyrins and B) the desirable properties of a porphyrin based multimodal theranostic agent. Adapted from Arja et al. ChemistryOpen 2018;7;495-503, with permission. ${ }^{148}$

group at C-2 with the radioactive fluorine-18 instead of fluorine-19, a potential PET tracer is obtained with the possibility for diagnosis on the organ to the full-body scale.

Recently, an improved fluoroglycosylation method was reported relying on $\beta$ configured FDGs equipped with either azide- or alkyne aglycons that readily underwent the CuAAC click reaction to click-functionalized amino acids in high yields. ${ }^{147}$ Due to the general scope of the CuAAC reaction, we foresaw that the developed method would be applicable for the synthesis of fluoroglycosylated glycoporphyrins, thus potentially induce metabolic trapping in the targeted malignant cells. A multimodal compound featuring moieties for targeting (carbohydrates), photodynamic therapy (porphyrin) and 
possible diagnostics $\left({ }^{18} \mathrm{FDG}\right)$ would render a single agent to carry through diagnoses and therapy as illustrated in Figure 36B.

\subsection{Synthesis of porphyrin scaffold}

As depicted in Figure 36, the porphyrin in question must feature orthogonally reactive groups in order to sequentially functionalize it with azido groups for click conjugation to two different types of sugars, one type at a time. Synthesis of asymmetrical porphyrins with appropriate substitution pattern is, as discussed earlier in Chapter 1.2. Porphyrin synthesis, a complicated task requiring time- and purification-demanding multi-step synthesis via di- or tri-pyrrolic intermediates that eventually form the desired porphyrin in low-yielding condensation reactions. ${ }^{22}$ This approach could not possibly be feasible in our study. Instead, a cheap and easily accessible starting porphyrin was desired owing to the fact that the porphyrin scaffold still needed to undergo multistep syntheses to render the target compounds.

Similarly to the synthesis of the porphyrin moiety in OTPH4, we started off with methyl mono-(p-carboxy)tetraphenylporphyrin (Me-pcTPP) 20 (Scheme 7). The reaction details are described in Chapter 3.4. Synthesis of porphyrins.

In Scheme 12 below, the synthesis of a shelf-stable orthogonally bifunctionalized porphyrin scaffold 32 is shown, which derives from Me-pcTPP 20. We now again applied chlorosulfonation of porphyrin $\mathbf{2 0}$ in neat chlorosulfonic acid at the remaining three vacant phenylic para-positions to yield porphyrin 29. After some simple purification with water extraction, 29 could be reacted with propargyl amine at the sulfonyl chloride groups to give trisalkynylated porphyrin 30. In preparation to $\mathrm{Cu}(\mathrm{I})-$ catalyzed click reaction at the alkyne side chains, $\mathbf{3 0}$ was metallated with zinc(II) using the excess of ten mole equivalents of $\mathrm{Zn}(\mathrm{OAc})_{2} * 2 \mathrm{H}_{2} \mathrm{O}$ in a solution of DCM and methanol at room temperature. The yield of zinc(II)-coordinated 31 was $40 \%$, calculated from 20. The insertion of zinc(II) protects the porphyrin cavity from metalating copper that catalyzes the upcoming cycloaddition reaction. Not only would it consume the catalyst, but demetallation of copper from a porphyrin can only be achieved under harsh conditions, not tolerated by the substituents on our porphyrin conjugates. Copper porphyrin complexes, however, are not suitable for our purposes as theranostics since both porphyrin fluorescence and the ability to generate singlet oxygen are greatly suppressed by the presence of the paramagnetic copper. Zinc(II), however, allows the fluorescence and the PDT effect. Moreover, according to a study by Pashkovskaya et. al, metalation of porphyrins with zinc(II) may mediate the cellular uptake of the compounds via zinc(II) coordination to phosphate groups of phospholipids in the cell membrane. ${ }^{149}$

Deprotection of the methyl ester of zinc(II)-porphyrin $\mathbf{3 1}$ was done via the Krapcho demethylation using $\mathrm{LiCl}$ in DMF under microwave irradiation ${ }^{118,119}$. The reaction was 
neat, furnishing the free acid porphyrin $\mathbf{3 2}$ in $77 \%$ yield after purification with flash column chromatography. This alternative ester deprotection was chosen over basic aqueous hydrolysis in order to avoid any effects on the sulfonamide bonds.

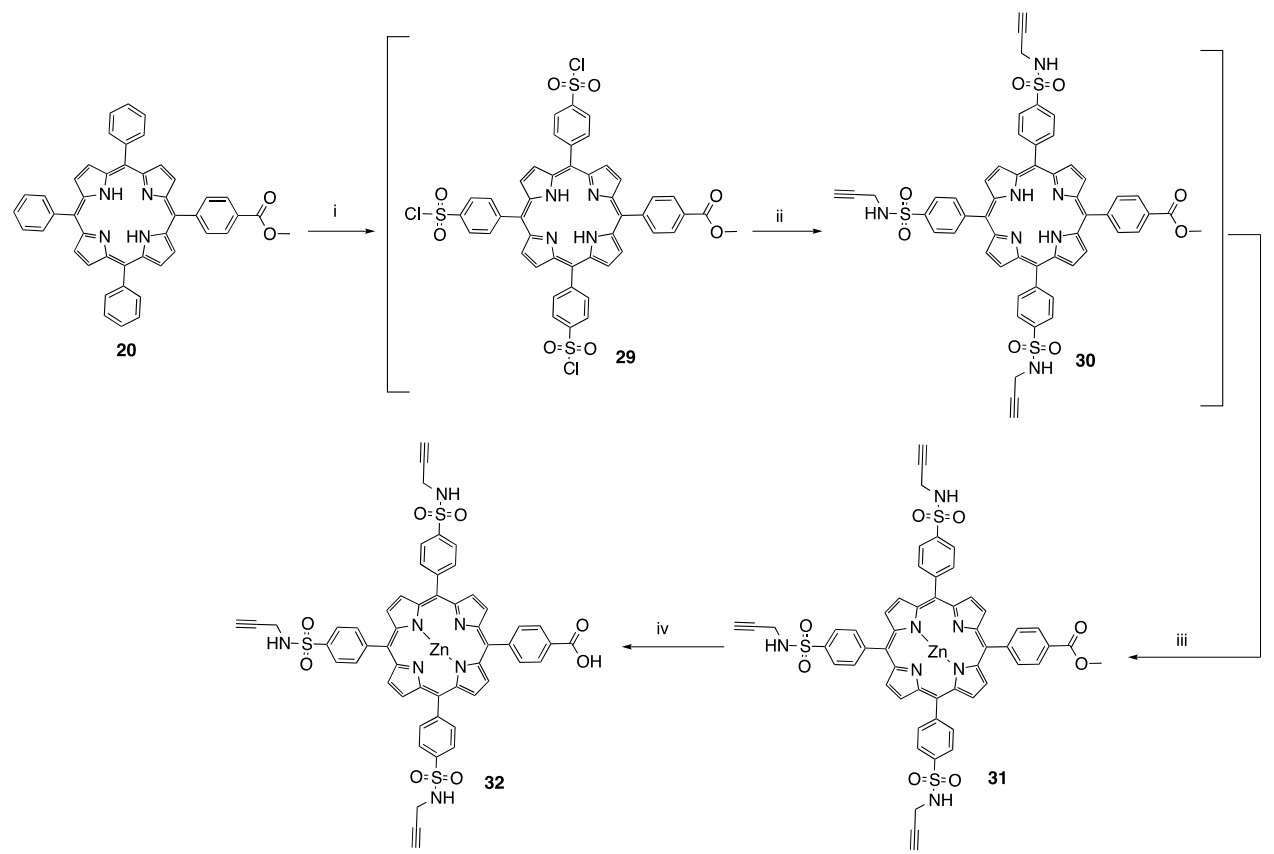

Scheme 12. General conditions and reagents: i) $\mathrm{HSO}_{3} \mathrm{Cl}$, r.t.; ii) propargylamine, DIPEA, DCM, r.t.; iii) $\mathrm{Zn}(\mathrm{OAc})_{2}{ }^{*} 2 \mathrm{H}_{2} \mathrm{O}, \mathrm{DCM}, \mathrm{MeOH}$, r.t., $40 \%$ over 3 steps; iv) LiCl, DMF, MW, $160{ }^{\circ} \mathrm{C}, 77 \%$. Adapted from Arja et al. ChemistryOpen 2018;7;495-503, with permission. 148

\subsection{Synthesis of azidosugars}

The monosaccharides that were to be conjugated to porphyrin scaffold $\mathbf{3 2}$ feature an azidoethyl linker and are depicted in Figure 37. The non-fluorinated azidosugars were synthesized according to known synthetic procedures. 2-azidoethyl $\beta$-D-glycosides $\mathbf{3 3}$ and 34 were synthesized according to the literature procedure by Chernyak et al. ${ }^{150}$ starting from per-acetylated D-glucose and D-galactose, respectively. The azideequipped $N$-acetyl glucosamine 35 was synthesized starting from per-acetylated Dglucosamine via its corresponding oxazoline. The detailed synthetic scheme for the syntheses can be found in the Appendix. 

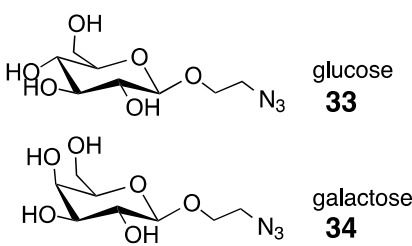
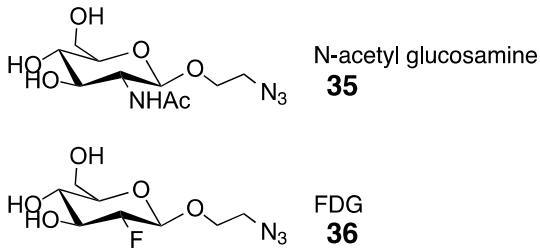

Figure 37. Azide functionalized monosaccharides that were conjugated to the porphyrin scaffold.

The synthesis of azide functionalized $\beta$-configured FDG $\mathbf{3 6}$ has recently been published by Elgland et. $\mathrm{al}^{147}$ and features in situ produced DMDO epoxidation of glucal 37 to the corresponding 1,2-anhydrosugar $\mathbf{3 8}$ that acts as a glucosyl donor to 2-chloroethanol (Scheme 13). The chloride substitution for an azide on the linker of $\mathbf{3 9}$ was achieved using the Finkelstein reaction via NaI, which rendered $\mathbf{4 0}$ in $77 \%$ yield. Inversion of the hydroxyl on C-2 was accomplished by the Lattrell-Dax reaction employing the sequence of triflation, nitrite substitution and hydrolysis. $\beta$-D-mannoside $\mathbf{4 1}$ could then be fluorinated with DAST to give FDG 36, ready to be conjugated to the porphyrin. Alternatively, $\mathbf{4 1}$ can be triflated to $\mathbf{4 2}$ for production of [18F]-radiolabelled FDG for the future use in the PET-active glycoporphyrin conjugates. For all the azido functionalized carbohydrates it is essential to separate the azide from C-1 with a linker instead of installing the azide directly to the anomeric positions. It has been previously observed that the close proximity of triazoles resulting from C-1 azides prevents the conjugated glycosides from being recognized as substrates for GLUT transporters. ${ }^{151}$ This would interfere with any possible active ligand-specific transport over the cell membrane and would jeopardize our goals with cancer cell selective theranostics.

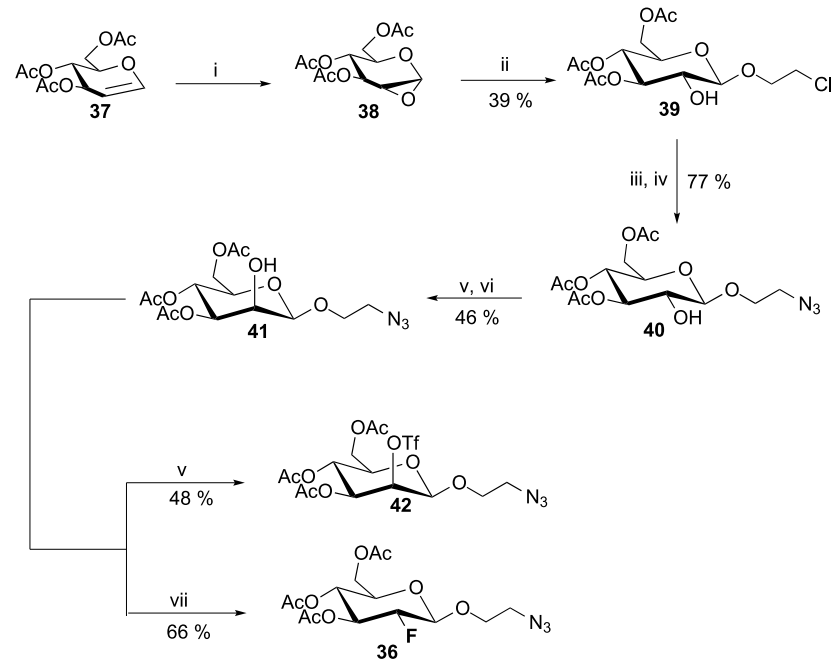

Scheme 13. General conditions and reagents: i) oxone, acetone, $\mathrm{TBAHSO}_{4}, \mathrm{DCM}$, satd. aq. $\mathrm{NaHCO}_{3}, \mathrm{O}^{\circ} \mathrm{C}$ to r.t. ii) $\mathrm{Cl}\left(\mathrm{CH}_{2}\right)_{2} \mathrm{OH}, \mathrm{ZnCl}$, $\mathrm{DCM}, 0{ }^{\circ} \mathrm{C}$ to r.t. iii) $\mathrm{Nal}$, acetone, $70{ }^{\circ} \mathrm{C}$; iv) $\mathrm{NaN}_{3}$, DMF, r.t. v) $\mathrm{Tf}_{2} \mathrm{O}$, py, $\mathrm{DCM}$, -15 to $10^{\circ} \mathrm{C}$; vi) $\mathrm{TBANO}_{2}$, toluene, $50^{\circ}$; . vii) DAST, diglyme, $100^{\circ} \mathrm{C}$. 


\subsection{Glycosylation of porphyrin}

Tris-alkynylated porphyrin $\mathbf{3 2}$ was reacted with non-fluorinated azidosugars 33, 34 and 35 using Sharpless' copper(I)-catalyzed modification of the Huisgen 1,3cycloaddition $^{120}$ (Scheme 14). The reactions were conducted under microwave activation according to the protocol adopted from Maillard and co. ${ }^{121}$ to yield triglycosylated porphyrins $\mathbf{4 3}, \mathbf{4 4}$ and $\mathbf{4 5}$, respectively. The microwave protocol used was mild and highly efficient, requiring only 5 minutes of reaction time at $85{ }^{\circ} \mathrm{C}$ in sealed vials. The employed catalytic system comprised 0.15 equivalents of aqueous $\mathrm{CuSO}_{4}$ and 0.3 equivalents of aqueous sodium L-(+)-ascorbate per alkyne group on the porphyrin in the solution of THF/water/tert-butanol. According to LC-MS analyses on the crude reaction mixtures, complete conversion of the porphyrin starting material into triglycosylated product was achieved for the all three reactions. Isolated yields varied in the range of 59 to $89 \%$. The NMR analysis with MS-data confirmed the identity of the triglycosylated porphyrins, where the triazole protons give rise to a characteristic singlet at around $8 \mathrm{ppm}$ in the ${ }^{1} \mathrm{H}-\mathrm{NMR}$ spectra (Figure 38). 


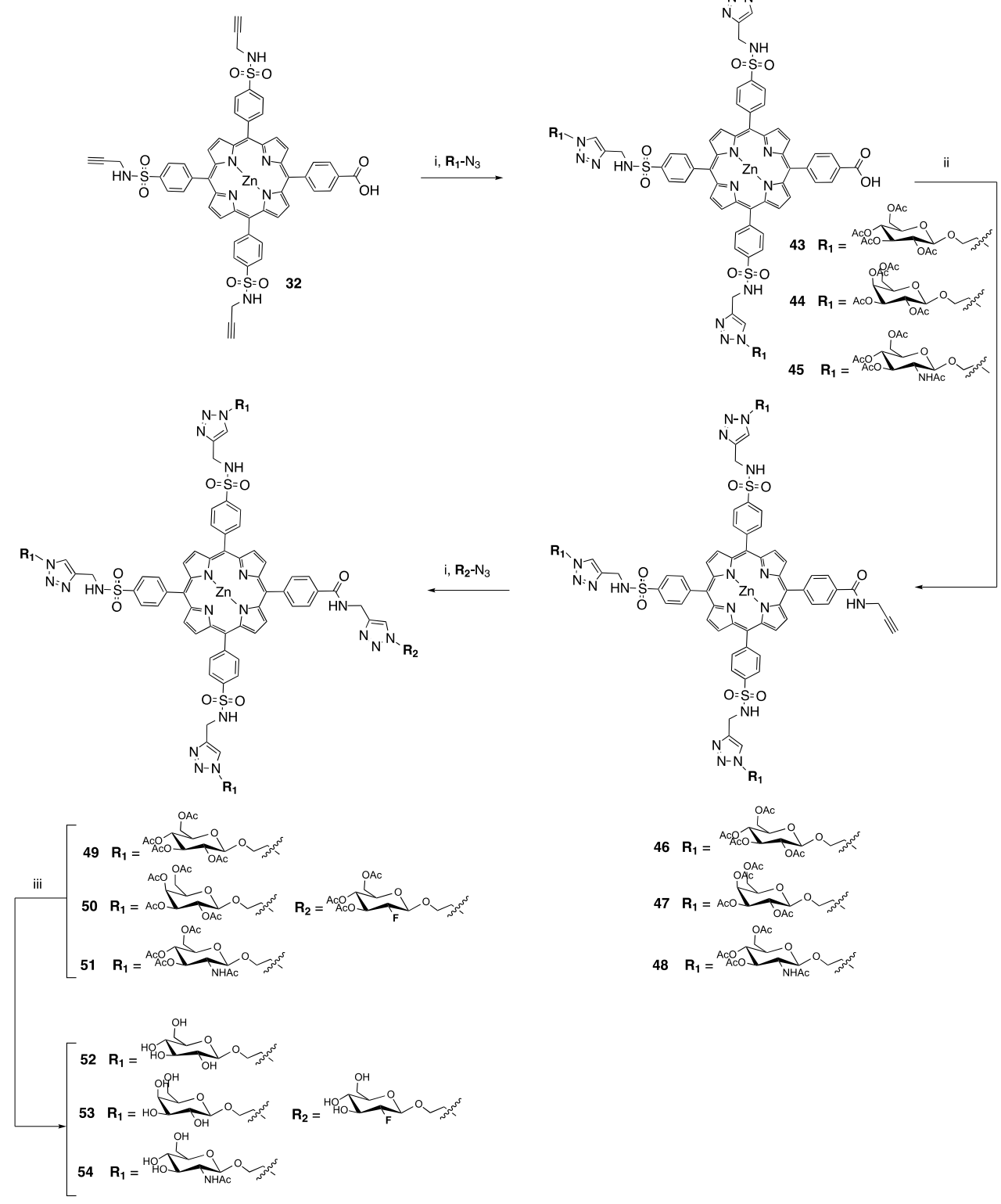

Scheme 14. General conditions and reagents: i) $\mathrm{CuSO}_{4}$, sodium $\mathrm{L}(+)$-ascorbate, $\mathrm{THF}, \mathrm{t}-\mathrm{BuOH}, \mathrm{H}_{2} \mathrm{O}, \mathrm{MW}$, $85{ }^{\circ} \mathrm{C}, 59$ \% (43), $89 \%$ (44), 84 \% (45), 62 \% (49), 55 \% (50), 78 \% (51); ii) 1. NHS, EDC, DMF, r.t.; 2. propargylamine, DIPEA, r.t., 85 \% (46), 61 \% (47), 52 \% (48); iii) $\mathrm{NaOH}, \mathrm{MeOH}, \mathrm{H}_{2}$ O, r.t., $99 \%$ (52), $80 \%$ (53), quant. (54). Adapted from Arja et al. ChemistryOpen 2018;7;495-503, with permission. ${ }^{148}$ 


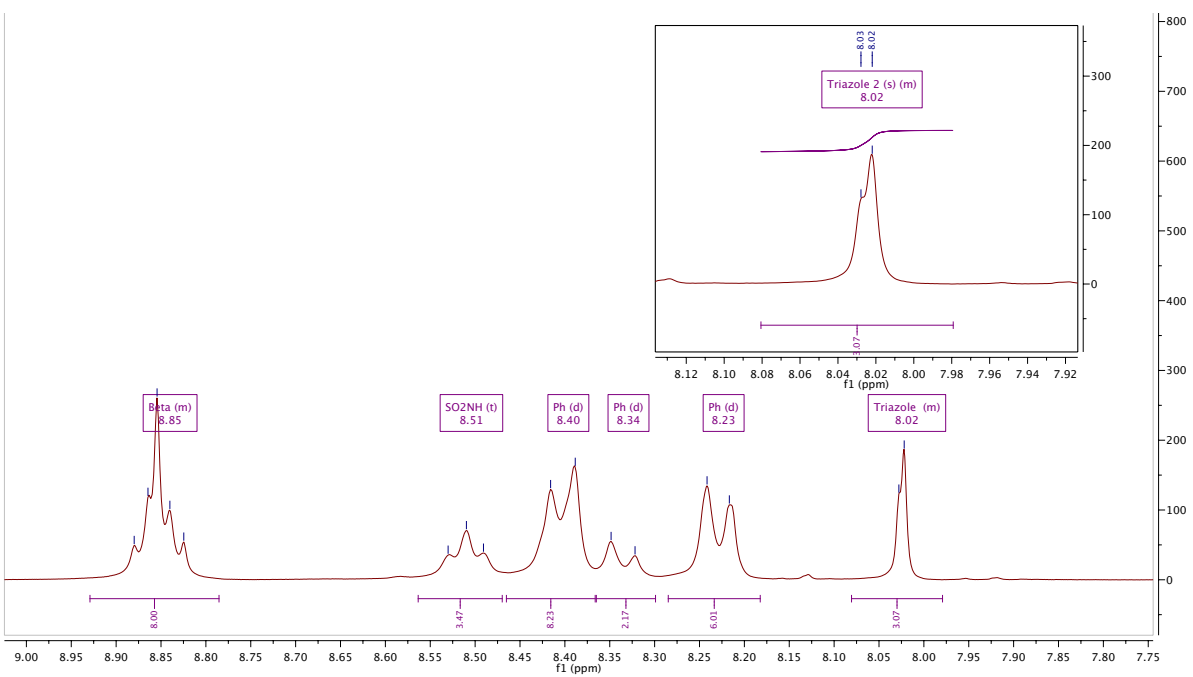

Figure 38. Triazole protons in triglycosylated porphyrins give rise to characteristic singlets in the aromatic area at around $8 \mathrm{ppm}$ as illustrated here with galactose conjugate 44 .

The simplicity and effectiveness of the microwave-assisted click-reaction made it the method of choice for the final, fluoro-glycosylation of the conjugates. Furthermore, the short reaction times and high yields make it compatible with radiochemistry, ensuring functioning radiolabeling with [18F]-FDG for our future studies. The microwaveassisted click reaction can be carried out using equimolar ratios of the starting compounds, which spares the limited amount of both the triglycosylated porphyrins and $\beta$-configured azido-FDG. Consequently, the free acid at 43, 44, and 45 underwent EDCNHS-facilitated amide coupling reactions to propargyl amine giving corresponding alkynes 46, 47 and 48 (Scheme 14).

The procedure for click-conjugation of FDG 36 to porphyrins 46,47 and 48 used the same conditions as described above, with the slight difference of prolonged reaction times, due to the reduced reactivity of the fluorine substituted glycosyl azide as compared to its non-fluorinated counterparts. The completion of fluoro-glycosylation could be confirmed with LC-MS analysis, as well as with NMR-data, with ${ }^{1} \mathrm{H}-\mathrm{NMR}$ indicating now a fourth triazole proton at around $8 \mathrm{ppm}$ and ${ }^{19} \mathrm{~F}$-NMR giving rise to a characteristic doublet of doublet of doublets at $-199 \mathrm{ppm}$. Fully glycosylated compounds were subsequently deacetylated yielding target molecules 52, 53 and 54 , respectively. 


\section{Evaluation of fluoroglycosylated porphyrins as potential theranostic agents}

\section{(Paper IV)}

After successfully synthesizing fluoroglycosylated porphyrins 52, 53 and 54, we proceeded to evaluate these conjugates for the properties as potential theranostic agents.

The fluoroglycosylated porphyrins were thereby characterized for their optical and photophysical properties as to evaluate their potential as fluorescent probes and photosensitizers. The absorption spectra of the compounds were recorded and studied in PBS buffer, displaying the porphyrin-characteristic absorption maxima of the Soret band at $430 \mathrm{~nm}$ and the two lower Q-bands at 565 and $605 \mathrm{~nm}$, confirming the metal complexation of the porphin ring. Excitation at either 430 or $565 \mathrm{~nm}$ gives rise to two distinct emission maxima at 615 and at $665 \mathrm{~nm}$.

To evaluate the required characteristics of a photosensitizer in our fluoroglycosylated porphyrins, such as the capability to form excited triplet state and the singlet oxygen generation, the proto-form 55 of glucosylated FDG-porphyrin conjugate (Figure 39A) was produced by demetallation of porphyrin 49, using TFA in DCM (1:4 v/v), followed by deacetylation. 55 was subjected to the UV-excitation at $355 \mathrm{~nm}$ in an oxygen-free THF solution. The triplet excited state absorption spectrum displayed a strong positive phase at around 450 and a weaker positive phase at around $325 \mathrm{~nm}$, confirming the effective intersystem crossing of the fluoroglycosylated porphyrin (Figure 39B). The capability of $\mathbf{5 5}$ to form cytotoxic singlet oxygen from molecular oxygen in its triplet state was verified by exciting the porphyrin at $440 \mathrm{~nm}$ in an oxygen rich THF solution and measuring the transient luminescence of singlet oxygen at $1270 \mathrm{~nm}$. Figure 39C represents the transient luminescence decay of the singlet oxygen generated by $\mathbf{5 5}$ confirming its potential as a photosensitizer in photodynamic therapy. 


\section{A)}

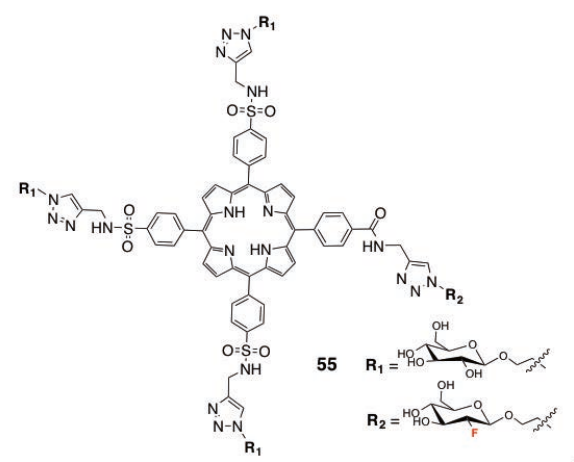

B)

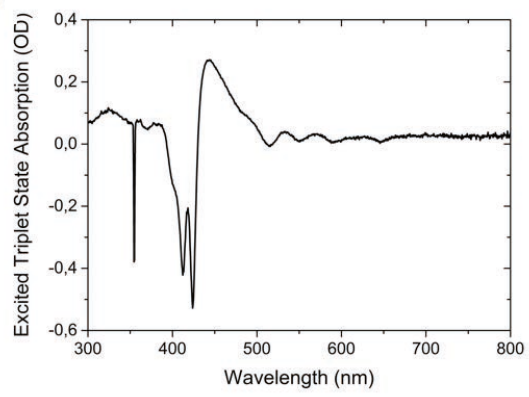

C)

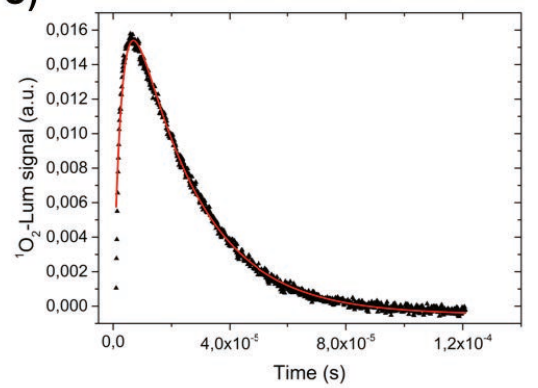

Figure 39. A) Chemical structure of the proto-form of glycosylated porphyrin-FDG conjugate 55 used in the photo-oxidation studies. B) Excited triplet state absorption spectrum of 55 (excitation at $355 \mathrm{~nm}$ ). C) Transient luminescence at $1270 \mathrm{~nm}$ of singlet oxygen produced by 55 (excitation at $440 \mathrm{~nm}$ ). Adapted from Arja et al. ChemistryOpen 2018;7;495-503, with permission. ${ }^{148}$

With the fluoroglycosylated porphyrin exhibiting appropriate photophysical characteristics, we proceeded to evaluate their behavior in biological systems. Compounds 52, $\mathbf{5 3}$ and $\mathbf{5 4}$ were consequently subjected to in vitro tests in cell culture models for cellular uptake and for toxicity, both in a healthy fibroblast cell line and a cancerous melanoma cell line. To evaluate the importance of the glycosylation of the porphyrins to cellular uptake, a non-glycosylated porphyrin, tetra-(4sulfonatophenyl)porphyrin 57, was used as the reference compound (Figure 40). Furthermore, to reveal any effects from the FDG moiety on the interaction of the probe with cells, a reference porphyrin with four glucose units, thus lacking the FDG, compound 56, was included in the study. 


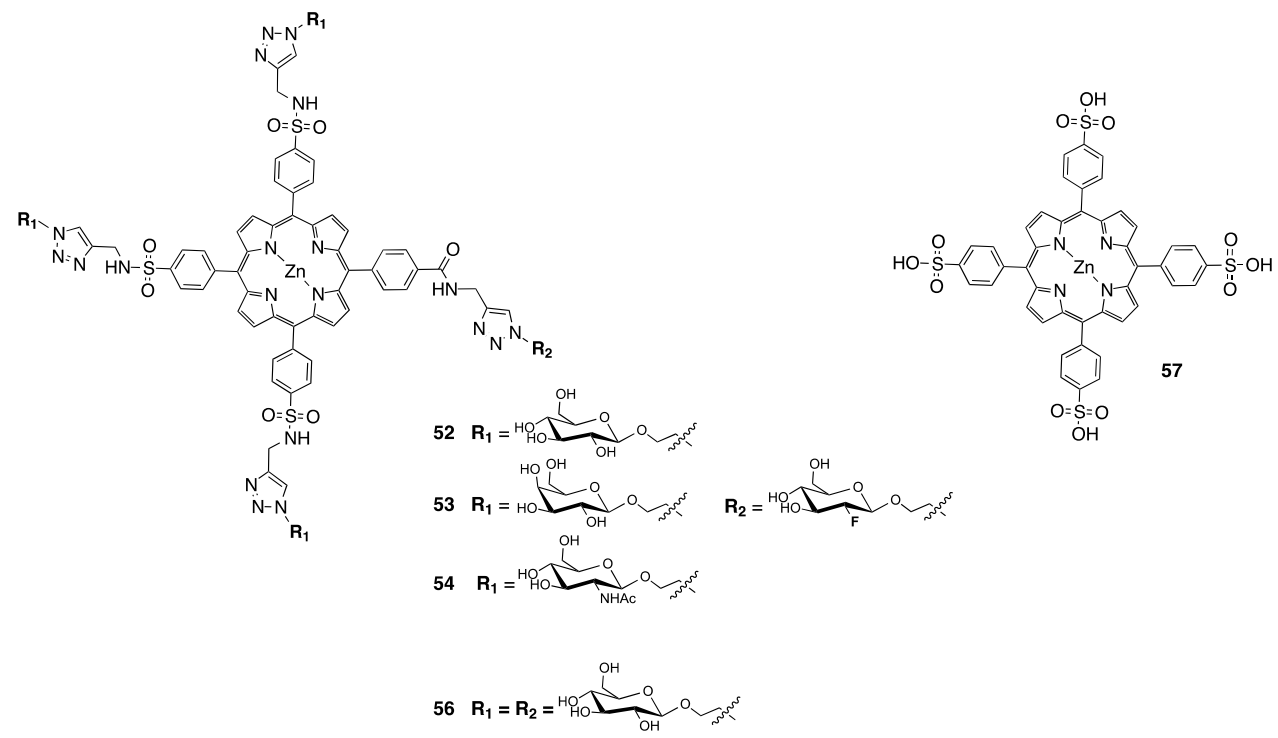

Figure 40. Chemical structures of fluoroglycosylated porphyrin $\mathbf{5 2 , 5 3}$ and $\mathbf{5 4}$, as well as reference compound $\mathbf{5 6}$ lacking FDG and $\mathbf{5 7}$ that is void of any carbohydrates. Adapted from Arja et al. ChemistryOpen 2018;7;495-503, with permission. ${ }^{148}$

The two chosen cell culture models were incubated with $20 \mu \mathrm{M}$ of fluoroglycosylated porphyrin or with a reference compound, depicted in Figure 40, in the complete cell culture medium for 24 hours. After fixation, the cell samples were studied under fluorescence microscopy. As evident in Figure 41, there are drastic differences in staining pattern between the porphyrin variants, as well as between the two cell lines. Interestingly, non-glycosylated porphyrin $\mathbf{5 7}$ lacks staining in the melanoma cells while the fibroblasts stained with $\mathbf{5 7}$ exhibit the distinct porphyrin fluorescence. Conversely, all the glycosylated porphyrins visually show more intense staining in the melanoma cells than in the fibroblasts. The finding strongly suggests that glycosylation is necessary for achieving higher accumulation of a porphyrin in cancer cells and to diminish it in healthy cells. The correlation may be explained with the altered nutrient metabolism in melanoma cells where carbohydrates are harvested to a significantly higher extent and rate as compared to healthy cells. 

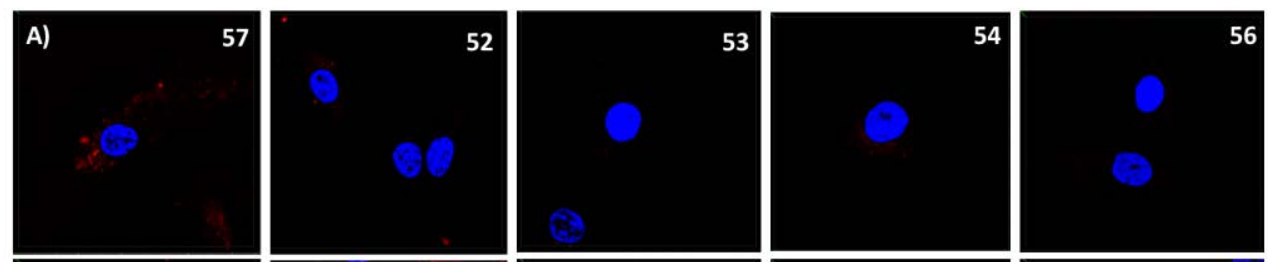

B)
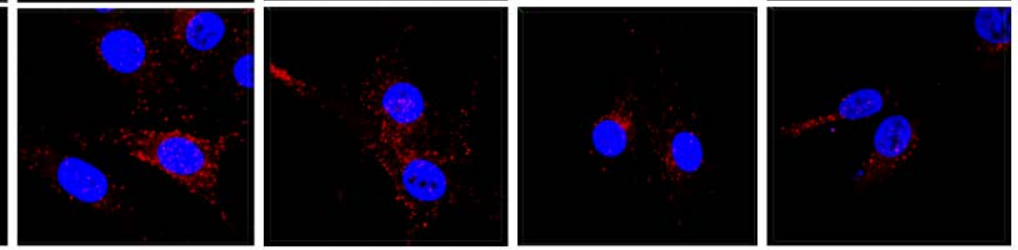

Figure 41. Confocal microscopy 3D images of A) fibroblasts and B) melanoma cells stained with porphyrins (red) and DAPI (nuclei staining; seen in blue). The cells were incubated with the porphyrin variants $(20 \mu \mathrm{M}, 24 \mathrm{~h})$ and thereafter fixated. Images were collected in z-stack spectral mode (excitation at 405 and $561 \mathrm{~nm}$ ) with the dimensions $\mathrm{x}=135 \mu \mathrm{m}, \mathrm{y}=135 \mu \mathrm{m}$ and $\mathrm{z}=20 \mu \mathrm{m}$. Scale bar $20 \mu \mathrm{m}$. Adapted from Arja et al. ChemistryOpen 2018;7;495-503, with permission. ${ }^{148}$

Furthermore, among the glycosylated porphyrins the most intense staining in the melanoma cells was achieved with glucosylated porphyrin-FDG conjugate $\mathbf{5 2}$ and with galactosylated porphyrin-FDG conjugate 53. The same trend was confirmed quantitively with flow cytometry experiments for which the results are shown in Figure 42. In the flow cytometry experiment with fluorescence-activated cell sorting (FACS), incubation completed cells are suspended in a liquid medium and passed through a detector one cell at a time. The detector counts the fluorescent cells according to the chosen threshold of a chosen wavelength, providing thus an exact numeric measure for quantification. Figure $\mathbf{4 2}$ shows clearly that sulfonated porphyrin $\mathbf{5 7}$ is the only porphyrin variant in this study that has a significantly higher uptake into fibroblasts than in melanoma cells. Porphyrins $\mathbf{5 2}$ and 53, featuring glucose and galactose, respectively, as well as the FDG moiety, display a superior cellular accumulation in melanoma cells, while $\mathrm{N}$-acetyl glucosaminosyl porphyrin $\mathbf{5 4}$ shows no significant difference in cellular uptake between melanoma cells and fibroblasts. A fascinating insight can be gained from the comparison of compound $\mathbf{5 2}$ with $\mathbf{5 6}$, where the only structural difference is the substitution of FDG for glucose. Porphyrin 56, lacking the FDG modality, displays a drastically decreased cellular enrichment in melanoma cells compared to 52. This finding could possibly be attributed to the metabolic trapping effect of the FDG moiety on $\mathbf{5 2}$ as described in greater details in Chapter 1.4.1 Carbohydrates in cancer and healthy cells. Nonetheless, further studies are required to elucidate the exact biological mechanism.

All the compounds used in the cell studies were also tested for their dark toxicity. In viability studies monitoring ATP production, none of the compounds induced any significant decrease in viability at $20 \mu \mathrm{M}$ concentrations, compared to the untreated control, after 24-hour incubation in either fibroblasts or melanoma cell. 


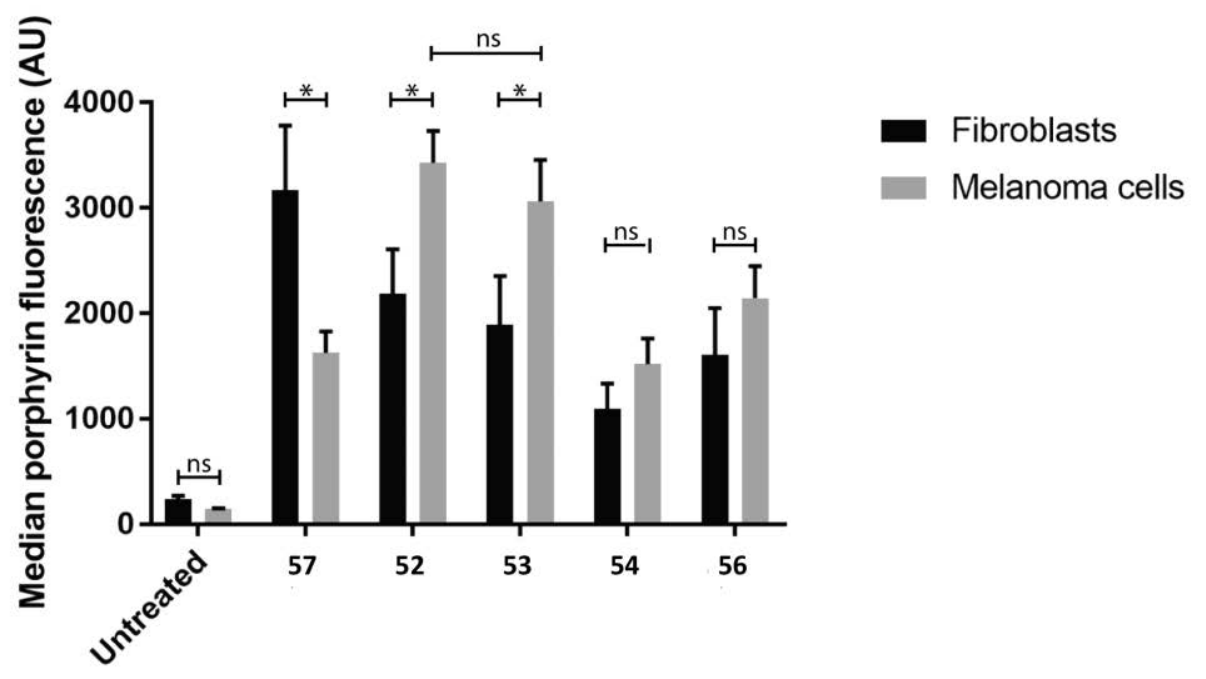

Figure 42. Flow cytometry analysis of cells exposed to porphyrin variants $(20 \mu \mathrm{M}, 24 \mathrm{~h})$ in complete cell culture medium. Diagram shows the combined results of four replicate measurements. Significant differences were determined by ANOVA and $p \leq 0.05$ are indicated with asterisks in the figure. Adapted from Arja et al. ChemistryOpen 2018;7;495-503, with permission. ${ }^{148}$ 


\section{Conclusions and Future Perspectives}

With this thesis we can conclude that we have successfully utilized some of porphyrins' many chemical, photophysical and biological properties to design porphyrin-based conjugates for a handful of attractive applications.

In Paper I, II and III, synthesis of oligothiophene porphyrin hybrid (OTPH) molecules is presented, with the weight on the convenient functionalization of the porphyrin core in order to easily produce a small set of OTPHs with structural variations. Two types of porphyrin condensation reactions were employed - the [2+2] condensation and the tetramerization from monopyrrole - to yield porphyrins with different aromatic structures. The key step in the derivatization process was chlorosulfonation that allowed for an easy and regioselective post-condensation functionalization of the porphyrin. The utilization of OTPHs as fluorescent amyloid ligands for enhanced assessment of aggregated protein deposits is demonstrated in Paper I and II. Their quality to detect and visualize the heterogenous nature of $A \beta$ plaque by spectral characterization and by FLIM is superior to the oligothiophene alone. In Paper III, OTPHs are studied as optoelectronic elements in non-covalent self-assembly of chiroptical biomaterials. When combined with OTPHs, two synthetic random coil peptides underwent specific structural rearrangements to adopt the $\alpha$-helical structure, whereas induced circular dichroism (ICD) was observed for the OTPHs. The observations witness of well-defined three-dimensional structures of the assembled material, as well as distinct induced chiroptical properties, which is of great interest for further studies with the aim of generating novel materials for a diversity of applications within organic bioelectronics.

Paper IV reports on the synthesis of glycosylated porphyrins to be utilized as theranostic agents. The function-guided molecular design yields glycoporphyrins featuring a common monosaccharide at three positions and 2-fluoro-2-deoxy-D-glucose (FDG) on the fourth site on a porphyrin scaffold. The conjugations were accomplished using $\mathrm{Cu}(\mathrm{I})$-catalyzed azide-alkyne [3+2] cycloaddition between the azidosugars and the alkyne-functionalized porphyrin, which gave us the means for fast and regiospecific late-stage glycosylation. The potential of the fluoroglycoporphyrins to function as theranostics was thereafter demonstrated by corroborating their fluorescent properties, as well as the ability to generate radical singlet oxygen needed for photodynamic therapy (PDT). Furthermore, the necessity for the presence of the common carbohydrates, and in particular that of FDG, for increased cellular accumulation of the conjugates into cancer cells, was demonstrated in the cell assays. With these encouraging results, PDT studies on the cell culture level are being planned for. Additionally, the carbohydratedependent selectivity for various cancer cell lines is another aspect for further investigations. 


\section{Appendix}

\section{Synthesis of non-fluorinated 2-azidoethyl $\beta$-D-glycosides}

The non-fluorinated azidosugars were synthesized according to known synthetic procedures (Scheme 15). 2-azidoethyl $\beta$-D-glycosides 33 and 34 were synthesized according to a literature procedure by Chernyak et al. ${ }^{150}$ starting from per-acetylated Dglucose 58 and D-galactose 59 respectively, that were subjected to a boron-trifluoride dietherate-promoted glycosylation to 2-chloroethanol followed by an azidation using $\mathrm{NaN}_{3}$ in DMF at $80^{\circ} \mathrm{C}$. The azide-equipped $\mathrm{N}$-acetyl glucosamine $\mathbf{3 5}$ was synthesized starting from per-acetylated D-glucosamine that was converted to its corresponding oxazoline 63 by the method described by Nakabayashi et al. ${ }^{152}$ followed by a PPTSpromoted glycosylation to 2-chloroethanol ${ }^{153}$, and finally, by azidation using $\mathrm{NaN}_{3}$ and $\mathrm{TBAB}$ in DMF at $80^{\circ} \mathrm{C}$.

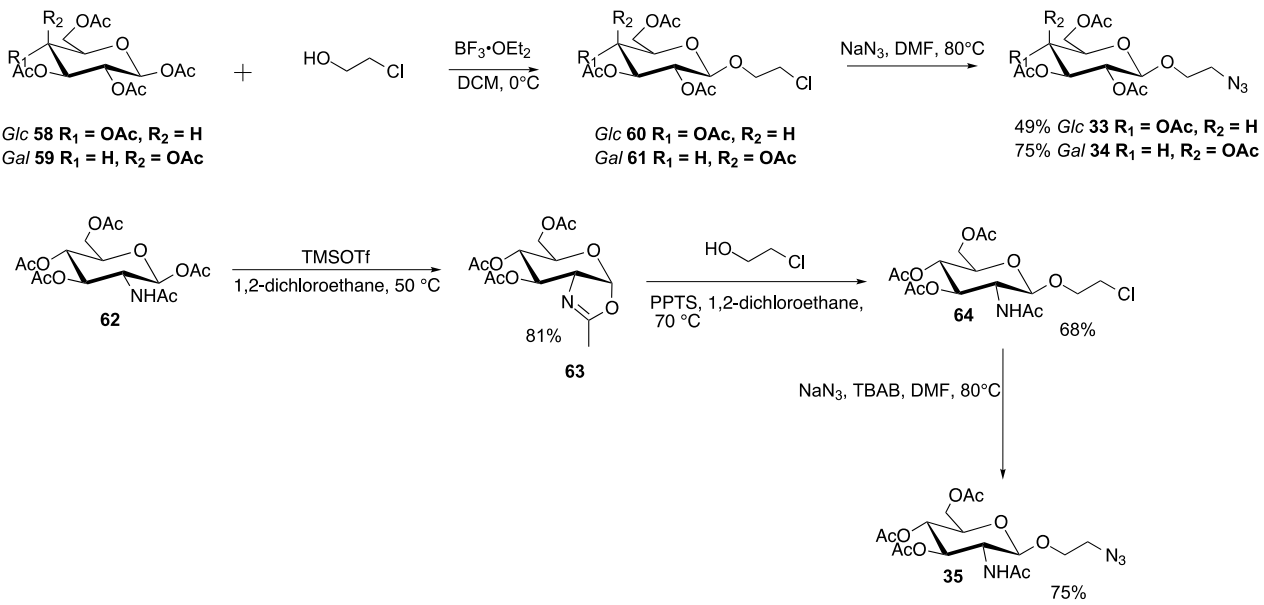

Scheme 15. Synthesis of non-fluorinated 2-azidoethyl $\beta$-D-glycosides 33, 34 and 35 . 


\section{References}

1. Hückel, E. Quanstentheoretische Beiträge zum Benzolproblem. Z. Physik 72, 310-337 (1931).

2. Schleyer, P. V. R. Introduction: Aromaticity. Chem. Rev. 101, 1115-1118 (2001).

3. Steiner, E. \& Fowler, P. W. Diamagnetic and paramagnetic ring currents in expanded porphyrins. Org. Biomol. Chem. 2, 34-37 (2004).

4. Fodor, M. A. et al. Photophysical and photochemical properties of manganese complexes with cationic porphyrin ligands: Effects of alkyl substituents and micellar environment. Journal of Photochemistry and Photobiology A:

Chemistry 328, 233-239 (2016).

5. Valicsek, Z. \& Horváth, O. Application of the electronic spectra of porphyrins for analytical purposes: The effects of metal ions and structural distortions. Microchemical Journal 107, 47-62 (2013).

6. Berg, J. M., Tymoczko, J. L. \& Stryer, L. Biochemistry. (W. H. Freeman and Company, 2007).

7. Song, R., Robert, A., Bernadou, J. \& Meunier, B. Sulfonated and acetamidosulfonylated tetraarylporphyrins as biomimetic oxidation catalysts under aqueous conditions. Inorganica Chimica Acta 272, 228-234 (1998).

8. Nestler, O. \& Severin, K. A Ruthenium Porphyrin Catalyst Immobilized in a Highly Cross-linked Polymer. Org. Lett. 3, 3907-3909 (2001).

9. Song, H., Liu, Q. \& Xie, Y. Porphyrin-sensitized solar cells: systematic molecular optimization, coadsorption and cosensitization. Chem. Commun. (Camb.) 54, 1811-1824 (2018).

10. Zamadar, M., Orr, C. \& Uherek, M. Water Soluble Cationic Porphyrin Sensor for Detection of $\mathrm{Hg}^{2+}, \mathrm{Pb}^{2+}, \mathrm{Cd}^{2+}$, and $\mathrm{Cu}$ 2. Journal of Sensors 2016, 1-8 (2016).

11. Diabate, P. D. et al. DNA structure-specific sensitization of a metalloporphyrin leads to an efficient in vitro quadruplex detection molecular tool. New Journal of Chemistry 40, 5683-5689 (2016).

12. Waghorn, P. A. Radiolabelled porphyrins in nuclear medicine. J. Label Compd. Radiopharm 57, 304-309 (2013).

13. Josefsen, L. B. \& Boyle, R. W. Unique Diagnostic and Therapeutic Roles of Porphyrins and Phthalocyanines in Photodynamic Therapy, Imaging and Theranostics. Theranostics 2, 916-966 (2012).

14. Schmidt, W. N. Heme and HO-1 inhibition of HCV, HBV, and HIV. 3, 1-13 (2012).

15. Fischer, H. \& Zeile, K. Synthese des Hämatoporphyrins, Protoporphyrins und Hämins. Justus Liebig's Annalen der Chemie 468, 98-116 (1929).

16. Rothemund, P. Formation of porphyrins from pyrrole and aldehydes. J. Am. Chem. Soc. 57, 2010-2011 (1935).

17. Adler, A. D. et al. A simplified synthesis for meso-tetraphenylporphine. $J$. Org. Chem. 32, 476-476 (1967).

18. Lindsey, J. S., Schreiman, I. C., Hsu, H. C., Kearney, P. C. \& Marguerettaz, A. M. Rothemund and Adler-Longo reactions revisited: synthesis of 
tetraphenylporphyrins under equilibrium conditions. J. Org. Chem. 52, $827-$ 836 (1987).

19. The Porphyrin Handbook. (Academic Press, Elsveier, 2000).

20. Lash, T. D. What's in a name? The MacDonald condensation. J. Porphyrins Phthalocyanines 20, 855-888 (2016).

21. Arsenault, G. P., Bullock, E. \& MacDonald, S. F. Pyrromethanes and Porphyrins Therefrom 1. J. Am. Chem. Soc. 82, 4384-4389 (1960).

22. Lindsey, J. S. Synthetic Routes to meso-Patterned Porphyrins. Acc. Chem. Res. 43, 300-311 (2010).

23. Lee, C.-H. \& S Lindsey, J. One-flask synthesis of meso-substituted dipyrromethanes and their application in the synthesis of trans-substituted porphyrin building blocks. Tetrahedron 50, 11427-11440 (1994).

24. Laha, J. K., Dhanalekshmi, S., Taniguchi, M., Ambroise, A. \& Lindsey, J. S. A Scalable Synthesis of Meso-Substituted Dipyrromethanes. Org. Process Res. Dev. 7, 799-812 (2003).

25. Lash, T. D. Porphyrin Synthesis by the ' $3+1$ ' Approach: New Applications for an Old Methodology. Chem. Eur. J. 2, 1197-1200 (1996).

26. Dogutan, D. K. \& Lindsey, J. S. Investigation of the scope of a new route to ABCD-bilanes and ABCD-porphyrins. J. Org. Chem. 73, 6728-6742 (2008).

27. Dogutan, D. K., Ptaszek, M. \& Lindsey, J. S. Rational or Statistical Routes from 1-Acyldipyrromethanes to meso-Substituted Porphyrins. Distinct Patterns, Multiple Pyridyl Substituents, and Amphipathic Architectures. $J$. Org. Chem. 73, 6187-6201 (2008).

28. Zenkevich, E. et al. Photophysical and photochemical properties of potential porphyrin and chlorin photosensitizers for PDT. Journal of Photochemistry \& Photobiology, B: Biology 33, 171-180 (1996).

29. Sternberg, E. D., Dolphin, D. \& Brückner, C. Porphyrin-based photosensitizers for use in photodynamic therapy. Tetrahedron 54, 4151-4202 (1998).

30. Turro, N. J. The triplet state. Journal of Chemical Education 46, 2 (1969).

31. Castano, A. P., Demidova, T. N. \& Hamblin, M. R. Mechanisms in photodynamic therapy: part one - photosensitizers, photochemistry and cellular localization. Photodiagnosis and Photodynamic Therapy 1, 279-293 (2004).

32. Moan, J. \& Berg, K. The photodegradation of porphyrins in cells can be used to estimate the lifetime of singlet oxygen. Photochem Photobiol 53, 549-553 (1991).

33. Bellnier, D. A. et al. Clinical Pharmacokinetics of the PDT Photosensitizers Porfimer Sodium (Photofrin), 2-[1-Hexyloxyethyl]-2-Devinyl Pyropheophorbide-a (Photochlor) and 5-ALA-Induced Protoporphyrin IX. Lasers in Surgery and Medicine 38, 439-444 (2006).

34. Takahashi, J., Misawa, M. \& Iwahashi, H. Transcriptome Analysis of Porphyrin-Accumulated and X-Ray-Irradiated Cell Cultures under Limited Proliferation and Non-Lethal Conditions. Microarrays 2015, Vol. 4, Pages $25-$ 40 4, 25-40 (2015).

35. Yoon, I., Li, J. Z. \& Shim, Y. K. Advance in Photosensitizers and Light Delivery for Photodynamic Therapy. Clin Endosc 46, 7-17 (2013). 
36. Abrahamse, H. \& Hamblin, M. R. New photosensitizers for photodynamic therapy. Biochem. J. 473, 347-364 (2016).

37. Usuda, J. et al. Photodynamic Therapy (PDT) for Lung Cancers. Journal of Thoracic Oncology 1, 489-493 (2006).

38. Chilakamarthi, U. \& Giribabu, L. Photodynamic Therapy: Past, Present and Future. Chem. Rec. 17, 1-29 (2017).

39. Muthiah, C. et al. Synthesis and Photophysical Characterization of Porphyrin, Chlorin and Bacteriochlorin Molecules Bearing Tethers for Surface Attachment. Photochem Photobiol 83, 1513-1528 (2007).

40. Gonzales, J. et al. One-Pot Synthesis of Four Chlorin Derivatives by a Divergent Ylide. J. Org. Chem. 83, 6307-6314 (2018).

41. Lindsey, J. S. De Novo Synthesis of Gem-Dialkyl Chlorophyll Analogues for Probing and Emulating Our Green World. 1-87 (2015).

42. Bryden, F., Savoie, H., Rosca, E. V. \& Boyle, R. W. PET/PDT theranostics: synthesis and biological evaluation of a peptide-targeted gallium porphyrin. Dalton Transactions 44, 4925-4932 (2015).

43. Entract, G. M. et al. Development of PDT/PET Theranostics: Synthesis and Biological Evaluation of an 18F-Radiolabeled Water-Soluble Porphyrin. Mol. Pharmaceutics 12, 4414-4423 (2015).

44. Rosenthal, I., Krishna, C. M., Riesz, P. \& Ben-Hur, E. The Role of Molecular Oxygen in the Photodynamic Effect of Phthalocyanines. Radiation Research 107, 136 (1986).

45. Mroz, P. et al. Imidazole metalloporphyrins as photosensitizers for photodynamic therapy: Role of molecular charge, central metal and hydroxyl radical production. Cancer Letters 282, 63-76 (2009).

46. Nakajima, S. et al. Hemopexin as a carrier protein of tumor-localizing Gametalloporphyrin-ATN-2. Cancer Letters 149, 221-226 (2000).

47. Munoz-Pinedo, C., Mjiyad, El, N. \& Ricci, J.-E. Cancer metabolism: current perspectives and future directions. Cell Death \& Disease 2012 3:1 3, e248e248 (2012).

48. Stuchinskaya, T., Moreno, M., Cook, M. J., Edwards, D. R. \& Russell, D. A. Targeted photodynamic therapy of breast cancer cells using antibodyphthalocyanine-gold nanoparticle conjugates. Photochemical \& Photobiological Sciences 10, 822-831 (2011).

49. Otvagin, V. F. et al. Synthesis and biological evaluation of new water-soluble photoactive chlorin conjugate for targeted delivery. Eur J Med Chem 144, 740-750 (2018).

50. Parker, N. et al. Folate receptor expression in carcinomas and normal tissues determined by a quantitative radioligand binding assay. Analytical Biochemistry 338, 284-293 (2005).

51. Gravier, J. et al. Improvement of meta-tetra(Hydroxyphenyl)chlorin-Like Photosensitizer Selectivity with Folate-Based Targeted Delivery. Synthesis and in Vivo Delivery Studies. J. Med. Chem. 51, 3867-3877 (2008).

52. Warburg, O. On the origin of cancer cells. Science 123, 309-314 (1956). 
53. Hayashi, N. et al. A Novel Photodynamic Therapy Targeting Cancer Cells and Tumor-Associated Macrophages. Molecular Cancer Therapeutics 14, 452-460 (2015).

54. Tanaka, M. et al. Antitumor Effects in Gastrointestinal Stromal Tumors Using Photodynamic Therapy with a Novel Glucose-Conjugated Chlorin. Molecular Cancer Therapeutics 13, 767-775 (2014).

55. Tamura, M. et al. Selective accumulation of [62Zn]-labeled glycoconjugated porphyrins as multi-functional positron emission tomography tracers in cancer cells. Bioorganic \& Medicinal Chemistry 22, 2563-2570 (2014).

56. Organic Chemistry. (John Wiley \& Sons, Inc).

57. Fügedi, D. E. L. A. P. The Organic Chemistry of Sugars. 1-869 (Taylor \& Francis Group, 2006).

58. Alberts, B. et al. Essential Cell Biology. (Garland Science, 2003).

59. Ganapathy, V., Thangaraju, M. \& Prasad, P. D. Nutrient transporters in cancer: Relevance to Warburg hypothesis and beyond. Pharmacology Therapeutics 121, 29-40 (2009).

60. Reux, B. et al. Synthesis and cytotoxic properties of new fluorodeoxyglucosecoupled chlorambucil derivatives. Bioorganic \& Medicinal Chemistry 16, 5004-5020 (2008).

61. Chiti, F. \& Dobson, C. M. Protein Misfolding, Amyloid Formation, and Human Disease: A Summary of Progress Over the Last Decade. Annu. Rev. Biochem. 86, 27-68 (2017).

62. Klingstedt, T. Fluorescent thiophene-based ligands for detection and characterization of disease-associated protein aggregates. 1-97 (2013).

63. Khan, M. V., Zakariya, S. M. \& Khan, R. H. Protein folding, misfolding and aggregation: A tale of constructive to destructive assembly. International Journal of Biological Macromolecules 112, 217-229 (2018).

64. Fändrich, M. et al. Amyloid fibril polymorphism: a challenge for molecular imaging and therapy. J Intern Med 283, 218-237 (2018).

65. Riek, R. \& Eisenberg, D. S. The activities of amyloids from a structural perspective. Nature 2004 432:7015 539, 227-235 (2016).

66. Selkoe, D. J. Alzheimer's disease: genes, proteins, and therapy. Physiol. Rev. 81, 741-766 (2001).

67. Groenning, M. Binding mode of Thioflavin T and other molecular probes in the context of amyloid fibrils-current status. J Chem Biol 3, 1-18 (2010).

68. Xu, M.-M., Ren, W.-M., Tang, X.-C., Hu, Y.-H. \& Zhang, H.-Y. Advances in development of fluorescent probes for detecting amyloid- $\beta$ aggregates. Acta Pharmacol. Sin. 37, 719-730 (2016).

69. Tong, H., Lou, K. \& Wang, W. Near-infrared fluorescent probes for imaging of amyloid plaques in Alzheimer's disease. Acta Pharmaceutica Sinica B 5, 25-33 (2015).

70. Klingstedt, T. et al. Synthesis of a library of oligothiophenes and their utilization as fluorescent ligands for spectral assignment of protein aggregates. Org. Biomol. Chem. 9, 8356-8370 (2011).

71. Shirani, H. et al. A Palette of Fluorescent Thiophene-Based Ligands for the Identification of Protein Aggregates. Chemistry 21, 15133-15137 (2015). 
72. Klingstedt, T. et al. Distinct Spacing Between Anionic Groups: An Essential Chemical Determinant for Achieving Thiophene-Based Ligands to Distinguish $\beta$-Amyloid or Tau Polymorphic Aggregates. Chemistry 21, 9072-9082 (2015).

73. Johansson, L. B. G. et al. An azide functionalized oligothiophene ligand - A versatile tool for multimodal detection of disease associated protein aggregates. Biosensors and Bioelectronic 63, 204-211 (2015).

74. Nyström, S. et al. Evidence for age-dependent in vivo conformational rearrangement within $\mathrm{A} \beta$ amyloid deposits. ACS Chem. Biol. 8, 1128-1133 (2013).

75. Åslund, A. et al. Novel pentameric thiophene derivatives for in vitro and in vivo optical imaging of a plethora of protein aggregates in cerebral amyloidoses. ACS Chem. Biol. 4, 673-684 (2009).

76. Shirani, H. et al. Synthesis of Thiophene-Based Optical Ligands That Selectively Detect Tau Pathology in Alzheimer's Disease. Chemistry 23, 17127-17135 (2017).

77. Mahajan, V. et al. Cross $\beta$-Sheet Conformation of Keratin 8 Is a Specific Feature of Mallory-Denk Bodies Compared With Other Hepatocyte Inclusions. YGAST 141, 1080-1090 (2011).

78. Jenkins, A. D., Kratochvil, P., Stepto, R. F. T. \& Suter, U. W. Glossary of basic terms in polymer science. Pure Applied Chemistry 68, 2287-2311 (1996).

79. Kaloni, T. P., Giesbrecht, P. K., Schreckenbach, G. \& Freund, M. S. Polythiophene: From Fundamental Perspectives to Applications. Chemistry of Materials 29, 10248-10283 (2017).

80. Brabec, C. J., Heeney, M., McCulloch, I. \& Nelson, J. Influence of blend microstructure on bulk heterojunction organic photovoltaic performance. Chemical Society Reviews 40, 1185-1199 (2011).

81. Nilsson, K. P. R., Herland, A., Hammarström, P. \& Inganäs, O. Conjugated polyelectrolytes: conformation-sensitive optical probes for detection of amyloid fibril formation. Biochemistry 44, 3718-3724 (2005).

82. Nilsson, K. P. R. et al. Imaging distinct conformational states of amyloid-beta fibrils in Alzheimer's disease using novel luminescent probes. ACS Chem. Biol. 2, 553-560 (2007).

83. Simon, R. A. et al. Pentameric thiophene-based ligands that spectrally discriminate amyloid- $\beta$ and tau aggregates display distinct solvatochromism and viscosity-induced spectral shifts. Chemistry 20, 12537-12543 (2014).

84. Sjölander, D. et al. Establishing the fluorescent amyloid ligand h-FTAA for studying human tissues with systemic and localized amyloid. Amyloid 23, 98108 (2016).

85. Choong, F. X. et al. Real-time optotracing of curli and cellulose in live Salmonella biofilms using luminescent oligothiophenes. npj Biofilms and Microbiomes 2, 16024 (2016).

86. Choong, F. X. et al. Nondestructive, real-time determination and visualization of cellulose, hemicellulose and lignin by luminescent oligothiophenes. Sci Rep 6, 35578 (2016). 
87. Che, J., Xiao, Y., Zhu, X. \& Sun, X. Electro-synthesized PEDOT/glutamate chemically modified electrode: a combination of electrical and biocompatible features. Polymer International 57, 750-755 (2008).

88. Lecommandoux, S. \& Garanger, É. Precision polymers with biological activity: Design towards self-assembly and bioactivity. Comptes Rendus Chimie 19, 143-147 (2016).

89. Jia, Z., Liu, J., Boyer, C., Davis, T. P. \& Bulmus, V. Functional disulfidestabilized polymer-protein particles. Biomacromolecules 10, 3253-3258 (2009).

90. Wen, Y. et al. DNA Nanostructure-based Interfacial engineering for PCR-free ultrasensitive electrochemical analysis of microRNA. Sci Rep 2, 867 (2012).

91. Dibbert, N. et al. A Synthetic Toolbox for the In Situ Formation of Functionalized Homo- and Heteropolysaccharide-Based Hydrogel Libraries. Chem. Eur. J. 22, 18777-18786 (2016).

92. Mendes, A. C., Baran, E. T., Reis, R. L. \& Azevedo, H. S. Self-assembly in nature: using the principles of nature to create complex nanobiomaterials. Wiley Interdiscip Rev Nanomed Nanobiotechnol 5, 582-612 (2013).

93. Tester, R. F., Karkalas, J. \& Qi, X. Starch — composition, fine structure and architecture. Journal of Cereal Science 39, 151-165 (2004).

94. P Fuenzalida, J. \& M Goycoolea, F. Polysaccharide-Protein Nanoassemblies: Novel Soft Materials for Biomedical and Biotechnological Applications.

95. Lee, S. S. et al. Sulfated glycopeptide nanostructures for multipotent protein activation. Nat Nanotechnol 12, 821-829 (2017).

96. Hendricks, M. P., Sato, K., Palmer, L. C. \& Stupp, S. I. Supramolecular Assembly of Peptide Amphiphiles. Acc. Chem. Res. 50, 2440-2448 (2017).

97. Bostick, C. Protein bioelectronics: a review of what we do and do not know. 1-158 (2017).

98. Mokkapati, S., Saxena, D., Tan, H. H. \& Jagadish, C. Semiconductor Nanowire Optoelectronic Devices. Semiconductor Nanowires: Part B 94, 1-15 (Elsevier Inc., 2016).

99. Sweeney, S. J. \& Mukherjee, J. in Springer Handbook of Electronic and Photonic Materials 1, 897-932 (Springer International Publishing, 2017).

100. Fuenzalida, J. P. \& Goycoolea, F. M. Polysaccharide-protein nanoassemblies: novel soft materials for biomedical and biotechnological applications. Curr. Protein Pept. Sci. 16, 89-99 (2015).

101. Choi, J. W., Oh, B.-K., Kim, Y. J. \& Min, J. Protein-based biomemory device consisting of the cysteine-modified azurin. Applied Physics Letters 91, 263902 (2007).

102. Li, Y.-T. et al. A Review on Bacteriorhodopsin-Based Bioelectronic Devices. Sensors (Basel) 18, 1368-21 (2018).

103. Prasad, M. \& Roy, S. Optoelectronic Logic Gates Based on Photovoltaic Response of Bacteriorhodopsin Polymer Composite Thin Films. IEEE Transactions on NanoBioscience 11, 410-420 (2012).

104. Allam, N. K., Yen, C.-W., Near, R. D. \& El-Sayed, M. A. Bacteriorhodopsin/TiO2 nanotube arrays hybrid system for enhanced 
photoelectrochemical water splitting. Energy Environ. Sci. 4, 2909-2914 (2011).

105. Rakovich, A. et al. Large Enhancement of Nonlinear Optical Response in a Hybrid Nanobiomaterial Consisting of Bacteriorhodopsin and Cadmium Telluride Quantum Dots. ACS Nano 7, 2154-2160 (2013).

106. Gong, R. et al. A clickable, highly soluble oligopeptide that easily forms organogels. Supramolecular Chemistry 25, 269-275 (2013).

107. Kumar, R. J., MacDonald, J. M., Singh, T. B., Waddington, L. J. \& Holmes, A. B. Hierarchical Self-Assembly of Semiconductor Functionalized Peptide $\alpha$ Helices and Optoelectronic Properties. J. Am. Chem. Soc. 133, 8564-8573 (2011).

108. Witus, L. S. \& Francis, M. B. Using Synthetically Modified Proteins to Make New Materials. Acc. Chem. Res. 44, 774-783 (2011).

109. Pei, H. et al. Reconfigurable Three-Dimensional DNA Nanostructures for the Construction of Intracellular Logic Sensors. Angew. Chem. Int. Ed. 51, 9020 9024 (2012).

110. Zhang, Z., Ma, R. \& Shi, L. Cooperative macromolecular self-assembly toward polymeric assemblies with multiple and bioactive functions. Acc. Chem. Res. 47, 1426-1437 (2014).

111. Nordeman, P. et al. (11)C and (18)F Radiolabeling of Tetra- and Pentathiophenes as PET-Ligands for Amyloid Protein Aggregates. ACS Med Chem Lett 7, 368-373 (2016).

112. ChemFiles, A. PEPPSI ${ }^{\mathrm{TM}}$ Catalyst. 6.3, (2006).

113. Taniguchi, M., Balakumar, A., Fan, D., McDowell, B. E. \& Lindsey, J. S. Imine-substituted dipyrromethanes in the synthesis of porphyrins bearing one or two mesosubstituents. J. Porphyrins Phthalocyanines 09, 554-574 (2005).

114. Vilsmeier, A. \& Haack, A. Über die Einwirkung von Halogenphosphor auf Alkyl-formanilide. Eine neue Methode zur Darstellung sekundärer und tertiärer p-Alkylamino-benzaldehyde. Berichte der deutschen chemischen Gesellschaft (A and B Series) 60, 119-122 (2006).

115. Brückner, C. et al. Novel and improved syntheses of 5,15-diphenylporphyrin and its dipyrrolic precursors. J. Porphyrins Phthalocyanines 2, 455-465 (1998).

116. Arja, K., Elgland, M. \& Nilsson, K. P. R. Synthesis and Characterization of Oligothiophene-Porphyrin-Based Molecules That Can Be Utilized for Optical Assignment of Aggregated Amyloid- $\beta$ Morphotypes. Frontiers in Chemistry 6, 391 (2018).

117. Li, F., Yang, K., Tyhonas, J. S., MacCrum, K. A. \& Lindsey, J. S. Beneficial effects of salts on an acid-catalyzed condensation leading to porphyrin formation. Tetrahedron 53, 12339-12360 (1997).

118. Mason, J. \& Murphree, S. Microwave-Assisted Aqueous Krapcho Decarboxylation. Synlett 24, 1391-1394 (2013).

119. Wu, X.-A. et al. Lithium Chloride-Assisted Selective Hydrolysis of Methyl Esters Under Microwave Irradiation. Synthetic Communications 39, 34593470 (2009). 
120. Rostovtsev, V. V., Green, L. G., Fokin, V. V. \& Sharpless, K. B. A Stepwise Huisgen Cycloaddition Process: Copper(I)-Catalyzed Regioselective 'Ligation' of Azides and Terminal Alkynes. Angewandte Chemie 114, 27082711 (2002).

121. Garcia, G., Naud-Martin, D., Carrez, D., Croisy, A. \& Maillard, P. Microwavemediated 'click-chemistry' synthesis of glycoporphyrin derivatives and in\&nbsp;vitro photocytotoxicity for application in photodynamic therapy. Tetrahedron 67, 4924-4932 (2011).

122. Lyons, D. M., Ono, R. J., Bielawski, C. W. \& Sessler, J. L. Porphyrinoligothiophene conjugates as additives for P3HT/PCBM solar cells. J. Mater. Chem. 22, 18956-5 (2012).

123. Stoltzfus, D. M. et al. Improved efficiency of polymer-fullerene bulk heterojunction solar cells by the addition of $\mathrm{Cu}$ (II)-porphyrin-oligothiophene conjugates. Synthetic Metals 218, 1-8 (2016).

124. Yan, W. et al. Conjugated Polythiophene/Porphyrin Complex for Rapid and Simple Detection of Bacteria in Drinking Water. Macromol. Chem. Phys. 216, 1603-1608 (2015).

125. Wang, F. et al. Synthesis and Characterization of Water-Soluble Polythiophene Derivatives for Cell Imaging. Sci Rep 5, 4564-8 (2015).

126. Xing, C., Xu, Q., Tang, H., Liu, L. \& Wang, S. Conjugated Polymer/Porphyrin Complexes for Efficient Energy Transfer and Improving Light-Activated Antibacterial Activity. J. Am. Chem. Soc. 131, 13117-13124 (2009).

127. Xing, C. et al. Conjugated Polymers for Light-Activated Antifungal Activity. Small 8, 525-529 (2012).

128. Arja, K. et al. Enhanced Fluorescent Assignment of Protein Aggregates by an Oligothiophene-Porphyrin-Based Amyloid Ligand. Macromol. Rapid Commun. 34, 723-730 (2013).

129. Iannuzzi, C., Irace, G. \& Sirangelo, I. The Effect of Glycosaminoglycans (GAGs) on Amyloid Aggregation and Toxicity. Molecules 20, 2510-2528 (2015).

130. Selegård, R. et al. Distinct Electrostatic Interactions Govern the Chiro-Optical Properties and Architectural Arrangement of Peptide-Oligothiophene Hybrid Materials. Macromolecules 50, 7102-7110 (2017).

131. Herbert, R., Kim, J.-H., Kim, Y., Lee, H. \& Yeo, W.-H. Soft Material-Enabled, Flexible Hybrid Electronics for Medicine, Healthcare, and Human-Machine Interfaces. Materials 11, 187-33 (2018).

132. Caló, E. \& Khutoryanskiy, V. V. Biomedical applications of hydrogels: A review of patents and commercial products. European Polymer Journal 65, 252-267 (2015).

133. Ma, X. et al. A Biocompatible and Biodegradable Protein Hydrogel with Green and Red Autofluorescence: Preparation, Characterization and In Vivo Biodegradation Tracking and Modeling. Sci Rep 6, 19370 (2016).

134. Dånmark, S., Aronsson, C. \& Aili, D. Tailoring Supramolecular PeptidePoly(ethylene glycol) Hydrogels by Coiled Coil Self-Assembly and SelfSorting. Biomacromolecules 17, 2260-2267 (2016). 
135. Aronsson, C. et al. Self-sorting heterodimeric coiled coil peptides with defined and tuneable self-assembly properties. Sci Rep 5, 14063 (2015).

136. Nilsson, K. P. R., Rydberg, J., Baltzer, L. \& Inganäs, O. Twisting macromolecular chains: self-assembly of a chiral supermolecule from nonchiral polythiophene polyanions and random-coil synthetic peptides. Proceedings of the National Academy of Sciences 101, 11197-11202 (2004).

137. Kelly, S. M., Jess, T. J. \& Price, N. C. How to study proteins by circular dichroism. Biochimica et Biophysica Acta (BBA) - Proteins and Proteomics 1751, 119-139 (2005).

138. Greenfield, N. J. Using circular dichroism spectra to estimate protein secondary structure. Nat Protoc 1, 2876-2890 (2006).

139. Huang, X., Nakanishi, K. \& Berova, N. Porphyrins and metalloporphyrins: Versatile circular dichroic reporter groups for structural studies. Chirality 12, 237-255 (2000).

140. Tamiaki, H., Matsumoto, N. \& Tsukube, H. Gadolinium(III) porphyrin as a novel circular dichroism probe for chirality of amino acids. Tetrahedron Letters 38, 4239-4242 (1997).

141. Lu, W. et al. Chiral Discrimination of Diamines by a Binaphthalene-Bridged Porphyrin Dimer. Inorg. Chem. 56, 8223-8231 (2017).

142. and, Z. G. \& Ini, S. Remarkable Effects of Metal, Solvent, and Oxidant on Metalloporphyrin-Catalyzed Enantioselective Epoxidation of Olefins. J. Org. Chem. 62, 5514-5521 (1997).

143. Nezu, T. \& Ikeda, S. Induction of Circular Dichroism on the Soret Bands of a Symmetric Water-Soluble Porphyrin by Poly(L-lysine) in Three Conformations. Bull. Chem. Soc. Jpn. 66, 25-31 (1993).

144. Mizutani, T., Ema, T., Yoshida, T., Kuroda, Y. \& Ogoshi, H. Recognition of alpha-amino acid esters by zinc porphyrin derivatives via coordination and hydrogen bonding interactions. Evidence for two-point fixation from thermodynamic and induced circular dichroism spectroscopic studies. Inorg. Chem. 32, 2072-2077 (1993).

145. Kovaric, B. C. et al. Self-Assembly of Peptide Porphyrin Complexes: Toward the Development of Smart Biomaterials. J. Am. Chem. Soc. 128, 4166-4167 (2006).

146. Pasternack, R. F., Giannetto, A., Pagano, P. \& Gibbs, E. J. Self-assembly of porphyrins on nucleic acids and polypeptides. J. Am. Chem. Soc. 113, 77997800 (1991).

147. Elgland, M. et al. Beta-Configured Clickable [18F]FDGs as Novel 18FFluoroglycosylation Tools for PET. 1-6 (2017). doi:10.1039/C7NJ00716G

148. Arja, K. et al. Synthesis and Characterization of Novel Fluoro-glycosylated Porphyrins that can be Utilized as Theranostic Agents. ChemistryOpen 7, 495503 (2018).

149. Pashkovskaya, A. A., Sokolenko, E. A., Sokolov, V. S., Kotova, E. A. \& Antonenko, Y. N. Photodynamic activity and binding of sulfonated metallophthalocyanines to phospholipid membranes: Contribution of metalphosphate coordination. Biochimica et Biophysica Acta (BBA) - Biomembranes 1768, 2459-2465 (2007). 
150. Chernyak, A. Y. et al. 2-Azidoethyl glycosides: glycosides potentially useful for the preparation of neoglycoconjugates. Carbohydrate Research 223, 303309 (1992).

151. Kim, D. H. et al. A 18F-labeled glucose analog: Synthesis using a click labeling method and in vitro evaluation. Arch. Pharm. Res. 31, 587-593 (2008).

152. Nakabayashi, S., Warren, C. D. \& Jeanloz, R. W. A new procedure for the preparation of oligosaccharide oxazolines. Carbohydrate Research 150, c7c10 (1986).

153. Yohino, T., Sato, K., Wanme, F., Takai, I. \& Ishido, Y. Efficient catalysis by pyridinium sulfonate in glycosylation involving an oxazoline intermediate derived from per-O-acetyl-N-acetyllactosamine and N,N'-diacetylchitobiose. Glycoconj. J. 9, 287-291 (1992). 


\section{Papers}

The papers associated with this thesis have been removed for copyright reasons. For more details about these see:

http://urn.kb.se/resolve?urn=urn:nbn:se:liu:diva-150522 